\begin{tabular}{|c|l|}
\hline Title & Direct enantio-convergent transformation of racemic substrates without racemization or symmetrization \\
\hline Author(s) & Ito, Hajime; Kunii, Shun; Sawamura, Masaya \\
\hline Citation & $\begin{array}{l}\text { Nature Chemistry, 2(11), 972-976 } \\
\text { https://doi.org/10.1038NCHEM.801 }\end{array}$ \\
\hline Issue Date & 2010-11 \\
\hline Doc URL & http://hdl.handle.net/2115/45373 \\
\hline Type & article (author version) \\
\hline File Information & NC2-11_972-976.pdf \\
\hline
\end{tabular}

Instructions for use 


\title{
Direct enantio-convergent transformation of racemic substrates without racemization or symmetrization
}

\author{
Hajime Ito, ${ }^{\dagger \ddagger}{ }^{\dagger}$ Shun Kunii, ${ }^{\dagger}$ and Masaya Sawamura ${ }^{\dagger}$ \\ ${ }^{\dagger}$ Department of Chemistry, Faculty of Science, Hokkaido University, Sapporo 060-0810, Japan \\ ${ }^{\ddagger}$ PRESTO, Japan Science and Technology Agency (JST), Honcho, Kawaguchi, Saitama 332-0012, Japan
}

\begin{abstract}
Asymmetric reactions that transform racemic mixtures into enantio-enriched products are in high demand; however, classical kinetic resolution (KR) can afford enantiopure compounds in $<50 \%$ yield even in an ideal case. Many deracemization processes thus have been developed including dynamic kinetic resolution (DKR) and dynamic kinetic asymmetric transformation (DYKAT), which can provide enantio-enriched products even after complete conversion of the racemic starting materials; however, these dynamic processes require racemization or symmetrization of the substrates or intermediates. We demonstrate a first chemical direct enantio-convergent transformation without racemization or symmetrization process. The copper(I)-catalyzed asymmetric allylic substitution of racemic allyl ethers afforded a single enantiomer of $\alpha$-chiral allylboronates with complete conversion and high enantioselectivity (up to $98 \% \mathrm{ee})$; one enantiomer of the substrate undergoes a anti-S $\mathrm{N}_{\mathrm{N}}$ '-type reaction whereas the other enantiomer reacts via a syn-S $\mathrm{S}_{\mathrm{N}}$ ' pathway. The products, $\alpha$-chiral allylboronates, cannot be prepared by dynamic procedures, were used in construction of all-carbon quaternary stereocentres.
\end{abstract}

The efficient production of enantiopure compounds from racemic starting materials is in high demand, especially in the pharmaceutical and agricultural industries, in addition to enantioselective catalysis that converts pro-chiral starting materials to desired enantio-enriched products (Figure 1). ${ }^{1-4}$ Reaction of a racemic substrate with a chiral catalyst usually results in kinetic resolution (KR) where two enantiomers of the racemate react with different reaction rates (Figure 1a). ${ }^{4-6}$ One enantiomer of the starting material $\left(\mathbf{S}_{\mathbf{A}}\right)$ is converted far more rapidly than the opposite enantiomer when the reaction rate of the one enantiomer is significantly higher than the other $\left(\mathrm{k}_{\mathrm{A}}>>\mathrm{k}_{\mathrm{B}}\right)$. Enantio-enriched product $\left(\mathbf{P}_{\mathbf{A}}\right)$ is thus obtained with high selectivity; however, the other substrate enantiomer with lower reactivity $\left(\mathbf{S}_{\mathbf{B}}\right)$ remained unreacted and the theoretical maximum yield of the desired product $\left(\mathbf{P}_{\mathrm{A}}\right)$ is only $50 \%$ even in an ideal case. To overcome the limitation caused by this incomplete conversion, many elegant deracemization processes have been designed that can transform both enantiomers of the racemic starting materials into a single enantiomer of the product. Dynamic kinetic resolution (DKR) ${ }^{7-9}$ and dynamic kinetic asymmetric transformation (DYKAT) ${ }^{10-18}$ are representative examples (Figures $1 \mathrm{~b}$ and 1c). Dynamic kinetic resolution can be achieved by combining an enantioselective reaction with the rapid racemization of the starting materials (Figure 1b). In this case, the less reactive substrate enantiomer $\left(\mathbf{S}_{\mathbf{B}}\right)$ can be converted into the more reactive enantiomer $\left(\mathbf{S}_{\mathbf{A}}\right)$ through the racemization process; when the reaction rates of the racemization is much higher than the favorable enantioselective step (from $\mathbf{S}_{\mathbf{A}}$ to $\mathbf{P}_{\mathbf{A}}$ ), and the rate of the favorable enantioselective step is enough larger than that of the disfavored one $\left(k_{A}>>k_{B}\right)$, the desirable enantiomer $\left(\mathbf{P}_{\mathrm{A}}\right)$ can be obtained with high enantiomeric purity after complete conversion of the starting material. For dynamic kinetic asymmetric transformation (DYKAT, Figure 1c), both enantiomers are initially converted into the common intermediate (I) where the substrate stereogenic center disappears. This is typically achieved by forming pseudo meso- or $\mathrm{C}_{2}$ symmetric complexes with chiral catalysts. The new chiral center is then established by the subsequent enantioselective step $\left(k_{A}>>k_{B}\right.$, Figure 1c) ${ }^{10-12}$ However, the majority of racemic compounds have significantly robust chiral centers and reaction procedures such as DKR or DYKAT are ineffective. Most racemic starting materials have no suitable means for racemization that is essential for DKR, whereas DYKAT requires the disappearance of the stereogenic center in the reaction intermediates; however, many chiral compounds cannot take symmetrical structures (pseudo meso- or $\mathrm{C}_{2}$-symmetric) even in the transformation to other chiral products. De-racemization of racemates with such robust chiral centers remains an unsolved problem in the field of asymmetric synthesis. a
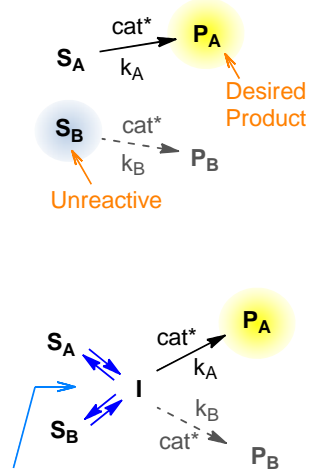
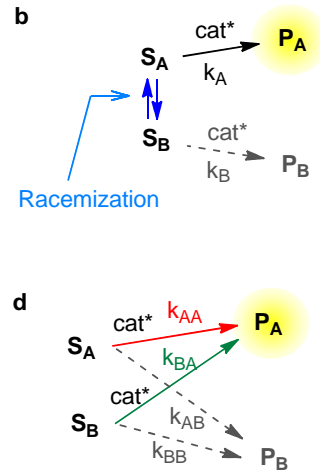

Figure 1 | Conceptual schemes for asymmetric reactions of racemic chiral substrates for production of enantio-enriched compounds. Solid arrows represent faster reaction pathways and dotted arrows show slower ones. Racemization and desymmetrization processes described in blue arrows. a, Kinetic resolution $(K R)$. One of the substrate enantiomer $\left(S_{A}\right)$ is converted into the product $\left(\mathbf{P}_{\mathrm{A}}\right)$ at the larger reaction rate in the presence of $\mathrm{a}$ chiral catalyst (cat*), whereas the other substrate enantiomer $\left(\mathbf{S}_{\mathrm{B}}\right)$ 
reacts at the much smaller rate $\left(k_{A}>>k_{B}\right)$. b, Dynamic kinetic resolution (DKR). The rapid racemization process of the substrate enables the conversion of the two enantiomer $\left(\mathbf{S}_{\mathbf{A}}\right.$ and $\left.\mathbf{S}_{B}\right)$ into one enantiomer of the product $\left(\mathbf{P}_{\mathbf{A}}\right)$. c, Dynamic kinetic asymmetric transformation (DYKAT). Desymmetrization process first converts the two substrate enantiomers $\left(\mathbf{S}_{\mathbf{A}}\right.$ and $\mathbf{S}_{\mathbf{B}}$ ) into an intermediate (I), where the substrate chiral centre is disappeared. The subsequent enantioselective path produces one enantiomer $\left(\mathrm{k}_{\mathrm{A}}>>\mathrm{k}_{\mathrm{B}}\right)$. d, Direct enantio-convergent transformation (DECT). One substrate enantiomer $\left(\mathbf{S}_{A}\right)$ is converted preferentially into one product enantiomer $\left(\mathbf{P}_{\mathrm{A}}\right)$ (red arrow, $\mathrm{k}_{\mathrm{AA}}>>\mathrm{k}_{\mathrm{AB}}$ ) and the other enantiomer $\left(\mathbf{S}_{\mathrm{B}}\right)$ is also converted into the same product $\left(\mathbf{P}_{A}\right)\left(k_{B A}>>k_{B B}\right)$ through $a$ different reaction pathway (green arrow).

If each enantiomer of a racemic mixture is converted into the same enantiomer of the product through different reaction pathways, the problem raised by racemization or symmetrization can be circumvented (Figure 1d). ${ }^{1,2,19,20}$ However, the requirements to achieve such reaction in a single operation with a single catalyst are challenging. The catalyst should promote two distinctive reaction pathways with opposite enantiomeric preference of the substrate $\left(\mathrm{k}_{\mathrm{AA}}>>\mathrm{k}_{\mathrm{AB}}\right.$ and $\left.\mathrm{k}_{\mathrm{BA}}>>\mathrm{k}_{\mathrm{BB}}\right)$; and each pathway should have opposite stereoselectivity to produce the same enantiomer of the product. Furthermore, the two preferred pathways should proceed at the similar reaction rates $\left(\mathrm{k}_{\mathrm{AA}} \approx \mathrm{k}_{\mathrm{BA}}\right)$ to avoid kinetic resolution of the substrate. Literatures describing such direct enantio-convergent reaction are scarce and are limited to a few biocatalytic reactions. ${ }^{19,20}$ To our knowledge, artificial catalysts that can promote this type of transformation with a practically useful level of selectivity are unknown. We recently reported the copper(I)-catalyzed enantioselective boryl substitution of prochiral allylic carbonates to produce enantio-enriched allylboronates, which are useful building blocks for asymmetric preparation of compounds with multiple chiral centers. ${ }^{21-23}$ We found that the copper(I)-catalyzed boryl substitution proceeds as the first chemical direct enantio-convergent transformation (DECT) without racemization or symmetrization process when the substrate racemic allylic ethers have a chiral center that cannot be treated by known de-racemization processes such as DKR or DYKAT. The synthetic utility of the allylboronates that can only be prepared by this direct enantio-convergent transformation was also demonstrated by construction of all-carbon quaternary stereo centers through stereoselective aldehyde allylation. ${ }^{24-26}$

\section{Results}

\section{Direct enantio-convergent reaction}

Racemic allylic ether 1a has a cyclic structure with an asymmetric substituent pattern around the allylic system (Table 1). This type of compound appears to be an example that cannot be applied to the known de-racemization procedures. There are no efficient ways to racemize such tertiary ethers, indicating DKR is not applicable. Although DYKAT of some racemic allylic esters have been reported in transition-metal-catalyzed asymmetric allylic alkylation, ${ }^{10,11,13-18}$ successful cases are limited to the acyclic allylic esters or cyclic ones bearing symmetrical substituents about the allylic system or bearing an electron withdrawing group. Such structures enable DYKAT by racemization through $\pi-\sigma-\pi$ isomerization ${ }^{10,11,15,16}$ or symmetrization via the formation of pseudo-meso $\pi$ allylmetal complexes. ${ }^{10,11,17,18}$

The reaction of (rac)-1a was first carried out with bis(pinacolato)diboron 3 (1.5 equiv.) in the presence of $5 \mathrm{~mol} \%$ of $\mathrm{Cu}(\mathrm{O}-\mathrm{t}-\mathrm{Bu})$ and a chiral phosphine ligand $[(R, R)-\mathrm{QuinoxP} *(2 \mathbf{a})]^{27}$ in diethyl ether at $30^{\circ} \mathrm{C}$ (Table 1). Complete conversion of (rac)1a was reached within $24 \mathrm{~h}$ and the corresponding allylboronate $(S)-4 a$, the $\mathrm{S}_{\mathrm{N}} 2$ ' product of boryl substitution, was obtained in high yield $(98 \%)$ with a high enantioselectivity (97\% ee) (entry 1$)$. The reaction was performed with the readily available catalyst $\mathrm{CuCl} / \mathrm{K}(\mathrm{O}-\mathrm{t}-\mathrm{Bu})$ instead of $\mathrm{Cu}(\mathrm{O}-\mathrm{t}-\mathrm{Bu})$; however, a longer reaction time was required (entry 2, $96 \mathrm{~h}$ ). Reaction with $(R, R)$-Me-Duphos (2b) instead of $(R, R)$-QuinoxP* (2a) also proceeded as the enantioconvergent transformation with a lower enantioselectivity (99\%, $88 \%$ ee, entry 3). Reaction with (R)-BINAP (2c) did not reach completion even after a long reaction time and gave poor enantioselectivity ( $59 \mathrm{~h}, 54 \%, 18 \%$ ee, entry 4 ). Reactions of enantiopure substrates, $(+)-\mathbf{1 a}$ and $(-)-\mathbf{1 a}$, also afforded the same enantiomer of the product, $(S)-4$ a with a high degree of ee (97\% ee, entries 5 and 6). These results represent the successful deracemization of the robust chirality compound (rac)-1a.

We next applied this enantio-convergent transformation catalysis to the secondary allylic ether $\mathbf{1 b}$ to investigate details of the reaction stereochemistry. This is because the use of $\mathbf{1 b}$ eases the stereochemical characterization of the starting material and the product. Reaction of (rac)-1b using the enantio-convergent transformation catalysis approach gave the corresponding allylboronate $(S)-\mathbf{4 b}$ in a good yield with high enantiomeric purity (92\% yield, $92 \%$ ee, entry 7 ). The reaction of the deuterium labeled (rac)-1c exclusively afforded the allylboronate (S)-4c with high enantioselectivity ( $92 \%$ ee) without the transposition of the deuterium atom. This indicates that this reaction does not include a pseudo-meso $\pi$ allylmetal intermediate which is observed in other transition-metal-catalyzed DYKAT processes (entry 8). ${ }^{9,10,16,17}$ Either enantio-enriched forms of the starting material, $(S)-\mathbf{1 b}$ (93\% ee) or $(R)-\mathbf{1 b}(94 \%$ ee) were also converted into the same enantiomer, (S)-4b (entries 9 and 10); the reaction of $(S)-\mathbf{1 b}$ resulted in a higher ee (99\% ee) than that obtained from ( $\mathrm{rac})-\mathbf{1 b}$, and the reaction of $(R)-\mathbf{1 b}$ gave a lower ee $(85 \%$ ee). The stereochemical outcomes indicate that the reactions of $(S)-\mathbf{1 b}$ and $(R)$-1b proceed via two distinct pathways, anti- $\mathrm{S}_{\mathrm{N}} 2$ ' with higher enantioselectivity and the syn- $\mathrm{S}_{\mathrm{N}} 2$ ' pathway with slightly lower enantioselectivity, respectively. The ee value of the product prepared from (rac)-1b (entry 7, 92\% ee) is roughly the average of the values from (S)-1b (entry 9, 99\% ee) and $(R)$-1b (entry 10, $85 \%$ ee). The reaction of $(S)$-1b with a low amount of $\mathbf{3}$ ( 0.6 equiv), where the reaction did not reach completion, gave $(S)-\mathbf{4 b}$ in $46 \%$ yield with $99 \%$ ee; $(S)$-1b was recovered in $44 \%$ yield with a slightly lower enantiomeric purity (89 \% ee) as compared to that of the starting material (entry 11). Conversely, a similar reaction of $(R)-\mathbf{1 b}$ with 0.6 equiv of $\mathbf{3}$ gave $(S)-\mathbf{4 b}$ with a lower product enantiomeric purity $(43 \%, 85 \%$ ee) and the recovered $(R)-\mathbf{1 b}$ showed a higher enantiomeric purity $(45 \%, 98 \%$ ee) than that of the starting material (entry 12). The ee values of the recovered $\mathbf{1 b}$ indicate that the reaction does not involve racemization of the starting material and that the consumption rate of $(S)-\mathbf{1 b}$ is slightly higher than that of $(R)-\mathbf{1 b}$, resulting in partial kinetic resolution (entries 11, 12). Reaction of (rac)-1b with 0.6 equiv of $\mathbf{3}$ resulted in $50 \%$ yield of (S)-4b with high enantioselectivity (95\% ee) and $48 \%$ recovery of the starting material with moderate enantiomeric excess (entries 13, 34\% ee $(R)$ ). This result is consistent with the assumption that $(S)$-1b reacts slightly faster than $(R)-\mathbf{1 b}$. The reaction of enantiomerically pure $(S)-\mathbf{4 b}$ with an achiral ligand BDPB (2d) with the similar backbone structure with chiral ligands, 2a and $\mathbf{2 b}$ proceeded via anti-S $\mathrm{S}_{\mathrm{N}} 2$ ' to afford $(S)-\mathbf{4 b}(84 \%, 77 \%$ ee (S), entry 14). Conversely, the reaction with Xantphos (2e), which showed high reactivity in our former copper(I)/diboron catalyst systems, preferentially gave a syn- $\mathrm{S}_{\mathrm{N}} 2$ ' product with a low ee (entry 15, 17\% ee). We suppose that the steric interaction between the catalyst with BDPB (2d) and the benzyloxy group would be responsible for the anti-stereoselectivity, whereas the catalyst with Xantphos (2e) would have no significant difference in the steric interactions in both pathways. 
Table 1 | Examination of direct enantio-convergent transformation in copper(I)-catalyzed asymmetric allylic boryl substitution*

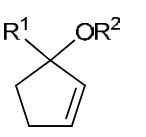
$\mathrm{Cu}(\mathrm{O}-t-\mathrm{Bu})(5 \mathrm{~mol} \%)$
or $\mathrm{CuCl} / \mathrm{K}(\mathrm{O}-t-\mathrm{Bu})(20 \mathrm{~mol} \%)$
chiral ligand $2(5 \mathrm{~mol} \%)$

$\mathrm{Et}_{2} \mathrm{O}, 30^{\circ} \mathrm{C}$

$>_{3(0.6-2.0 \text { equiv) }}^{\mathrm{O}}{ }_{\mathrm{O}}^{\mathrm{B}-\mathrm{B}^{\prime}}$<smiles>COC1(CCc2ccccc2)C=CCC1</smiles>

$1 \mathbf{a}$<smiles>C1=CC(OCc2ccccc2)CC1</smiles>

1b<smiles>[2H]C1(OCc2ccccc2)C=CCC1</smiles>

1c<smiles>[Li]C1=CC(Br)CC1</smiles>

4<smiles>CC1(C)OB(C#CBr)OC1(C)C</smiles><smiles>C(=C1CCCC1)c1ccccc1</smiles>

(S)-4a<smiles>BrC1C=CCC1</smiles>

(S) $-\mathbf{4 b}$<smiles>[2H]C1=C[C@@H](Br)CC1</smiles>

$(S)-4 c$<smiles>CCCCC(C)(C)P(C)c1nc2ccccc2nc1P(C)(C)(C)C</smiles><smiles>C[C@@H]1CC[C@H]2C[C@H]3CC[C@@H](C)P3c3ccccc3P21</smiles>

$(R, R)$-Me-Duphos (2b)<smiles></smiles>

(R)-BINAP (2c)<smiles>Pc1cccc(Pc2ccccc2)c1P</smiles><smiles>CCCc1cccc2c1Oc1c(P)cccc1C2(C)C</smiles>

1,2-Bis(diphenylphosphino)- Xantphos (2e) benzene (BDPB) (2d)

\begin{tabular}{|c|c|c|c|c|c|c|c|c|}
\hline Entry & Substrate & Ligand 2 & $\begin{array}{l}\text { Equiv. } \\
\text { of } 3\end{array}$ & $\begin{array}{l}\text { Time } \\
\text { (h) }\end{array}$ & $\begin{array}{l}\text { Yield of } \\
(\%)^{\dagger}\end{array}$ & $\begin{array}{c}\text { 4ee of } \\
(\%)^{\ddagger}\end{array}$ & 4Recov. of $1(\%)^{\top}$ & ${ }^{\top}$ ee of $1(\%)^{8}$ \\
\hline 1 & $(r a c)-1 a$ & $(R, R)$-QuinoxP* (2a) & 1.5 & 24 & 98 & $97(S)$ & 0 & - \\
\hline $2^{1}$ & $(r a c)-1 \mathbf{a}$ & $(R, R)$-QuinoxP* $(2 \mathbf{a})$ & 2.0 & 96 & 98 & $95(S)$ & 0 & - \\
\hline 3 & $(r a c)-\mathbf{1 a}$ & $(R, R)$-Me-Duphos (2b) & 2.0 & 16.5 & 99 & $88(S)$ & 0 & - \\
\hline 4 & $(r a c)-\mathbf{1 a}$ & $(R)$-BINAP $(2 \mathrm{c})$ & 2.0 & 59 & 54 & $18(S)$ & 46 & 28 \\
\hline 5 & $(+)-1 \mathbf{a}(99 \%$ ee $)$ & $(R, R)$-QuinoxP* (2a) & 1.5 & 24 & 95 & $97(S)$ & 0 & - \\
\hline 6 & $(-)-1 \mathbf{a}(>99 \%$ ee $)$ & $(R, R)$-QuinoxP* $(2 \mathbf{a})$ & 1.5 & 24 & 92 & $97(S)$ & 0 & - \\
\hline 7 & $(r a c)-\mathbf{1 b}$ & $(R, R)$-QuinoxP* $(2 \mathbf{a})$ & 1.5 & 12 & 92 & $92(S)$ & 0 & - \\
\hline 8 & $(\mathrm{rac})-\mathbf{1 c}$ & $(R, R)$-QuinoxP* (2a) & 1.5 & 12 & 91 & $92(S)$ & 0 & - \\
\hline 9" & $(S)-\mathbf{1 b}(93 \%$ ee) & $(R, R)$-QuinoxP* (2a) & 1.5 & 10 & 88 & $99(S)$ & 0 & - \\
\hline $10^{\pi}$ & $(R)-\mathbf{1 b}(94 \%$ ee $)$ & $(R, R)$-QuinoxP* $(2 \mathbf{a})$ & 1.5 & 10 & 90 & $85(S)$ & 0 & - \\
\hline $11^{\pi}$ & $(S)-\mathbf{1 b}(93 \%$ ee $)$ & $(R, R)$-QuinoxP* (2a) & 0.6 & 7.5 & 46 & $99(S)$ & 44 & $89(S)$ \\
\hline $12^{\pi}$ & $(R)-\mathbf{1 b}(94 \%$ ee $)$ & $(R, R)$-QuinoxP* $(2 \mathbf{a})$ & 0.6 & 7 & 43 & $85(S)$ & 45 & $98(R)$ \\
\hline 13 & $(r a c)-\mathbf{1 b}$ & $(R, R)$-QuinoxP* $(\mathbf{2 a})$ & 0.6 & 5.5 & 50 & $95(S)$ & 48 & $34(R)$ \\
\hline $14^{\#}$ & $(S)-\mathbf{1 b}(>99 \%$ ee $)$ & $\operatorname{BDPB}(\mathbf{2 d})$ & 1.5 & 9 & 84 & $77(S)$ & 0 & - \\
\hline $15^{\#}$ & $(S)-\mathbf{1 b}(>99 \%$ ee $)$ & Xantphos (2e) & 1.5 & 8 & 88 & $17(R)$ & 0 & - \\
\hline
\end{tabular}

${ }^{*}$ Reaction conditions: $1(0.5 \mathrm{mmol}), \mathrm{Cu}(\mathrm{O}-t-\mathrm{Bu})(0.025 \mathrm{mmol})$, ligand $2(0.025 \mathrm{mmol}), \mathbf{3}(0.75 \mathrm{mmol})$ in diethyl ether at $30{ }^{\circ} \mathrm{C}$. tYield of the allylboronate and recovery of the starting material were determined by $1 \mathrm{H}$ NMR of an unpurified reaction mixture using an internal standard. ₹The value of the enantiomeric excess was determined by HPLC analysis of an oxidative derivative or a carbonyl addition product of the allylboronate. SEnantiomeric ratio was determined by HPLC analysis. $\| \mathrm{CuCl}(0.1 \mathrm{mmol})$ and $\mathrm{K}(\mathrm{O}-\mathrm{t}-\mathrm{Bu})(0.1 \mathrm{mmol})$ were used instead of $\mathrm{Cu}(\mathrm{O}-\mathrm{t}-\mathrm{Bu})$. TThe reaction was carried out at a $0.25 \mathrm{mmol}$ scale with $5 \mathrm{~mol} \%$ of catalyst. \#The reaction was carried out at a $0.20 \mathrm{mmol}$ scale with $10 \mathrm{~mol} \%$ of catalyst. 


\section{Mechanism}

Further experiments with deuterated substrates clearly showed that the two enantiomers were converted via distinct pathways, anti- $\mathrm{S}_{\mathrm{N}} 2^{\prime}$ and syn- $\mathrm{S}_{\mathrm{N}} 2$ ' (Figure 2a,b). The reaction of $(1 S, 5 R)-1 d$, deuterated substrate at the 5-position, gave the anti$\mathrm{S}_{\mathrm{N}} 2$ ' product, $(1 S, 4 R)-\mathbf{4 d}$, without regio- and stereochemical disposition of the deuterium (Figure $2 \mathrm{a})$. $(1 R, 5 S)-\mathbf{1 d}$, which is the enantiomer of $(1 S, 5 R)-\mathbf{1 d}$, afforded the diastereomeric syn- $\mathrm{S}_{\mathrm{N}} 2$ ' product, $(1 S, 4 S)-4 d$ (Figure $2 \mathrm{~b})$. The two opposite stereogenic centres at the $\alpha$-carbon of the alkoxy group in the allylic systems in $(1 S, 5 R)-\mathbf{1 d}$ and $(1 S, 4 R)-\mathbf{4 d}$ were dissappered and the new chiral centre at the $\gamma$-carbon with the same absolute configuration was formed, whereas the chiral centres around deuteride remain unchanged. This led to the formation of two product diastereomers from two substrate enantiomers. This stereo-divergent fashion is a characteristic of this type of enantio-convergent transformation when the substrate racemates that have multiple-chiral centers. ${ }^{1}$ As shown in Figure 2c, the experimental results are clearly explained by assuming direct enantio-convergent reaction. The substrate $(S)$ 1b is attacked by the borylcopper(I), a catalytic intermediate generated from alkoxycopper(I) and diboron 3 . When $(R, R)$ QuinoxP* (2a) was used as the ligand, in the reaction of $(S)-\mathbf{1 b}$, the nucleophilic attack takes place on the opposite face (of the carboncarbon double bond) to the leaving alkoxy group $\left(\mathrm{OR}^{2}\right)$ to afford (S)-4b via an anti-S $\mathrm{S}_{\mathrm{N}} 2$ '-type pathway with $99 \%$ ee (Figure $2 \mathrm{c}$ ). In contrast, the same borylcopper(I) intermediate approaches $(R)-\mathbf{1}$ from the same side as the leaving alkoxy group $\left(\mathrm{OR}^{2}\right)$ to give $(S)$ 4b through a syn- $\mathrm{S}_{\mathrm{N}} 2$ '-type reaction with $85 \%$ ee. As shown in Figure $2 \mathrm{~d}$ and c, the reaction of $(S)-\mathbf{1 b}$ predominantly proceeds through an anti- $\mathrm{S}_{\mathrm{N}} 2$ ' pathway when an achiral BDPB ligand was used, whereas when Xantphos was used the reaction tended to proceed via a syn- $\mathrm{S}_{\mathrm{N}} 2$ ' pathway (Table 1 , entries 14 and 15). These results indicate that the anti- or syn- $\mathrm{S}_{\mathrm{N}} 2$ '-type reaction route is flexible and controllable by the ligand structure. Thus, it is reasonable to assume that catalysts with the $(R, R)$-QuinoxP* ligand have sound face selectivity on the double bond and that this overcomes the inherent stereoselectivity (anti- or syn- $\mathrm{S}_{\mathrm{N}} 2$ ') of the borylcopper(I) intermediate toward the allylic substrate. DFT calculations (M05-2X/6-31G(d)) using model compounds were carried out along with four distinct reaction pathways (anti- or syn$\mathrm{S}_{\mathrm{N}} 2$ ' pathways from $(S)-\mathbf{1}$ or $\left.(R)-\mathbf{1}\right)$. The results support our proposed mechanism. For the reaction of $(S)-\mathbf{1}$, anti- $S_{\mathrm{N}} 2^{\prime}$ is favorable over syn- $\mathrm{S}_{\mathrm{N}} 2^{\prime}$; for the reaction of $(R)-\mathbf{1}$, syn- $\mathrm{S}_{\mathrm{N}} 2^{\prime}$ is favorable over the anti- $S_{N} 2$ ' reaction (See Supplementary Information). 


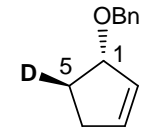

$(1 S, 5 R)-1 d$ $>99 \%$ ee

$\mathrm{Cu}(\mathrm{O}-\mathrm{t}-\mathrm{Bu})(5 \mathrm{~mol} \%)$

$2 \mathrm{a}(5 \mathrm{~mol} \%)$

3 (1.5 equiv)

$\mathrm{Et}_{2} \mathrm{O}, 30^{\circ} \mathrm{C}, 13 \mathrm{~h}$

anti-S ${ }_{\mathrm{N}} 2^{\prime}$

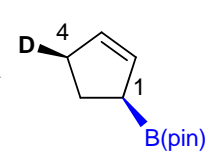

$(1 S, 4 R)-4 d$

$94 \%, 99 \%$ de

\begin{tabular}{|c|c|c|}
\hline $\mathrm{OBn}$ & $\begin{array}{l}\mathrm{Cu}(\mathrm{O}-t-\mathrm{Bu})(5 \mathrm{~mol} \%) \\
2 \mathrm{a}(5 \mathrm{~mol} \%)\end{array}$ & $D_{\prime \prime \prime,}^{4}$ \\
\hline & $\begin{array}{l}3 \text { (1.5 equiv) } \\
\mathrm{Et}_{2} \mathrm{O}, 30^{\circ} \mathrm{C}, 13 \mathrm{~h}\end{array}$ & \\
\hline $\begin{array}{l}(1 R, 5 S)-1 d \\
>99 \% \text { ee }\end{array}$ & syn- $\mathrm{S}_{\mathrm{N}} 2^{\prime}$ & $\begin{array}{l}(1 S, 4 S)-4 d \\
92 \%, 88 \% \text { de }\end{array}$ \\
\hline
\end{tabular}

d

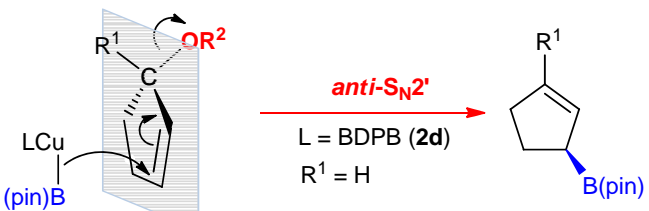

(S)-1b

(S)-4b, 77\% ee

(S)-4b, 92\% ee

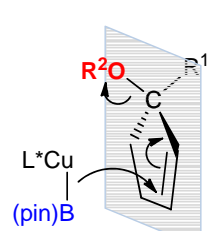

syn- $\mathrm{S}_{\mathrm{N}} 2^{\prime}$

"85\% ee"

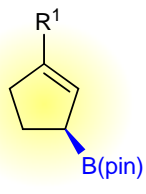

$\mathrm{R}^{1}=\mathrm{H}$

$L^{*}=$ QuinoxP* (2a)

(R)-1b

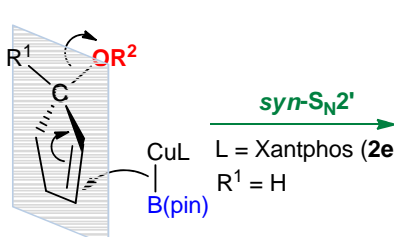

(S)-1b

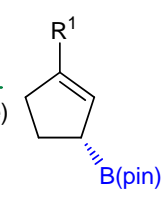

(R)-4b, $17 \%$ ee

Figure 2 | Experimental studies and plausible schematic explanations on mechanism of the direct enantio-convergent transformation. $\mathbf{a}$, The reaction of deuterium labeled substrate, $(1 S, 5 R)-\mathbf{1 d}$, resulted in anti-S $\mathrm{S}_{\mathrm{N}}$ ' product $(1 S, 4 R)-\mathbf{4 d}$. $\mathbf{b}$, The reaction of $(1 R, 5 S)-\mathbf{1 d}$, which is the enantiomer starting material in $\mathbf{a}$, afforded syn- $S_{N} 2$ ' product $(1 S, 4 S)-\mathbf{4 d}$, which is the diastereomer of the product in a. c, Mechanistic scheme for the direct enantio-convergent transformation. The chiral borylcopper(I) intermediate with the chiral ligand (2a or $\mathbf{2 b}$ ) reacts to $(S)-\mathbf{1 b}$ via anti-S $2^{\prime}$ pathway (red arrow) and to $(R)-\mathbf{1 b}$ via syn- $\mathrm{S}_{\mathrm{N}} 2$ ' pathway (green arrow). The same product, $(S)-\mathbf{4 b}$, is produced from both substrate enantiomers by the two distinct pathways. d, Reaction of borylcopper(I) with achiral ligand BDPB (2d) via anti-S $\mathrm{S}_{\mathrm{N}}$ 'route. e, Reaction of borylcopper(I) with achiral ligand Xantphos $(\mathbf{2 e})$ tends to proceed via syn- $\mathrm{S}_{\mathrm{N}} 2^{\prime}$ route 


\section{Construction of all-carbon quaternary stereocentre}

The enantio-enriched allylboronates prepared by the enantio-convergent transformation through copper(I)-catalyzed asymmetric boryl substitution are a valuable synthetic reagent. ${ }^{28-30}$ In particular, the $\alpha$-chiral cyclic allylboronates bearing a substituent at the 3-position can be prepared only by this reaction and provide the homoallylic alcohols with an all-carbon quaternary stereo center, of which selective construction is a challenging issue in synthetic chemistry, by stereoselective aldehyde allylation. The racemic substrates 1a-e were initially subjected to the copper(I)catalyzed enantio-convergent transformation to afford enantioenriched allylboronates, which were subsequently reacted with aldehydes (Figure 3). The aldehyde addition proceeded in a highly stereoselective manner through a six-membered transition state to give homoallylic alcohols $\mathbf{6}$ with an all-carbon quaternary or tertiary stereo-center in high yields with high diastereo- and enantioselectivities (72-91\%, 93-98\% ee, dr >99:1->97:3). The borylation reaction with substrate with a bulky isopropyl substituent (1f) gave the corresponding allylboronate in good yield with slightly lower enantioselectivity $(78 \%, 85 \%$ ee) when $(R, R)$ Me-Duphos ligand (2b) was used; however the subsequent aldehyde addition was very slow. A carbonate with cyclohexenyl structure (1g) also gave a good result with $10 \mathrm{~mol} \%$ catalyst (84\%, $91 \%$ ee, dr>99:1); however the reaction with a similar sevenmembered ring substrate, 2-cyclohepten-1-yl methyl carbonate, resulted in a poor enantioselectivity $(65 \%, 44 \%$ ee). Interestingly, the reaction of a linear substrate with unsymmetrical substituents, (Z)-methyl (6-phenylhex-3-en-2-yl) carbonate, proceeded in a typical kinetic resolution manner (allylboronate product, 47\%, $80 \%$ ee; recovered starting material, $46 \%$ yield, $82 \%$ ee, See Supplementary
Information).
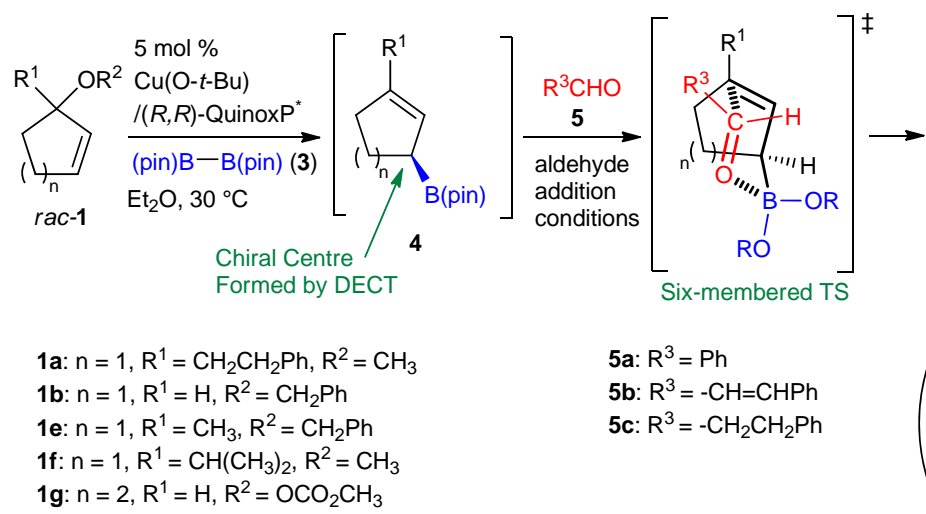

5a: $\mathrm{R}^{3}=\mathrm{Ph}$

5b: $\mathrm{R}^{3}=-\mathrm{CH}=\mathrm{CHPh}$

5c: $\mathrm{R}^{3}=-\mathrm{CH}_{2} \mathrm{CH}_{2} \mathrm{Ph}$

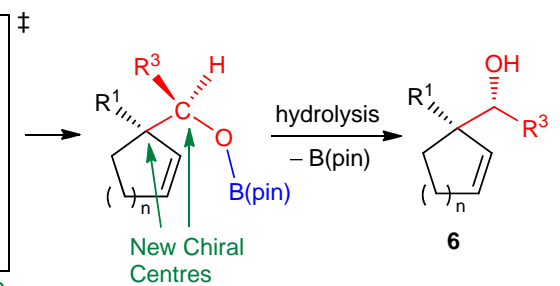

Centres

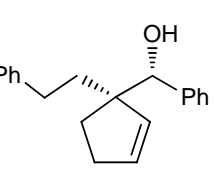

(S,S)-6aa, 85\% $97 \%$ ee, $d r>99: 1$

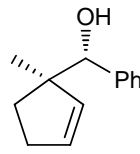

$(S, R)-6$ ea, $80 \%$ $98 \%$ ee, dr $>99: 1$<smiles>O[C@H](/C=C/c1ccccc1)[C@]1(CCc2ccccc2)C=CCC1</smiles>

$(R, S)-6 \mathbf{a b}, 72 \%$ $97 \%$ ee, $d r>97: 3$

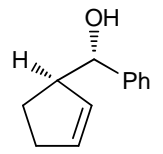

$(S, R)-6$ ba, $91 \%$ $93 \%$ ee, $d r>99: 1$

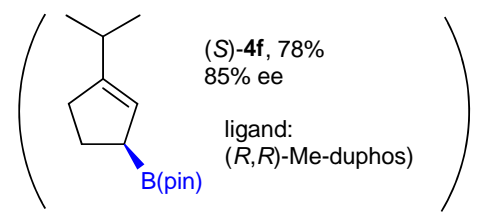

Figure 3 | Synthesis of enantio-enriched homoallylic alcohols with an all-carbon quaternary or tertiary stereocentre via the copper(I)catalyzed enantio-convergent transformation and subsequent stereoselective aldehyde allylation. The direct enantio-convergent reaction of allylic ether or carbonate ( $r a c-1)$ with diboron 3 was first conducted in the presence of $\mathrm{Cu}(\mathrm{O}-\mathrm{t}-\mathrm{Bu}) / \mathrm{QuinoxP}{ }^{*} \mathrm{catalyst}$ at $30^{\circ} \mathrm{C}$. After completion of the copper(I)-catalyzed reaction and rough purification of the allylboronate $\mathbf{4}$, subsequent reaction with aldehyde $\mathbf{5}$ was carried out in the presence $\left(30^{\circ} \mathrm{C}\right.$ in toluene) or absence of a Lewis acid catalyst $\left(\mathrm{BF}_{3} \cdot \mathrm{OEt}_{2},-78^{\circ} \mathrm{C}\right.$ in $\left.\mathrm{CH}_{2} \mathrm{Cl}_{2}\right)$. The addition reaction proceeded via six-membered ring transition state to produce homoallylic alcohol 6 with two newly formed chiral stereocentres after hydrolysis. The ee values of 6 were determined by HPLC analysis with a chiral stationary phase.

\section{Discussion}

The present transformation shows interesting similarity to a class of asymmetric reactions that are called as "divergent reactions on a racemic mixture" by Kagan; ${ }^{3}$ these reactions may include parallel kinetic resolution, regio- and stereo-divergent reactions. $^{31-37}$ In such reactions, two enantiomers of a racemic mixture were converted into "distinct" enantioenriched products through different pathways. Contrary to this, the present reaction transforms the substrate enantiomers into the "same" enantioenriched product through different pathways. The divergent or parallel asymmetric reactions are advantageous as compared to classical kinetic resolution in efficiency because the efficiency of the resolution was the simple sum of the selectivity of the two independent pathways when the two pathways have similar reaction rates. ${ }^{3,31}$ The similar feature was also observed in the present transformation (Table 1, entries 11-13). This enantio- convergent transformation can be considered as a special "convergent" case of the "divergent reactions on a racemic mixture".

The key to the success in the present enantio-convergent reaction as well as other divergent type reactions is that the reagent control ability of the external chiral reactive species is significantly more superior to the substrate control nature that was caused by the influence of the internal chiral structure of the racemic substrate. Tomioka et al. reported a relevant two step enantio-convergent procedure, which includes a reagent-controlled reaction. ${ }^{38}$ In our reaction, the single catalytic reaction promotes the reagentcontrolled enantioselective addition and the elimination of the stereogenic leaving groups. 
In summary, we have presented the first chemical direct enantio-convergent transformation (DECT) without racemization or symmetrization process promoted by an artificial catalyst. The known dynamic processes (e.g., DKR and DYKAT) require racemization or symmetrization of the substrates or the intermediates; thus only "labile" racemates can be treated by these dynamic procedures. In contrast, the present reaction can access racemates with the structural feature that is not suitable for racemization or symmetrization. Reaction of such "robust" racemic compounds with a chiral catalyst usually results in KR because the substrate-controlled stereoselectivity and reagent-controlled enantioselectivity of the catalyst are in conflict with the conversion of the less reactive substrate enantiomer. In our direct enantioconvergent reaction, superiority in reagent-controlling enantioselective ability against the stereoselectivity occurred under the influence of the substrate chiral center enables the convergence of both substrate enantiomers into the single chiral product. Although the present reaction is effective on rather limited substrates, we believe that our study provides a novel principle for the development of chemical enantio-convergent reactions for the robust racemates that cannot be treated by known dynamic methods.

\section{Methods.}

In a nitrogen gas filled glove box, copper(I) tert-butoxide (3.4 mg, $0.025 \mathrm{mmol})$, ligand $(0.025 \mathrm{mmol})$ and bis(pinacolato)diboron 2 (190 mg, $0.75 \mathrm{mmol}$ ) were placed into a vial and mixed with dry diethyl ether $(0.5 \mathrm{ml})$ with stirring. After being sealed with a rubber septum, the reaction vial was removed from the glovebox and was connected to an argon line through a needle. Allylic ether $1(0.5 \mathrm{mmol})$ was added drop wise to the mixture at $30^{\circ} \mathrm{C}$. After the reaction was complete, the reaction mixture was directly subjected to column chromatography $\left(\mathrm{SiO}_{2}\right.$, hexane:diethyl ether=100:0-99.0:1.0) to give the crude allylboronate 3 as a colourless oil. The yield was estimated by ${ }^{1} \mathrm{H}$ NMR using mesitylene as the internal standard.

\section{References}

1 Faber, K., Non-sequential processes for the transformation of a racemate into a single stereoisomeric product: proposal for stereochemical classification. Chem. Eur. J. 7, 5004-5010 (2001).

2 Steinreiber, J., Faber, K., \& Griengl, H., De-racemization of enantiomers versus de-epimerization of diastereomersclassification of dynamic kinetic asymmetric transformations (DYKAT). Chem. Eur. J. 14, 8060-8072 (2008).

3 Kagan, H. B. Various aspects of the reaction of a chiral catalyst or reagent with a racemic or enantiopure substrate. Tetrahedron 57, 2449-2459 (2001).

4 Vedejs, E. \& Jure, M., Efficiency in nonenzymatic kinetic resolution. Angew. Chem. Int. Ed. 44, 3974-4001 (2005).

5 Gao, Y. et al., Catalytic asymmetric epoxidation and kinetic resolution: modified procedures including in situ derivatization. J. Am. Chem. Soc. 109, 5765-5780 (1987).

6 Tokunaga, M., Larrow, J. F., Kakiuchi, F., \& Jacobsen, E. N., Asymmetric catalysis with water: efficient kinetic resolution of terminal epoxides by means of catalytic hydrolysis. Science 277, 936-938 (1997).

7 Noyori, R., Tokunaga, M., \& Kitamura, M., Stereoselective organic synthesis via dynamic kinetic resolution. Bull. Chem. Soc. Jpn. 68, 36-55 (1995).

8 Huerta, F. F., Minidis, A. B. E., \& Bäckvall, J. E., Racemization in asymmetric synthesis. Dynamic kinetic resolution and related processes in enzyme and metal catalysis. Chem. Soc. Rev. 30, 321-331 (2001).

9 Pellissier, H., Recent developments in dynamic kinetic resolution. Tetrahedron 64, 1563-1601 (2008).
10 Trost, B. M., Pd asymmetric allylic alkylation (AAA). A powerful synthetic tool. Chem. Pharm. Bull. 50, 1-14 (2002).

11 Trost, B. M. \& Crawley, M. L., Asymmetric transition-metalcatalyzed allylic alkylations: Applications in total synthesis. Chem. Rew. 103, 2921-2943 (2003).

12 Hayashi, T. et al., Chiral ( $\beta$-aminoalkyl)phosphines. Highly efficient phosphine ligands for catalytic asymmetric Grignard cross-coupling. J. Org. Chem. 48, 2195-2202 (1983).

13 Norinder, J. \& Bäckvall, J., Dynamic processes in the coppercatalyzed substitution of chiral allylic acetates leading to loss of chiral information. Chem. Eur. J. 13, 4094-4102 (2007).

$14 \mathrm{Lu}, \mathrm{Z}$. \& Ma, S., Metal-catalyzed enantioselective allylation in asymmetric synthesis. Angew. Chem. Int. Ed. 47, 258-297 (2008).

15 Trost, B. M., Bunt, R. C., Lemoine, R. C., \& Calkins, T. L., Dynamic kinetic asymmetric transformation of diene monoepoxides: A practical asymmetric synthesis of vinylglycinol, vigabatrin, and ethambutol. J. Am. Chem. Soc. 122, 5968-5976 (2000).

16 Trost, B. M. \& Toste, F. D., Palladium-catalyzed kinetic and dynamic kinetic asymmetric transformation of 5-acyloxy-2$(5 \mathrm{H})$-furanone. Enantioselective synthesis of (-)-aflatoxin B lactone. J. Am. Chem. Soc. 121, 3543-3544 (1999).

17 Trost, B. M., Dudash, J., \& Hembre, E. J., Asymmetric induction of conduritols via AAA reactions: synthesis of the aminocyclohexitol of hygromycin A. Chem. Eur. J. 7, 16191629 (2001)

18 Langlois, J. \& Alexakis, A., Dynamic kinetic asymmetric transformation in copper-catalyzed allylic alkylation. Chem. Commun. 3868-3870 (2009).

19 Pedragosa-Moreau, S., Archelas, A., \& Furstoss, R., Microbiological transformations 28. Enantiocomplementary epoxide hydrolyzes as a preparative access to both enantiomers of styrene oxide. J. Org. Chem. 58, 5533-5536 (1993).

20 Kroutil, W., Mischitz, M., \& Faber, K., Deracemization of (+/)-2,3-disubstituted oxiranes via biocatalytic hydrolysis using epoxide hydrolases: kinetics of an enantioconvergent process. J. Chem. Soc., Perkin Trans. 1 3629-3636 (1997).

21 Ito, H. et al., Copper-catalyzed enantioselective substitution of allylic carbonates with diboron: An efficient route to optically active $\alpha$-chiral allylboronates. J. Am. Chem. Soc. 129, 1485614857 (2007).

22 Ito, H. et al., Synthesis of optically active boron-silicon bifunctional cyclopropane derivatives through enantioselective copper(I)-catalyzed reaction of allylic carbonates with a diboron derivative. Angew. Chem., Int. Ed. 47, 7424-7427 (2008).

23 Ito, H., Okura, T., Matsuura, K., \& Sawamura, M., Desymmetrization of meso-2-alkene-1,4-diol derivatives through copper(I)-catalyzed asymmetric boryl substitution and stereoselective allylation of aldehydes. Angew. Chem. Int. Ed. 49, 560-563 (2010).

24 Corey, E. \& Guzman-Perez, A., The catalytic enantioselective construction of molecules with quaternary carbon stereocenters. Angew. Chem. Int. Ed. 37, 388-401 (1998).

25 Christoffers, J. \& Baro, A. (eds) Quaternary Stereocenters: Challenges and Solutions for Organic Synthesis. (Wiley-VCH, Weinheim, 2006).

26 Trost, B. \& Jiang, C., Catalytic enantioselective construction of all-carbon quaternary stereocenters. Synthesis 369-396 (2006).

27 Imamoto, T., Sugita, K., \& Yoshida, K., An air-stable P-chiral phosphine ligand for highly enantioselective transition-metalcatalyzed reactions. J. Am. Chem. Soc. 127, 11934-11935 (2005).

28 Hall, D. G. (ed) Boronic acids: preparation and applications in organic synthesis and medicine. (Wiley-VCH, Weinheim, 2005).

29 Ramachandran, R. V. Pinane-based versatile "allyl"boranes. Aldrichimica Acta 35, 23-35 (2002). 
30 Hall, D. G., Lewis and Brønsted acid catalyzed allylboration of carbonyl compounds: from discovery to mechanism and applications. Synlett, 1644-1655 (2007).

31 Vedejs, E. \& Chen, X. H. Parallel kinetic resolution. J. Am. Chem. Soc. 119, 2584-2585 (1997).

32 Tanaka, K. \& Fu, G. C. Parallel kinetic resolution of 4-alkynals catalyzed by Rh(I)/Tol-BINAP: synthesis of enantioenriched cyclobutanones and cyclopentenones. J. Am. Chem. Soc. 125, 8078-8079 (2003).

33 Webster, R., Boing, C. \& Lautens, M. Reagent-controlled regiodivergent resolution of unsymmetrical oxabicyclic alkenes using a cationic rhodium catalyst. J. Am. Chem. Soc. 131, 444-445 (2009).

$34 \mathrm{Wu}$, B., Parquette, J. R. \& RajanBabu, T. V. Regiodivergent ring opening of chiral aziridines. Science 326, 1662-1662 (2009).

35 Reetz, M. T., Strack, T. J., Mutulis, F. \& Goddard, R. Asymmetric dihydroxylation of chiral gamma-amino $\alpha, \beta-$ unsaturated esters: turning the mismatched into the matched case via protective group tuning. Tetrahedron Lett 37, 92939296 (1996).

36 Matsumura, K., Hashiguchi, S., Ikariya, T. \& Noyori, R. Asymmetric transfer hydrogenation of $\alpha, \beta$-acetylenic ketones. J. Am. Chem. Soc. 119, 8738-8739 (1997).

37 Ohmura, T. \& Suginome, M. Asymmetric silaboration of terminal allenes bearing $\alpha$-stereogenic centers: stereoselection based on "reagent control". Org. Lett. 8, 2503-2506 (2006).

38 Chen, O. et al. Asymmetric synthesis of 5-arylcyclohexenones by rhodium(I)-catalyzed conjugate arylation of racemic 5(trimethylsilyl)cyclohexenone with arylboronic acids. Org. Lett. 7, 4439-4441 (2005).

Supplementary Information accompanies the paper on http://www.nature.com/nchem.

Acknowledgments This work was supported by a Grant-in-Aid for Scientific Research (B) (JSPS) and the PRESTO program (JST). We thank Prof. Tamotsu Inabe, Hokkaido University, for his assistance in X-ray analysis. Nippon Chemical Industrial Co., Ltd. is gratefully acknowledged for gift of $(R, R)$-QuinoxP* We also acknowledge DAICEL chemical industries for their help on the optical resolution of some starting materials.

Author Contributions H. I. directed this study. Experiments were carried out by S. K. and H. I. DFT calculations (Supplementary Information) were carried out by H. I. M. S. gave comments on the reaction mechanism and the preparation of the enantio-enriched starting materials.

Author Information Reprints and permission information is available online at http://www.nature.com/nchem. Correspondence and requests for materials should be addressed to $\mathrm{H}$. I. (hajito@sci.hokudai.ac.jp). 


\section{Direct enantio-convergent transformation of racemic substrates without racemization or symmetrization}

Hajime Ito, $^{\dagger * *}$ Shun Kunii, ${ }^{\dagger}$ and Masaya Sawamura ${ }^{\dagger}$

${ }^{\dagger}$ Department of Chemistry, Faculty of Science, Hokkaido University, Sapporo 060-0810, Japan

${ }^{\ddagger}$ PRESTO, Japan Science and Technology Agency (JST), Honcho, Kawaguchi, Saitama 332-0012, Japan

e-mail: hajito@sci.hokudai.ac.jp

1. General p S2

2. Preparation and Spectral Data of Allylic Ethers (for Table 1)

p S3-7

3. Synthesis, Spectral Data of Allylboronates (for Table 1) p S8-11

4. Synthesis, Spectral Data and Stereochemical Assignment of Homoallylalcohols (for Figure 3)

5. Synthesis and Reaction of 1d (for Figure 2a,b)

6. DFT Studies

7. References p S26

8. $\quad{ }^{1} \mathrm{H}$ and ${ }^{13} \mathrm{C}$ NMR Spectra Charts p S27-60 
General. Materials were obtained from commercial suppliers and purified by the standard procedure unless otherwise noted. Solvents were purchased from commercial suppliers, degassed via three freeze-pump-thaw cycles, and further dried on MS 4A. Bis(pinacolato)diboron was purchased from AllyChem, Co., Ltd. (70,000 JPY/250 g). (R,R)- and (S,S)-QuinoxP* were provided from Nippon Chemical Industrial Co. and used as received. Other chiral phosphine ligands were purchased from commercial suppliers. $\mathrm{Cu}(\mathrm{O}-\mathrm{t}-\mathrm{Bu})$ was prepared according to the reported procedure. $^{1,2}$ The reproducibirity of the reaction rate depends on the purity of $\mathrm{Cu}(\mathrm{O}-\mathrm{t}-\mathrm{Bu})$. When the reaction is found to be slow, the re-sublimation of $\mathrm{Cu}(\mathrm{O}-t-\mathrm{Bu})$ can improve the activity. Copper(I) chloride (ReagentPlus grade), THF solution of potassium tert-butoxide (1.0 M) were purchased from Aldrich Chemical Co., Ltd. Optical resolution of (rac)-1a using preparative HPLC on a chiral phase was conducted by DAICEL Chemical Industries, Ltd. (rac)-1b was prepared form 2-cyclopentenol and benzyl bromide according to the standard procedure. ${ }^{3}$ Recycle gel-permeation chromatography was conducted using JAI LC-9101.

NMR spectra were recorded on Varian Gemini $2000\left({ }^{1} \mathrm{H}: 300 \mathrm{MHz},{ }^{13} \mathrm{C}: 75.4 \mathrm{MHz}\right)$ and JEOL JNM-ECA-500 ( $\left.{ }^{1} \mathrm{H}: 500 \mathrm{MHz},{ }^{13} \mathrm{C}: 125.7 \mathrm{MHz}\right)$ spectrometers. Tetramethylsilane $\left({ }^{1} \mathrm{H}\right)$ and $\mathrm{CDCl}_{3}$ $\left({ }^{13} \mathrm{C}\right)$ were employed as internal standards, respectively. Gas chromatographic (GLC) analyses were conducted on a Shimadzu GC-14B equipped with a flame ionization detector. HPLC analyses were carried out using Hitachi Elite LaChrome HPLC system with L-2400 UV detector. IR spectra were recorded on a Perkin-Elmer Spectrum One. Low- and high-resolution mass spectra were recorded on a JEOL JMS-700TZ, JMS-T100L, JMS-T100GC, Thermo Fisher Scientific LTQ-Orbitrap XL, and Thermo Fisher Scientific Exactive mass spectrometers at the Center for Instrumental Analysis, Hokkaido University. 


\section{Preparation and spectral data of allylic ethers.}

\section{[2-(1-Methoxycyclopent-2-enyl)ethyl]benzene (1a).}

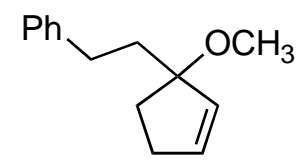

$1 a$

Pre-dehydrated $\mathrm{CeCl}_{3}$ was prepared by heating $\mathrm{CeCl}_{3} \cdot 7 \mathrm{H}_{2} \mathrm{O}$ at $100{ }^{\circ} \mathrm{C}$ under reduced pressure (approx. $30 \mathrm{~Pa}$ ). The pre-dried $\mathrm{CeCl}_{3}(6.43 \mathrm{~g}, 26 \mathrm{mmol}$ ) was placed in a three-necked $200 \mathrm{~mL}$ flask equipped with a dropping funnel and a magnetic stirrer bar. The flask was connected to a vacuum line and evacuated and heated. The temperature was gradually raised from room temperature to $145{ }^{\circ} \mathrm{C}$ for $40 \mathrm{~min}$ with gentle stirring. After being heated at $145^{\circ} \mathrm{C}$ for additional $2 \mathrm{~h}$ and then cooled to room temperature, the flask was carefully backfilled with argon gas. Dry THF (60 mL) was added to the flask and stirred over night. A THF solution of 2-phenethylmagnesium bromide (1.62 M, $16.05 \mathrm{~mL}, 26 \mathrm{mmol}$ ) was added dropwise to the resultant white-gray slurry at $0{ }^{\circ} \mathrm{C}$ with stirring. After 2 h, 2-cyclopenten-1-one (1.64 g, $20 \mathrm{mmol})$ was added dropwise and reaction mixture was stirred at $0{ }^{\circ} \mathrm{C}$ for $2 \mathrm{~h}$ and at room temperature for $2.5 \mathrm{~h}$. The reaction mixture was added by $\mathrm{NH}_{4} \mathrm{Cl}$ aq. and the resultant gray slurry was filtered through a celite pad. THF solvent was evaporated under reduced pressure, and the resultant mixture was extracted with ethyl acetate three times, washed with brine. The combined organic layer was dried over $\mathrm{MgSO}_{4}$, then filtered and evaporated. The crude product was purified by column chromatography $\left(\mathrm{SiO}_{2}\right.$, hexane:EtOAc, 85:15 v/v) to give 1-phenethylcyclopent-2-enol as a colorless oil (2.92 g, $15.4 \mathrm{mmol}, 77 \%)$.

In a two-necked $200 \mathrm{~mL}$ flask, 60\% sodium hydride in mineral oil (1.13 g, $28.3 \mathrm{mmol}$ ) was placed and washed with dry hexane three times under an argon atmosphere. To the flask, dry THF (75 ml) and 1-phenethylcyclopent-2-enol (2.92 g, $15.4 \mathrm{mmol}$ ) was successively added with stirring. Methyl iodide $(0.92 \mathrm{~mL}, 18.6 \mathrm{mmol})$ was added at $0{ }^{\circ} \mathrm{C}$ and the reaction mixture was stirred for 17 h. After treatment with $\mathrm{Na}_{2} \mathrm{CO}_{3}$ aq., the mixture was extracted with ethyl acetate three times, washed with brine. The combined organic layer was dried over $\mathrm{MgSO}_{4}$, then filtered and 
evaporated. The crude product was purified by column chromatography $\left(\mathrm{SiO}_{2}\right.$, hexane:EtOAc, 98:2 v/v) and bulb-to-bulb distillation (bath temp., $90{ }^{\circ} \mathrm{C}, 10 \mathrm{~Pa}$ ) to give $\mathbf{1 a}$ as a colorless oil (2.17 $\mathrm{g}$, 15.4 mmol, 69\%). TLC (hexane:EtOAc, 90:10 v/v): $\mathrm{R}_{\mathrm{F}}=0.47 ;{ }^{1} \mathrm{H}-\mathrm{NMR}\left(300 \mathrm{MHz}, \mathrm{CDCl}_{3}\right): \delta$ 7.32-7.12 (m, 5H), 6.02 (dt, $J=5.8,2.3 \mathrm{~Hz}, 1 \mathrm{H}), 5.66$ (dt, $J=5.8,2.2 \mathrm{~Hz}, 1 \mathrm{H}), 3.18$ (s, 3H), 2.68 (t, $J=8.5 \mathrm{~Hz}, 2 \mathrm{H}), 2.53-2.28$ (m, 2H), 2.08-1.79 (m, 4H) p.p.m.; ${ }^{13} \mathrm{C}-\mathrm{NMR}\left(75.4 \mathrm{MHz}, \mathrm{CDCl}_{3}\right): \delta$ $142.9(\mathrm{C}), 135.2(\mathrm{CH}), 133.3(\mathrm{CH}), 128.39(\mathrm{CH}), 128.36(\mathrm{CH}), 125.7(\mathrm{CH}), 90.8(\mathrm{C}), 50.1\left(\mathrm{CH}_{3}\right)$, $41.4\left(\mathrm{CH}_{2}\right), 31.8\left(\mathrm{CH}_{2}\right), 31.7\left(\mathrm{CH}_{2}\right), 30.5\left(\mathrm{CH}_{2}\right)$ p.p.m.; IR (neat): $3027(\mathrm{w}), 2934(\mathrm{~m}), 1603(\mathrm{w})$, 1455 (s), 1070 (s), 697 (s) cm ${ }^{-1}$; HRMS-ESI (m/z): [M+Na $]^{+}$calcd for $\mathrm{C}_{14} \mathrm{H}_{18} \mathrm{ONa}, 225.12553$; found, 225.12486; analysis (\% calcd, \% found for $\left.\mathrm{C}_{14} \mathrm{H}_{18} \mathrm{O}\right)$ : C (83.12, 82.75), $\mathrm{H}(8.97,9.09)$.

(+)-1a and (-)-1a were prepared by optical resolution using preparative HPLC on a chiral stationary phase (CHIRALPAK IB, hexane:tert-butyl methyl ether, 98:2 v/v). The ee values of the resolved samples were checked by HPLC analysis on a chiral phase (CHIRALCEL OD-3, hexane:2-propanol, 99.5:0.5 v/v, $\left.0.5 \mathrm{~mL} / \mathrm{min}, 40^{\circ} \mathrm{C}\right) .(+)-1 \mathrm{a}: \mathrm{t}_{\mathrm{R}}=21.6 \mathrm{~min} .[\alpha]^{\mathrm{D}}{ }_{26}\left(\mathrm{deg} \mathrm{cm}^{3} \mathrm{~g}^{-1} \mathrm{dm}^{-1}\right)$ $=+29.7\left(99 \%\right.$ ee, $c=0.98$ in $\left.\mathrm{CHCl}_{3}\right) .(-)-\mathbf{1 a}: \mathrm{t}_{\mathrm{R}}=20.2 \mathrm{~min} .[\alpha]_{24}^{\mathrm{D}}\left(\mathrm{deg} \mathrm{cm}^{3} \mathrm{~g}^{-1} \mathrm{dm}^{-1}\right)=-30.1(>99 \%$ ee, $c=0.99$ in $\left.\mathrm{CHCl}_{3}\right)$.

\section{Benzyl 3-d-cyclopent-2-en-1-yl ether (1c).}

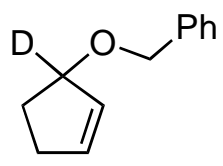

1c

In a 200mL round bottomed flask, $\mathrm{NaBD}_{4}(1.0 \mathrm{~g}, 23.9 \mathrm{mmol}, 99 \mathrm{~atm} \% \mathrm{D})$ was added portionwise to a mixture of 2-cyclopetenone $(1.96 \mathrm{~g}, 23.9 \mathrm{mmol})$ and $\mathrm{CeCl}_{3} \cdot 7 \mathrm{H}_{2} \mathrm{O}(2.67 \mathrm{~g}, 7.2$ mmol) and $\mathrm{MeOH}(60 \mathrm{~mL})$ at $0{ }^{\circ} \mathrm{C}$. After vigorous evolution of gas was ceased, the reaction mixture was allowed to warm to room temperature, evaporated to remove $\mathrm{MeOH}$, and separated after addition of water and $\mathrm{Et}_{2} \mathrm{O}$. The aqueous layer was further extracted four times with $\mathrm{Et}_{2} \mathrm{O}$ and the combined organic layer was washed with brine, dried over $\mathrm{Na}_{2} \mathrm{SO}_{4}$, filtered and evaporated. The 
resultant crude mixture was further dried by passed through a small $\mathrm{K}_{2} \mathrm{CO}_{3}$ column with a small volume of $\mathrm{Et}_{2} \mathrm{O}$ eluent. The crude alcohol was transferred into a THF (100 mL) suspension of NaH, which was prepared by washing $\mathrm{NaH}$ in mineral oil $(60 \%, 1.48 \mathrm{~g}, 37 \mathrm{mmol})$ with hexane three times, at $0{ }^{\circ} \mathrm{C}$ under an argon atmosphere. After stirred for $40 \mathrm{~min}$, benzyl bromide (2.38 mL, 20 mmol) and tetrabutylammonium iodide (1.18 g, $3.19 \mathrm{mmol})$ were successively added at room temperature. After being stirred for 2 h, the reaction mixture was quenched by addition of $\mathrm{NH}_{3}$ aq., extracted three times with $\mathrm{Et}_{2} \mathrm{O}$ after addition of $\mathrm{NaCl}$. The combined organic layer was dried over $\mathrm{Na}_{2} \mathrm{SO}_{4}$, filtered and evaporated. The crude product was purified by column chromatography $\left(\mathrm{SiO}_{2}\right.$, hexane:EtOAc, 95.5:0.5 v/v) and bulb-to-bulb distillation (bath temp., $80{ }^{\circ} \mathrm{C}, 20 \mathrm{~Pa}$ ) to give $\mathbf{1 c}$ as a colorless oil (1.49 g, 8.5 mmol, 36\%, 95 atm \% D). TLC (hexane:EtOAc, 90:10 v/v): $\mathrm{R}_{\mathrm{F}}=0.48$; ${ }^{1} \mathrm{H}-$ NMR (300 MHz, $\left.\mathrm{CDCl}_{3}\right): \delta 7.38-7.20(\mathrm{~m}, 5 \mathrm{H}), 6.03$ (dt, $\left.J=6.0,2.3 \mathrm{~Hz}, 1 \mathrm{H}\right), 5.89(\mathrm{dt}, J=5.8,2.2$ Hz, 1H), 4.56 (d, $J=11.6 \mathrm{~Hz}, 1 \mathrm{H}), 4.50$ (d, $J=11.8 \mathrm{~Hz}, 1 \mathrm{H}), 2.58-2.44$ (m, 1H), 2.30-2.18 (m, 1H), 2.18-2.11 (m, 1H), 1.85 (ddd, $J=13.2,8.5,4.4$ Hz, 1H) p.p.m.; ${ }^{13}$ C-NMR (75.4 MHz, $\mathrm{CDCl}_{3}$ ):

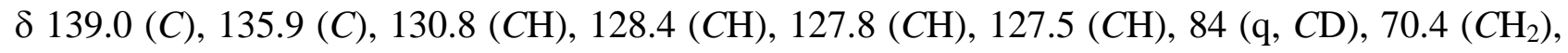
$31.0\left(\mathrm{CH}_{2}\right)$, $29.5\left(\mathrm{CH}_{2}\right)$ p.p.m.; IR (neat): 3062 (m), 2853 (m), $2121(\mathrm{w}), 1354(\mathrm{~m}), 1070$ (s), 695 (s) $\mathrm{cm}^{-1}$; HRMS-EI (m/z): [M+Na] $]^{+}$calcd for $\mathrm{C}_{12} \mathrm{H}_{13} \mathrm{DO}, 175.11074$; found, 175.11074 .

\section{Benzyl 1-methylcyclopent-2-en-1-yl ether (1e).}

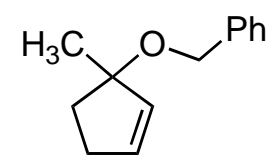

$1 e$

This compound was prepared by the similar procedure described for 1a by using MeLi instead of 2-phenethylmagnesium bromide. The crude product was purified by column chromatography $\left(\mathrm{SiO}_{2}\right.$, hexane:EtOAc, 99.5:0.5 v/v) and recycle gel-permeation chromatography (15\% isolated yield). The compound was dried under reduced pressure before use. Distillation led to decomposition even under reduced pressure. 1e: TLC (hexane:EtOAc, 90:10 v/v): $\mathrm{R}_{\mathrm{F}}=0.46 ;{ }^{1} \mathrm{H}-\mathrm{NMR}(300 \mathrm{MHz}$, 
$\left.\mathrm{CDCl}_{3}\right): \delta 7.37-7.20(\mathrm{~m}, 5 \mathrm{H}), 5.96(\mathrm{dt}, J=5.8,2.2 \mathrm{~Hz}, 1 \mathrm{H}), 5.70(\mathrm{dt}, J=5.8,2.2 \mathrm{~Hz}, 1 \mathrm{H}), 4.39(\mathrm{~d}$, $J=11.6 \mathrm{~Hz}, 1 \mathrm{H}), 4.34(\mathrm{~d}, J=11.6 \mathrm{~Hz}, 1 \mathrm{H}), 2.55-2.31(\mathrm{~m}, 2 \mathrm{H}), 2.14$ (ddd, $J=13.7,8.8,4.7 \mathrm{~Hz}$, 1H), 1.84 (ddd, $J=13.7,8.5,4.9 \mathrm{~Hz}, 1 \mathrm{H}), 1.44$ (s, 3H) p.p.m. ${ }^{13} \mathrm{C}-\mathrm{NMR}\left(75.4 \mathrm{MHz}, \mathrm{CDCl}_{3}\right): \delta$ $140.0(\mathrm{C}), 135.5(\mathrm{CH}), 134.2(\mathrm{CH}), 128.3(\mathrm{CH}), 127.5(\mathrm{CH}), 127.2(\mathrm{CH}), 88.8(\mathrm{C}), 65.0\left(\mathrm{CH}_{2}\right), 34.5$ ( $\left.\mathrm{CH}_{2}\right)$, $31.7\left(\mathrm{CH}_{2}\right), 26.6\left(\mathrm{CH}_{3}\right)$ p.p.m.; IR (neat): 3031 (m), 2968 (m), 1453 (m), 1355 (m), 1082 (s), 695 (s) $\mathrm{cm}^{-1}$; HRMS-ESI (m/z): $[\mathrm{M}+\mathrm{Na}]^{+}$calcd for $\mathrm{C}_{13} \mathrm{H}_{16} \mathrm{ONa}, 211.10934$; found, 211.10950; analysis (\% calcd, \% found for $\left.\mathrm{C}_{13} \mathrm{H}_{16} \mathrm{O}\right)$ : $\mathrm{C}$ (82.94, 82.65), $\mathrm{H}(8.57,8.70)$.

\section{3-Isopropyl-3-methoxycyclopent-1-ene (1f).}

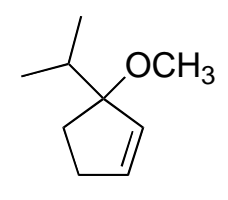

$1 f$

This compound was prepared by the similar procedure described for 1a by using 2propylmagnesium bromide instead of 2-phenethylmagnesium bromide. The crude product was purified by column chromatography ( $\mathrm{SiO}_{2}$, hexane: $\left.\mathrm{Et}_{2} \mathrm{O}, 98: 2 \mathrm{v} / \mathrm{v}\right)$ and bulb-to-bulb distillation (bath temp., $50{ }^{\circ} \mathrm{C}, 20 \mathrm{~Pa}$ ) to give $\mathbf{1 f}$ as a colorless oil (19\% isolated yield). 1f: TLC (hexane:EtOAc, 90:10 v/v): $\mathrm{R}_{\mathrm{F}}=0.47 ;{ }^{1} \mathrm{H}-\mathrm{NMR}\left(300 \mathrm{MHz} \mathrm{CDCl}_{3}\right): \delta 6.01(\mathrm{dt}, J=5.8,2.5 \mathrm{~Hz}, 1 \mathrm{H}), 5.54(\mathrm{dt}, J=$ 5.8, $2.2 \mathrm{~Hz}, 1 \mathrm{H}), 3.11$ (s, 3H), 2.48-2.34 (m, 1H), 2.32-2.19 (m, 1H), 1.93 (quint, $J=6.9 \mathrm{~Hz}, 1 \mathrm{H}$ ), 1.82 (dt, $J=8.5,5.5 \mathrm{~Hz}, 2 \mathrm{H}), 0.90$ (d, $J=6.9 \mathrm{~Hz}, 1 \mathrm{H}), 0.85$ (d, $J=6.9 \mathrm{~Hz}, 1 \mathrm{H})$ p.p.m. ${ }^{13} \mathrm{C}-\mathrm{NMR}$ (75.4 MHz, $\left.\mathrm{CDCl}_{3}\right): \delta 135.2(\mathrm{CH}), 132.3(\mathrm{CH}), 94.5(\mathrm{C}), 49.9\left(\mathrm{CH}_{3}\right), 35.1\left(\mathrm{CH}_{3}\right), 32.1\left(\mathrm{CH}_{2}\right), 28.0$ $\left(\mathrm{CH}_{2}\right), 17.7\left(\mathrm{CH}_{3}\right), 17.0\left(\mathrm{CH}_{3}\right)$ p.p.m. HRMS-ESI (m/z): [M] $]^{+}$calcd for $\mathrm{C}_{9} \mathrm{H}_{16} \mathrm{O}, 140.1201$; found, 140.1204.

(S)-3-Benzyloxycyclopentene $[(S)-1 b]$ and $(R)$-3-benzyloxycyclopentene $[(R)-1 b]$.

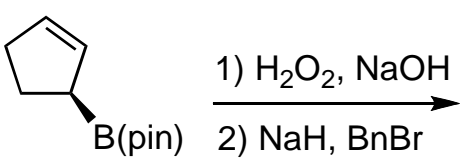

(S)-4b<smiles>CCCC1C=CCC1</smiles>

(S)-1b (94\% ee) 
(S)-1b (94\% ee) was obtained form (S)-4b. (S)-4b, which was prepared from (rac)-1b (3.0 mmol) according to the procedure described in the following section (p S10), was dissolved in THF (3.0 $\mathrm{mL})$ and added dropwise to a mixture of aqueous $\mathrm{NaOH}(1.0 \mathrm{M}, 12.0 \mathrm{~mL})$ and $\mathrm{H}_{2} \mathrm{O}_{2}(30 \%, 3 \mathrm{~mL})$ at $0{ }^{\circ} \mathrm{C}$. After being stirred for $2 \mathrm{~h}$ at $0{ }^{\circ} \mathrm{C}$, the reaction mixture was quenched by addition of saturated $\mathrm{Na}_{2} \mathrm{~S}_{2} \mathrm{O}_{3}$ aq. (12.0 mL) and then extracted five times with $\mathrm{Et}_{2} \mathrm{O}$. The combined organic layer was washed with brine, and dried over $\mathrm{MgSO}_{4}$. The organic layer was filtered and carefully evaporated (bath $0{ }^{\circ} \mathrm{C}, 50 \mathrm{hPa}$ ). After rough purification with column chromatography (pentane:AcOEt, 70:30 v/v) and careful evaporation (bath $0{ }^{\circ} \mathrm{C}, 50 \mathrm{hPa}$ ), the resultant alcohol was subjected to the etheration with benzyl bromide according to the similar procedure for $\mathbf{1 c}$. (S)-1b was obtained as a colorless oil (274 mg, 52\%). (S)-1b: TLC (hexane:EtOAc, 90:10 v/v): $\mathrm{R}_{\mathrm{F}}=0.48$;

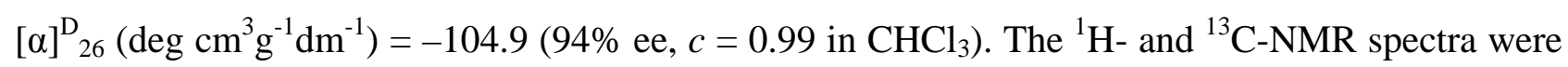
identical to those reported. The ee value (94\% ee) of (S)-1b was determined by HPLC analysis on a chiral phase (CHIRALCEL OJ-H, hexane, $\left.0.5 \mathrm{~mL} / \mathrm{min}, 40^{\circ} \mathrm{C}\right) .(S)-\mathbf{1 b}: \mathrm{t}_{\mathrm{R}}=34.6 \mathrm{~min} .,(R)-\mathbf{1 b}: \mathrm{t}_{\mathrm{R}}=$ $39.2 \mathrm{~min}$.

(R)-1b (93\% ee) was obtained form ( $R$ )-4b, which was prepared form (rac)-1b and bis(pinacolato)diboron by using $(S, S)$-QuinoxP*. $(R)-\mathbf{1 b}:[\alpha]_{26}^{\mathrm{D}}\left(\operatorname{deg} \mathrm{cm}^{3} \mathrm{~g}^{-1} \mathrm{dm}^{-1}\right)=+100.0(93 \%$ ee, $c=1.00$ in $\mathrm{CHCl}_{3}$ ). The ${ }^{1} \mathrm{H}$ - and ${ }^{13} \mathrm{C}$-NMR spectra were identical to those reported. The ee value (93\% ee) of (S)-1b was determined by HPLC analysis on a chiral phase (CHIRALCEL OJ-H, hexane, $\left.0.5 \mathrm{~mL} / \mathrm{min}, 40^{\circ} \mathrm{C}\right) .(S)-\mathbf{1 b}: \mathrm{t}_{\mathrm{R}}=35.0 \mathrm{~min} .,(R)-\mathbf{1 b}: \mathrm{t}_{\mathrm{R}}=36.4 \mathrm{~min}$.

Enantiomerically pure $(S)-\mathbf{1 b}$ (>99\% ee) was obtained by purification of $(S)-\mathbf{1 b}(94 \%$ ee) by using preparative HPLC on a chiral stationary phase (CHIRALCEL OJ-H, hexane:ethanol, 98:2, v/v). The ee values of the resolved samples were checked by HPLC analysis on a chiral phase (CHIRALCEL OJ-H, hexane, $0.5 \mathrm{~mL} / \mathrm{min}, 40^{\circ} \mathrm{C}$ ). (S)-1b: $\mathrm{t}_{\mathrm{R}}=33.2 \mathrm{~min}$. 


\section{General procedure of copper(I)-catalyzed allylic substitution of allyl ethers with diboron via} enantio-convergent transformation (Table 1).

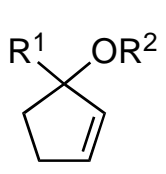

1

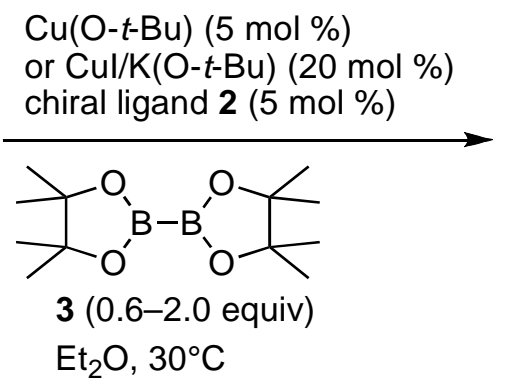

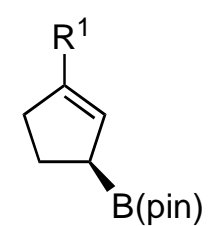

4

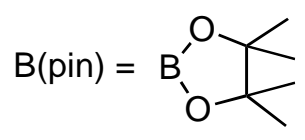

In a glove box, $\mathrm{Cu}(\mathrm{O}-\mathrm{t}-\mathrm{Bu})(3.4 \mathrm{mg}, 0.025 \mathrm{mmol})$, bis(pinacolato)diboron 2 (190 mg, $0.75 \mathrm{mmol})$ and $(R, R)$-QuinoxP* $(8.4 \mathrm{mg}, 0.025 \mathrm{mmol})$ was placed into a vial with a screw cap containing a PTFE coated rubber septum and mixed with dry $\mathrm{Et}_{2} \mathrm{O}(0.5 \mathrm{~mL})$. After being sealed with the rubber septum, the reaction vial was removed from the glove box and connected to an argon line through a needle. An allylic ether $1(0.5 \mathrm{mmol})$ was added dropwise via syringe at $30{ }^{\circ} \mathrm{C}$. After the reaction was complete, the reaction mixture was directly subjected to column chromatography (Florisil, hexane:EtOAc $=95: 5)$ to give crude allylboronates 4 . The ${ }^{1} \mathrm{H}$-NMR yield of $\mathbf{4}$ was determined using mesitylene (typically $35 \mathrm{mg})$. The product 4 was further purified by column chromatography $\left(\mathrm{SiO}_{2}\right.$, hexane:EtOAc, 99.5:0.5 v/v) to give 4 in pure form. When 98\% NMR yield was observed, the isolated yield was typically $85 \%$. To achieve high isolated yield, the column chromatography purification should be complete within 10 min to avoid the decomposition of 4 .

The reaction can be conducted with $\mathrm{CuCl} / \mathrm{K}(\mathrm{O}-t-\mathrm{Bu})$ instead of $\mathrm{Cu}(\mathrm{O}-\mathrm{t}-\mathrm{Bu})$. Into a reaction vial, CuCl (10.0 mg, $0.10 \mathrm{mmol}),(R, R)-Q u i n o x P^{*}(8.4 \mathrm{mg}, 0.025 \mathrm{mmol})$ and bis(pinacolato)diboron (253.2 mg, $1.00 \mathrm{mmol}$ ) were placed. After being sealed with a screw cap, the vial was connected to an argon line through a needle. The vial was evacuated and backfilled with argon and $\mathrm{Et}_{2} \mathrm{O}(0.5$ $\mathrm{mL})$ and a THF solution of potassium tert-butoxide $(1.0 \mathrm{M}, 0.10 \mathrm{~mL})$ were added with stirring. An allylic ether $\mathbf{1}(0.5 \mathrm{mmol})$ was added dropwise via syringe. The product was obtained after the work up procedure similar to that when $\mathrm{Cu}(\mathrm{O}-\mathrm{t}-\mathrm{Bu})$ was employed. 
(S)-4,4,5,5-Tetramethyl-2-(3-phenethylcyclopent-2-enyl)-1,3,2-dioxaborolane [(S)-4a].

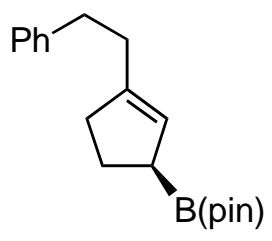

$(S)-\mathbf{4 a}$

TLC (hexane:EtOAc, 90:10 v/v): $\mathrm{R}_{\mathrm{F}}=0.42 ;[\alpha]_{26}^{\mathrm{D}}\left(\mathrm{deg} \mathrm{cm}^{3} \mathrm{~g}^{-1} \mathrm{dm}^{-1}\right)=-56.1(97 \%$ ee, $c=0.995$ in $\mathrm{CHCl}_{3}$ ); ${ }^{1} \mathrm{H}-\mathrm{NMR}\left(300 \mathrm{MHz}, \mathrm{CDCl}_{3}\right): \delta$ 7.31-7.15 (m, 5H), 5.38-5.34 (m, 1H), 2.76 (dd, $J=7.3,7$ Hz, 1H), 2.41-2.26 (m, 1H), 2.22-2.11 (m, 1H), 2.11-1.98 (m, 1H), 1.96-1.82 (m 1H), 1.24 (s, 12H) p.p.m.; ${ }^{13} \mathrm{C}-\mathrm{NMR}\left(75.4 \mathrm{MHz}, \mathrm{CDCl}_{3}\right): \delta 143.6(\mathrm{C}), 142.7(\mathrm{C}), 128.37(\mathrm{CH}), 128.28(\mathrm{CH})$, $125.7(\mathrm{CH}), 124.2(\mathrm{CH}), 83.0(\mathrm{C}), 35.7\left(\mathrm{CH}_{2}\right), 34.2\left(\mathrm{CH}_{2}\right), 33.0\left(\mathrm{CH}_{2}\right), 25.9\left(\mathrm{CH}_{2}\right), 24.62\left(\mathrm{CH}_{3}\right)$, $24.60\left(\mathrm{CH}_{3}\right)$ p.p.m. The carbon directly attached to the boron atom was not detected, likely due to quadropolar relaxation. $^{2,4,5}$ IR (neat): 2978 (m), 1604 (w), 1359 (s), 1314 (s), 1143 (s); HRMS-EI (m/z): $[\mathrm{M}+]^{+}$calcd for $\mathrm{C}_{19} \mathrm{H}_{27} \mathrm{BO}_{2}, 298.21041$; found, 298.21093. The ee values of (S)-4a was determined by HPLC analysis on a chiral phase after $\mathrm{H}_{2} \mathrm{O}_{2} / \mathrm{NaOH}$ aq. oxidation of (S)-4a as described following procedure.

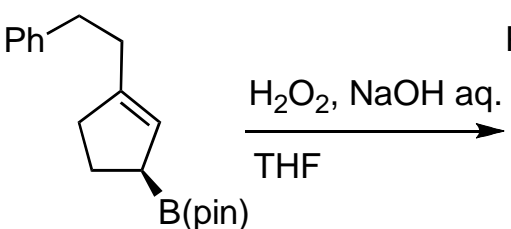

(S)-4a

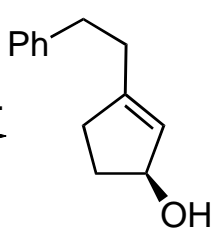

$(S)-7 a$

In $50 \mathrm{~mL}$ round-bottomed flask, allylboronate $(S)$-4a was dissolved in THF (0.5 mL) and cooled at $0{ }^{\circ} \mathrm{C}$. Aqueous $\mathrm{NaOH}(1.0 \mathrm{M}, 2.0 \mathrm{~mL})$ and $\mathrm{H}_{2} \mathrm{O}_{2}(30 \%, 1.0 \mathrm{~mL})$, was successively added to the solution dropwise. After being stirred for $5 \mathrm{~h}$ at $0{ }^{\circ} \mathrm{C}$, the reaction mixture was quenched by addition of saturated $\mathrm{Na}_{2} \mathrm{~S}_{2} \mathrm{O}_{3}$ aq. $(2.0 \mathrm{~mL})$ and then extracted three times with EtOAc. The combined layer was washed with brine, and dried over $\mathrm{MgSO}_{4}$. The organic layer was filtered and evaporated. The crude product was purified by column chromatography $\left(\mathrm{SiO}_{2}\right.$, hexane:EtOAc, 95:5 
v/v) to give $(S)-7 \mathbf{a}$ as a colourless oil (31.2 $\mathrm{mg}, 70 \%)$. The ee values of $(S)$-7a was determined by HPLC analysis on a chiral phase (CHIRALCEL OD-3, hexane:2-propanol, 95:5 v/v, $0.5 \mathrm{~mL} / \mathrm{min}$, $\left.40{ }^{\circ} \mathrm{C}\right) .(R)-7 \mathrm{a}: \mathrm{t}_{\mathrm{R}}=20.0$ min., $(S)-7 \mathrm{a}: \mathrm{t}_{\mathrm{R}}=22.5 \mathrm{~min}$.

(S)-2-(Cyclopent-2-enyl)-4,4,5,5-tetramethyl-1,3,2-dioxaborolane [(S)-4b].

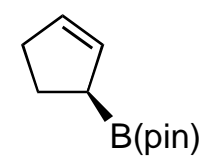

(S)-4b

The ${ }^{1} \mathrm{H}$-and ${ }^{13} \mathrm{C}$-NMR and IR spectra were identical with those reported. ${ }^{2}$ TLC (hexane:EtOAc, $90: 10 \mathrm{v} / \mathrm{v}): \mathrm{R}_{\mathrm{F}}=0.43 ;[\alpha]_{26}^{\mathrm{D}}\left(\mathrm{deg} \mathrm{cm}^{3} \mathrm{~g}^{-1} \mathrm{dm}^{-1}\right)=-106.3\left(92 \%\right.$ ee, $c=1.04$ in $\left.\mathrm{CHCl}_{3}\right)$. The ee value of (S)-4a was determined by HPLC analysis on a chiral phase determined after reaction with benzaldehyde according to the reported procedure. ${ }^{2}$

(S)-2-(Cyclopent-3-d-2-enyl)-4,4,5,5-tetramethyl-1,3,2-dioxaborolane [(S)-4c].

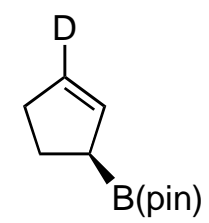

(S)-4c

TLC (hexane:EtOAc, 90:10 v/v): $\mathrm{R}_{\mathrm{F}}=0.43 ;[\alpha]_{25}^{\mathrm{D}}\left(\mathrm{deg} \mathrm{cm}^{3} \mathrm{~g}^{-1} \mathrm{dm}^{-1}\right)=-104.7(92 \%$ ee, $c=1.02$ in $\mathrm{CHCl}_{3}$ ); ${ }^{1} \mathrm{H}-\mathrm{NMR}\left(300 \mathrm{MHz}, \mathrm{CDCl}_{3}\right): \delta$ 5.75-5.71 (m, 1H), 2.39-2.25 (m, 2H), 2.23-2.12 (m, 1H), 2.10-1.95 (m, 1H), 1.93-1.79 (m, 1H), 1.24 (s, 12H) p.p.m.; ${ }^{13} \mathrm{C}-\mathrm{NMR}\left(75.4 \mathrm{MHz}, \mathrm{CDCl}_{3}\right): \delta$ $131.3(\mathrm{CH}) 129.6(\mathrm{q}, \mathrm{CD}), 83.1(\mathrm{C}), 32.6\left(\mathrm{CH}_{2}\right), 25.4\left(\mathrm{CH}_{2}\right), 24.6\left(\mathrm{CH}_{3}\right)$ p.p.m. The carbon directly attached to the boron atom was not detected, likely due to quadropolar relaxation. ${ }^{2,4,5}$ IR (neat): 2979 (m), 2276 (w), 1590 (w), 1356 (s), 1314 (s), 1143 (s); HRMS-EI (m/z): [M+] calcd for $\mathrm{C}_{11} \mathrm{H}_{18} \mathrm{DBO}_{2}$, 195.15409; found, 195.15411. Ratio for $(S)-4 \mathbf{c} /(S)-4 \mathbf{b}$ was determined by ${ }^{1} \mathrm{H}-\mathrm{NMR}$ after reaction with benzaldehyde [(S)-4c/(S)-4b 95:5]. The ee values of (S)-4c was determined by 
HPLC analysis on a chiral phase determined after reaction with benzaldehyde according to the same procedure for $(S)-\mathbf{4 b} .^{2}$

[(S)-3-Isopropylcyclopent-2-enyl]-4,4,5,5-tetramethyl-2-1,3,2-dioxaborolane [(S)-4f].

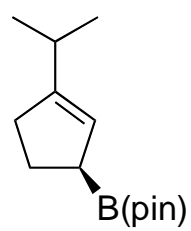

(S)-4f

TLC (hexane:EtOAc, 90:10 v/v): $\mathrm{R}_{\mathrm{F}}=0.43 ;[\alpha]_{25}^{\mathrm{D}}\left(\mathrm{deg} \mathrm{cm}^{3} \mathrm{~g}^{-1} \mathrm{dm}^{-1}\right)=-65.8(85 \%$ ee, $c=0.95$ in $\mathrm{CHCl}_{3}$ ); ${ }^{1} \mathrm{H}-\mathrm{NMR}\left(300 \mathrm{MHz}, \mathrm{CDCl}_{3}\right.$ ): $\delta 5.28$ (quint, $\left.J=1.9 \mathrm{~Hz}, 1 \mathrm{H}\right), 2.39-2.23(\mathrm{~m}, 3 \mathrm{H}), 2.19$ 2.09 (m, 1H), 2.09-1.78 (m, 2H), 1.24 (s, 12H), 1.03 (d, $J=6.6 \mathrm{~Hz}, 3 \mathrm{H}), 1.02$ (d, $J=6.9 \mathrm{~Hz}, 3 \mathrm{H})$ p.p.m. ${ }^{13} \mathrm{C}-\mathrm{NMR}\left(75.4 \mathrm{MHz}, \mathrm{CDCl}_{3}\right): \delta 150.4(\mathrm{C}), 121.5(\mathrm{CH}), 82.9(\mathrm{C}), 35.6\left(\mathrm{CH}_{2}\right), 29.7(\mathrm{CH})$, $26.0\left(\mathrm{CH}_{2}\right), 24.60\left(\mathrm{CH}_{3}\right), 24.56\left(\mathrm{CH}_{3}\right), 21.5\left(\mathrm{CH}_{3}\right)$ p.p.m. The ee value of this compound (85\% ee) was determined after the reaction with benzaldehyde (10 equiv) in $\mathrm{CH}_{2} \mathrm{Cl}_{2}$. (CHIRALCEL OD-3, hexane:2-propanol, 95:5 v/v, $0.5 \mathrm{~mL} / \mathrm{min}, 40{ }^{\circ} \mathrm{C}$ ). major isomer: $\mathrm{t}_{\mathrm{R}}=14.2 \mathrm{~min}$., minor isomer: $\mathrm{t}_{\mathrm{R}}=$ $18.6 \mathrm{~min}$.

A typical procedure for synthesis of enantio-enriched homoallylic alcohols via copper(I)catalyzed enantio-convergent transformation and subsequent carbonyl addition (Figure 3).

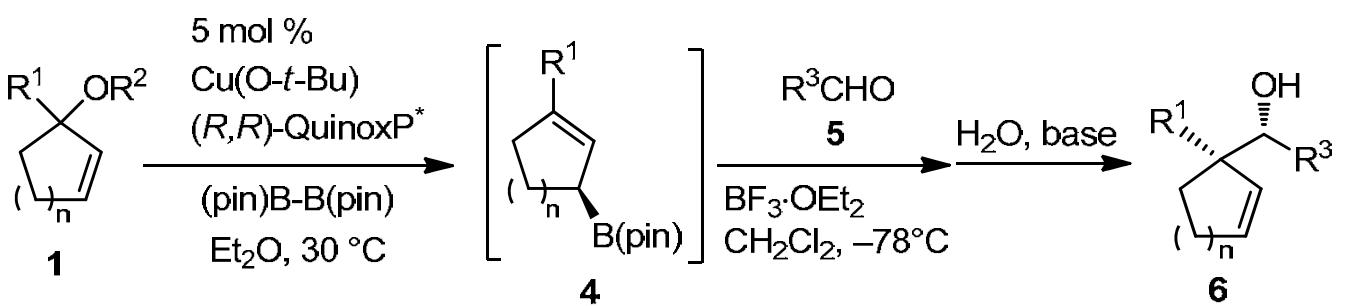

In a glove box, $\mathrm{Cu}(\mathrm{O}-\mathrm{t}$-Bu) (3.4 mg, $0.025 \mathrm{mmol})$, bis(pinacolato)diboron 2 (190 mg, $0.75 \mathrm{mmol}$ ) and $(R, R)$-QuinoxP* (8.4 mg, $0.025 \mathrm{mmol})$ was placed into a vial with a screw cap containing a PTFE coated rubber septum and mixed with dry $\mathrm{Et}_{2} \mathrm{O}(0.5 \mathrm{~mL})$. After being sealed with the rubber septum, the reaction vial was removed from the glove box and was connected to an argon line 
through a needle. An allylic ether $1(0.5 \mathrm{mmol})$ was added dropwise via syringe at $30{ }^{\circ} \mathrm{C}$. After reaction completion was checked by NMR measurement on a quenched aliquot of the reaction mixture, the reaction mixture was directly subjected to column chromatography (Florisil, EtOAc $=$ 95:5 v/v) to give crude allylboronates 4 as a colorless oil. In a reaction tube, the crude product was dissolved in dry $\mathrm{CH}_{2} \mathrm{Cl}_{2}(0.5 \mathrm{~mL})$ and cooled to $-78{ }^{\circ} \mathrm{C}$. An aldehyde $5(0.55 \mathrm{mmol})$ and $\mathrm{BF}_{3} \cdot \mathrm{OEt}_{2}$ (0.5 mmol) was successively added, and stirred for $16 \mathrm{~h}$ at $-78{ }^{\circ} \mathrm{C}$. The reaction mixture was quenched by $\mathrm{CH}_{2} \mathrm{Cl}_{2}$ solution of triethanolamine $(10 \% \mathrm{v} / \mathrm{v}, 3.0 \mathrm{~mL})$ and then allowed to warm to room temperature. The mixture was separated with water and EtOAc, and then extracted three times with EtOAc. The combined organic layer was washed with brine, dried over $\mathrm{MgSO}_{4}$, filtered and evaporated. The crude product was purified by column chromatography $\left(\mathrm{SiO}_{2}\right.$, hexane:EtOAc, 100:0-98:2 v/v) to give 6 as a colourless oil. The ee values of 6 was determined by HPLC analysis on a chiral phase.

\section{(S)-((S)-1-Phenethylcyclopent-2-enyl)(phenyl)methanol [(S,S)-6aa].}

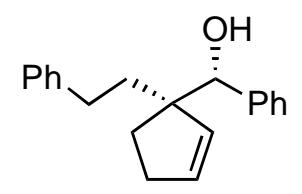

$(S, S)-6 a a, 85 \%$

$97 \%$ ee, $d r>99: 1$

TLC (hexane:EtOAc, 80:20 v/v): $\mathrm{R}_{\mathrm{F}}=0.39 ;[\alpha]_{25}^{\mathrm{D}}\left(\mathrm{deg} \mathrm{cm}^{3} \mathrm{~g}^{-1} \mathrm{dm}^{-1}\right)=-57.5(97 \%$ ee, $c=1.02$ in $\left.\mathrm{CHCl}_{3}\right) ;{ }^{1} \mathrm{H}-\mathrm{NMR}\left(300 \mathrm{MHz}, \mathrm{CDCl}_{3}\right): \delta$ 7.40-7.10 (m, 10H), 5.94 (dt, $\left.J=5.8,2.0 \mathrm{~Hz}, 1 \mathrm{H}\right), 5.57$ (dt, $J=5.8,2.2 \mathrm{~Hz}, 1 \mathrm{H}), 4.69$ (s, 1H), 2.57-2.49 (m, 2H), 2.40-2.13 (m, 3H), 1.95 (brs, 1H), 1.75-1.53 (m, 3H) p.p.m.; ${ }^{13} \mathrm{C}-\mathrm{NMR}\left(75.4 \mathrm{MHz}, \mathrm{CDCl}_{3}\right): \delta 143.1(\mathrm{C}), 141.5(\mathrm{C}), 135.0(\mathrm{CH}), 133.9(\mathrm{CH})$, $128.41(\mathrm{CH}), 128.36(\mathrm{CH}), 127.79(\mathrm{CH}), 127.77(\mathrm{CH}), 127.5(\mathrm{CH}), 125.7(\mathrm{CH}), 79.0(\mathrm{CH}), 58.8$ (C), $38.1\left(\mathrm{CH}_{2}\right), 32.7\left(\mathrm{CH}_{2}\right), 30.9\left(\mathrm{CH}_{2}\right), 28.6\left(\mathrm{CH}_{2}\right)$ p.p.m.; IR (neat): 3466 (br), 3027 (m), 2850 (m), 1453 (m), 1280 (s), 1123 (s), 698 (s) cm ${ }^{-1}$; HRMS-ESI (m/z): [M+Na] $]^{+}$calcd for $\mathrm{C}_{20} \mathrm{H}_{22} \mathrm{ONa}$, 301.15629; found, 301.15659. The ee value (97\% ee) of $(S, S)-6$ aa was determined by HPLC analysis on a chiral phase (CHIRALCEL OD-3, hexane:2-propanol, 95:5 v/v, $0.5 \mathrm{~mL} / \mathrm{min}, 40{ }^{\circ} \mathrm{C}$ ). 
$(S, S)$-6aa: $\mathrm{t}_{\mathrm{R}}=21.0$ min., $(R, R)-6 \mathbf{a a}: \mathrm{t}_{\mathrm{R}}=24.7 \mathrm{~min}$. Only one diastereomer was found in NMR and HPLC.

(S)-((R)-1-Methylcyclopent-2-enyl)(phenyl)methanol [(S,R)-6ea].

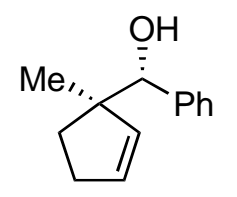

$(S, R)-6$ ea, $80 \%$

$98 \%$ ee, $d r>99: 1$

TLC (hexane:EtOAc, 80:20 v/v): $\mathrm{R}_{\mathrm{F}}=0.46 ;[\alpha]^{\mathrm{D}}{ }_{28}\left(\mathrm{deg} \mathrm{cm}^{3} \mathrm{~g}^{-1} \mathrm{dm}^{-1}\right)=-42.3(98 \%$ ee, $c=1.02$ in $\mathrm{CHCl}_{3}$ ); ${ }^{1} \mathrm{H}-\mathrm{NMR}\left(300 \mathrm{MHz}, \mathrm{CDCl}_{3}\right): \delta$ 7.39-7.22 (m, 5H), 5.80 (dt, $\left.J=5.5,2.2 \mathrm{~Hz}, 1 \mathrm{H}\right), 5.49$ (dt, $J=5.5,2.1 \mathrm{~Hz}, 1 \mathrm{H}), 4.58$ (d, $J=1.9 \mathrm{~Hz}, 1 \mathrm{H}), 2.42-2.25$ (m, 2H), 2.25-2.12 (m, 1H), 1.95 (d, $J$ $=1.9 \mathrm{~Hz}, 1 \mathrm{H}), 1.46-1.35$ (m, 1H), 1.02 (s, 3H) p.p.m.; ${ }^{13} \mathrm{C}-\mathrm{NMR}\left(75.4 \mathrm{MHz}, \mathrm{CDCl}_{3}\right): \delta 141.7(C)$, 137.4 (CH), $132.0(\mathrm{CH}), 127.65(\mathrm{CH}), 127.56(\mathrm{CH}), 127.3(\mathrm{CH}), 79.6(\mathrm{CH}), 54.6(\mathrm{C}), 32.0\left(\mathrm{CH}_{2}\right)$, $31.8\left(\mathrm{CH}_{2}\right)$, $22.6\left(\mathrm{CH}_{3}\right)$ p.p.m.; IR (neat): 3398 (br), 3030 (m), 2962 (m), $1736(\mathrm{~m}), 1451$ (m), 1014 (s), 700 (s) $\mathrm{cm}^{-1}$; HRMS-ESI (m/z): $[\mathrm{M}+\mathrm{Na}]^{+}$calcd for $\mathrm{C}_{13} \mathrm{H}_{16} \mathrm{ONa}, 211.10934$; found, 211.10959. The ee value (98\% ee) of $(S, R)$-6aa was determined by HPLC analysis on a chiral phase (CHIRALCEL OD-3, hexane:2-propanol, 95:5 v/v, $0.5 \mathrm{~mL} / \mathrm{min}, 40{ }^{\circ} \mathrm{C}$ ). $(S, R)-6 e a: \mathrm{t}_{\mathrm{R}}=12.7$ min., $(R, S)-6 e a: t_{\mathrm{R}}=16.7 \mathrm{~min}$. Only one diastereomer was found in NMR and HPLC.

(R,E)-1-((S)-1-Phenethylcyclopent-2-enyl)-3-phenylprop-2-en-1-ol [(R,S)-6ab].<smiles>O[C@H](/C=C/c1ccccc1)[C@]1(CCc2ccccc2)C=CCC1</smiles>

$(R, S)-6 \mathbf{a b}, 72 \%$

$97 \%$ ee, $d r>97: 3$

The carbonyl addition was conducted in toluene $(0.3 \mathrm{~mL})$ at $30^{\circ} \mathrm{C}$ for 2 days without Lewis acid $\left(\mathrm{BF}_{3} \cdot \mathrm{OEt}_{2}\right)$. TLC (hexane:EtOAc, 80:20 v/v): $\mathrm{R}_{\mathrm{F}}=0.40 ;[\alpha]_{26}^{\mathrm{D}}\left(\mathrm{deg} \mathrm{cm}^{3} \mathrm{~g}^{-1} \mathrm{dm}^{-1}\right)=+11.03(97 \%$ ee, $c=0.975$ in $\left.\mathrm{CHCl}_{3}\right) ;{ }^{1} \mathrm{H}-\mathrm{NMR}\left(300 \mathrm{MHz}, \mathrm{CDCl}_{3}\right): \delta 7.40-7.10(\mathrm{~m}, 10 \mathrm{H}), 6.64(\mathrm{~d}, J=15.7 \mathrm{~Hz}, 1 \mathrm{H})$, 
6.24 (dd, $J=15.7,7.1 \mathrm{~Hz}, 1 \mathrm{H}), 5.99$ (dt, $J=5.8,2.3 \mathrm{~Hz}), 5.60$ (dt, $J=5.8,2.2 \mathrm{~Hz}), 4.22(\mathrm{~d}, J=7.1$ Hz, 1H), 2.63-2.51 (m, 2H), 2.47-2.32 (m, 2H), 2.16-2.02 (m, 1H), 1.88-1.63 (m, 4H) p.p.m.; ${ }^{13} \mathrm{C}-$ NMR (75.4 MHz, $\left.\mathrm{CDCl}_{3}\right): \delta 143.0(C), 136.9(C), 134.5(\mathrm{CH}), 134.0(\mathrm{CH}), 132.4(\mathrm{CH}), 128.8(\mathrm{CH})$, 128.6 (CH), $128.4(\mathrm{CH}), 127.6(\mathrm{CH}), 126.5(\mathrm{CH}), 125.7(\mathrm{CH}), 77.7(\mathrm{CH}), 58.3(\mathrm{C}), 38.7\left(\mathrm{CH}_{2}\right)$, $32.7\left(\mathrm{CH}_{2}\right), 30.9\left(\mathrm{CH}_{2}\right), 28.7\left(\mathrm{CH}_{2}\right)$ p.p.m.; IR (neat): 3462 (br), 3025 (m), 2941 (m), 1601 (m), 1495 (m), 966 (s), 691 (s) $\mathrm{cm}^{-1}$; HRMS-ESI (m/z): [M+Na] calcd for $\mathrm{C}_{22} \mathrm{H}_{24} \mathrm{ONa}$, 327.17194; found, 327.17203. The ee value (97\% ee) of $(R, S)-6 \mathbf{a b}$ was determined by HPLC analysis on a chiral phase (CHIRALCEL AD-H, hexane:2-propanol, 95:5 v/v, $\left.0.5 \mathrm{~mL} / \mathrm{min}, 40^{\circ} \mathrm{C}\right) .(S, R)-6 \mathbf{a b}: \mathrm{t}_{\mathrm{R}}$ $=24.8$ min., $(R, S)-6 a b: t_{R}=29.6$ min. A diastereometric isomer $(<3 \%)$ was found in NMR and HPLC analysis $\left(t_{R}=27.0 \mathrm{~min}\right)$.

\section{(S)-[(R)-Cyclopent-2-enyl](phenyl)methanol [(S,R)-6ba].}

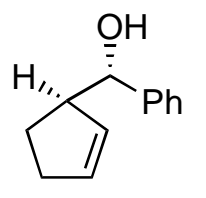

$(S, R)-6 \mathbf{b a}, 91 \%$

93\% ee, dr >99:1

The carbonyl addition was conducted by addition of benzaldehyde (1.1 equiv) into the reaction mixture after cooper(I)-catalyzed enantio-convergent transformation of $\mathbf{1 f}$ and $\mathbf{3}$. Lewis acid $\left(\mathrm{BF}_{3} \cdot \mathrm{OEt}_{2}\right)$ was not used. TLC (hexane:EtOAc, 80:20 v/v): $\mathrm{R}_{\mathrm{F}}=0.35 ;[\alpha]_{27}^{\mathrm{D}}\left(\mathrm{deg} \mathrm{cm}^{3} \mathrm{~g}^{-1} \mathrm{dm}^{-1}\right)=$ $+29.9\left(93 \%\right.$ ee, $c=0.96$ in $\left.\mathrm{CHCl}_{3}\right)\left\{\right.$ lit. $^{2}[\alpha]_{26}^{\mathrm{D}}\left(\mathrm{deg} \mathrm{cm}^{3} \mathrm{~g}^{-1} \mathrm{dm}^{-1}\right)=+29.3(97 \%$ ee, $c=1.32$ in $\left.\left.\mathrm{CHCl}_{3}\right)\right\} ;{ }^{1} \mathrm{H}-\mathrm{NMR}\left(300 \mathrm{MHz}, \mathrm{CDCl}_{3}\right): \delta$ 7.35-7.23 (m, 5H), 5.85 (dt, $\left.J=7.9,2.2 \mathrm{~Hz}, 1 \mathrm{H}\right), 5.41$ (dt, $J=8.0,2.2 \mathrm{~Hz}, 1 \mathrm{H}), 4.55(\mathrm{~d}, J=6.3 \mathrm{~Hz}, 1 \mathrm{H}), 3.15-3.04(\mathrm{~m}, 1 \mathrm{H}), 2.45-2.22(\mathrm{~m}, 2 \mathrm{H}), 2.01-1.77(\mathrm{~m}$, 3H) p.p.m.; ${ }^{13} \mathrm{C}-\mathrm{NMR}$ (75.4 MHz, $\left.\mathrm{CDCl}_{3}\right)$ : $\delta 143.5$ (1C, C), 133.8 (1C, CH), 131.3 (1C, CH), 128.3 (2C, $\mathrm{CH}), 127.4$ (1C, CH), 126.4 (2C, $\mathrm{CH}), 76.9$ (1C, $\mathrm{CH}), 53.8$ (1C, $\mathrm{CH}), 32.1\left(1 \mathrm{C}, \mathrm{CH}_{2}\right), 24.9$ (1C, $\mathrm{CH}_{2}$ ) p.p.m. The ${ }^{1} \mathrm{H}$ and ${ }^{13} \mathrm{C}$ NMR spectra were identical to those reported. ${ }^{2}$ The ee value (93\% ee) of $(S, R)$-6ba was determined by HPLC analysis on a chiral phase (CHIRALCEL OD-H or OD-3, 
hexane:2-propanol, 99:1 v/v, $\left.0.5 \mathrm{~mL} / \mathrm{min}, 40{ }^{\circ} \mathrm{C}\right)$. $(S, R)-6 \mathbf{b a}: \mathrm{t}_{\mathrm{R}}=32.8 \mathrm{~min}$.; $(R, S)-\mathbf{6 b a}: \mathrm{t}_{\mathrm{R}}=34.7$ min (for OD-H). Only one diastereomer was found in NMR and HPLC.

(R)-1-((R)-Cyclopent-2-enyl)-3-phenylpropan-1-ol [(R,R)-6bc].<smiles>O[C@H](CCc1ccccc1)C1C=CCC1</smiles>

$(R, R)-6 \mathbf{b c}, 86 \%$

$93 \%$ ee, $d r>99: 1$

TLC (hexane:EtOAc, 80:20 v/v): $\mathrm{R}_{\mathrm{F}}=0.36 ;[\alpha]_{25}^{\mathrm{D}}\left(\mathrm{deg} \mathrm{cm}^{3} \mathrm{~g}^{-1} \mathrm{dm}^{-1}\right)=+93.3(93 \%$ ee, $c=1.02$ in $\mathrm{CHCl}_{3}$ ); ${ }^{1} \mathrm{H}-\mathrm{NMR}\left(300 \mathrm{MHz}, \mathrm{CDCl}_{3}\right): \delta$ 7.35-7.27 (m, 5H), 5.92-5.86 (m, 1H), 5.62-5.56 (m, 1H), 3.67-3.58 (m, 1H), 2.91-2.80 (m, 2H), 2.74-2.61 (m, 1H), 2.47-2.24 (m, 2H), 1.98-1.71 (m, 4H), 1.44 (d, $J=3.0 \mathrm{~Hz}, 1 \mathrm{H}$ ) p.p.m.; ${ }^{13} \mathrm{C}-\mathrm{NMR}\left(75.4 \mathrm{MHz}, \mathrm{CDCl}_{3}\right): \delta 142.3(1 \mathrm{C}, C), 133.8(1 \mathrm{C}, C \mathrm{H})$, 131.4 (1C, $\mathrm{CH}), 128.5$ (2C, $\mathrm{CH}), 128.4$ (2C, $\mathrm{CH}), 125.8$ (1C, $\mathrm{CH}), 73.0(1 \mathrm{C}, \mathrm{CH}), 52.1(1 \mathrm{C}, \mathrm{CH})$, 36.6 (1C, $\mathrm{CH}_{2}$ ), 32.21 (1C, $\left.\mathrm{CH}_{2}\right), 32.17\left(1 \mathrm{C}, \mathrm{CH}_{2}\right), 23.4\left(1 \mathrm{C}, \mathrm{CH}_{2}\right)$ p.p.m. The ${ }^{1} \mathrm{H}$ and ${ }^{13} \mathrm{C} \mathrm{NMR}$ spectra were identical to those reported. ${ }^{6}$ The ee value $(93 \%$ ee) of $(R, R)-\mathbf{6 b c}$ was determined by HPLC analysis on a chiral phase (CHIRALCEL OJ-H, hexane:2-propanol, 98:2, v/v, $0.5 \mathrm{~mL} / \mathrm{min}$, $\left.40{ }^{\circ} \mathrm{C}\right) .(S, S)-6 \mathbf{b c}: \mathrm{t}_{\mathrm{R}}=23.6 \mathrm{~min} .,(R, R)-6 \mathbf{b c}: \mathrm{t}_{\mathrm{R}}=25.8 \mathrm{~min}$. Only one diastereomer was found in NMR and HPLC.

\section{(S)-1-((R)-Cyclohex-2-enyl)-3-phenylpropan-1-ol [(S,R)-6ga].}<smiles>O[C@H](c1ccccc1)[C@H]1C=CCCC1</smiles>

$(S, R)-6$ ga, $84 \%$

$91 \%$ ee, $d r>99: 1$

The enantio-convergent borylation was carried out with 10 mol \% catalyst. The carbonyl addition was conducted by addition of benzaldehyde (1.1 equiv) into the reaction mixture after $\mathrm{Cu}(\mathrm{I})$ catalyzed enantio-convergent transformation of $\mathbf{1 g}$ and $\mathbf{3}$. Lewis acid $\left(\mathrm{BF}_{3} \cdot \mathrm{OEt}_{2}\right)$ was not used. TLC 
(hexane:EtOAc, 80:20 v/v): $\mathrm{R}_{\mathrm{F}}=0.40 ;[\alpha]_{26}^{\mathrm{D}}\left(\mathrm{deg} \mathrm{cm}^{3} \mathrm{~g}^{-1} \mathrm{dm}^{-1}\right)=+15.3(91 \%$ ee, $c=0.97$ in

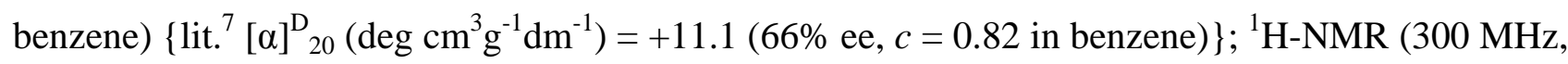
$\left.\mathrm{CDCl}_{3}\right): \delta 7.40-7.20(\mathrm{~m}, 5 \mathrm{H}), 5.85-5.78(\mathrm{~m}, 1 \mathrm{H}), 5.38$ (d, $\left.J=9.9 \mathrm{~Hz}, 1 \mathrm{H}\right), 4.58(\mathrm{~d}, J=6.3 \mathrm{~Hz}, 1 \mathrm{H})$, 2.56-2.43 (m, 1H), 2.03-1.87 (m, 2H), 1.83-1.41 (m, 4H) p.p.m.; ${ }^{13} \mathrm{C}-\mathrm{NMR}\left(75.4 \mathrm{MHz}, \mathrm{CDCl}_{3}\right): \delta$ $143.0(\mathrm{C}), 130.5(\mathrm{CH}), 128.3(\mathrm{CH}), 128.1(\mathrm{CH}), 127.5(\mathrm{CH}), 126.6(\mathrm{CH}), 77.4(\mathrm{CH}), 42.9\left(\mathrm{CH}_{2}\right)$, $25.1\left(\mathrm{CH}_{2}\right), 23.7$ (1C, $\left.\mathrm{CH}_{2}\right), 21.0\left(1 \mathrm{C}, \mathrm{CH}_{2}\right)$ p.p.m. The ${ }^{1} \mathrm{H}$ and ${ }^{13} \mathrm{C}$ NMR spectra were identical to those reported. ${ }^{6}$ The ee value (91\% ee) of $(S, R)$-6ga was determined by HPLC analysis on a chiral phase (CHIRALCEL OD-3, hexane:2-propanol, 97:3 v/v, $\left.0.5 \mathrm{~mL} / \mathrm{min}, 40{ }^{\circ} \mathrm{C}\right) .(S, R)-6$ ga: $\mathrm{t}_{\mathrm{R}}=16.0$ min., $(R, S)$-6ga: $t_{\mathrm{R}}=17.7 \mathrm{~min}$. Only one diastereomer was found in NMR and HPLC.

\section{Kinetic resolution of (Z)-methyl (6-phenylhex-3-en-2-yl) carbonate.}

In a glove box, $\mathrm{Cu}(\mathrm{O}-\mathrm{t}-\mathrm{Bu})$ (6.8 mg, $0.05 \mathrm{mmol})$, bis(pinacolato)diboron 2 (158.7 mg, 0.625 mmol) and $(R, R)$-QuinoxP* (16.8 $\mathrm{mg}, 0.05 \mathrm{mmol})$ was placed into a vial with a screw cap containing a PTFE coated rubber septum and mixed with dry $\mathrm{Et}_{2} \mathrm{O}(0.5 \mathrm{~mL})$. After being sealed with the rubber septum, the reaction vial was removed from the glove box and was connected to an argon line through a needle. (Z)-Methyl (6-phenylhex-3-en-2-yl) carbonate (0.5 mmol) was added dropwise via syringe at $30^{\circ} \mathrm{C}$. After 3 days, the reaction mixture was directly subjected to column chromatography (Florisil, hexane:EtOAc=95:5). The yields and enantioselectivties of the allylboronate product and the starting material were determined by HPLC analysis on a chiral phase (CHIRALCEL OD-3, hexane, $0.5 \mathrm{~mL} / \mathrm{min}, 40^{\circ} \mathrm{C}$ ) by using an internal standard with the calibration curve prepared from racemic mixtures of the starting material and the allylboronate product.

\section{Stereochemical characterization of 6.}

The relative and absolute configurations of $(S, R)-\mathbf{6 b a},{ }^{2,8}(R, R)-\mathbf{6 b c},{ }^{6}(S, R)-\mathbf{6 g a}^{8}$ were determined by comparison of NMR data and the optical rotatory power values with those described in the literatures. The relative stereochemistry of $\operatorname{rac}-\left(S^{*}, R^{*}\right)$-6ea was determined by X-ray crystallography after 4-bromobenzoate derivatization (Figure S1). 

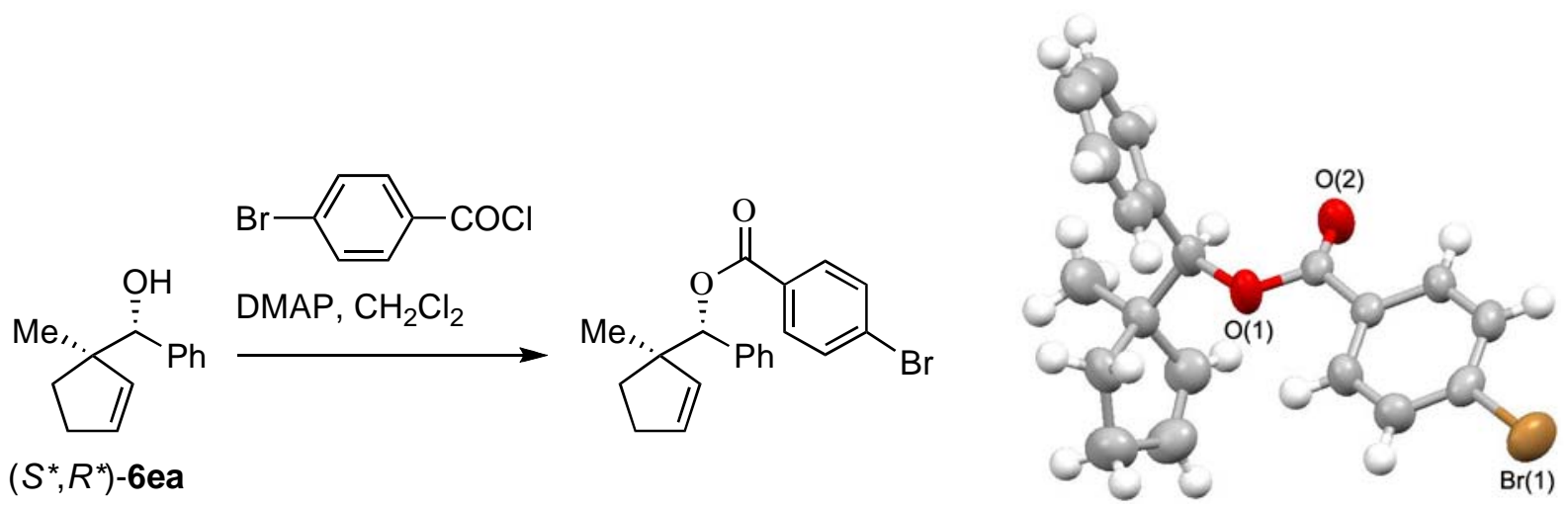

$\left(S^{\star}, R^{\star}\right)-6 \mathrm{ea}$

Figure S1. X-ray and schematic structure of 4-boromobenzoate derivative of rac-( $\left.S^{*}, R^{*}\right)$-6ea. Thermal ellipsoids are drawn at the 50\% probability level. Crystal data (CCDC 760815): monoclinic, $P 21 / c$ (No. 14), $a=11.980(6) \AA, b=6.098(3) \AA, c=23.525(10) \AA, \beta=93.43(4)^{\circ}, V=$ 966(2) $\AA^{3}, Z=4, T=296.2 \mathrm{~K}, 2 \theta_{\max }=55.0, R=0.0436(I>2.00 \sigma(I)), R \mathrm{~W}=0.1055, \mathrm{GOF}=0.835$.

Determination of absolute configuration of $(S, R)$-6ea was described as follows. Stereochemistry of $(S, S)-6 \mathbf{a a},(R, S)-\mathbf{6 a b}$ was inferred from these results.

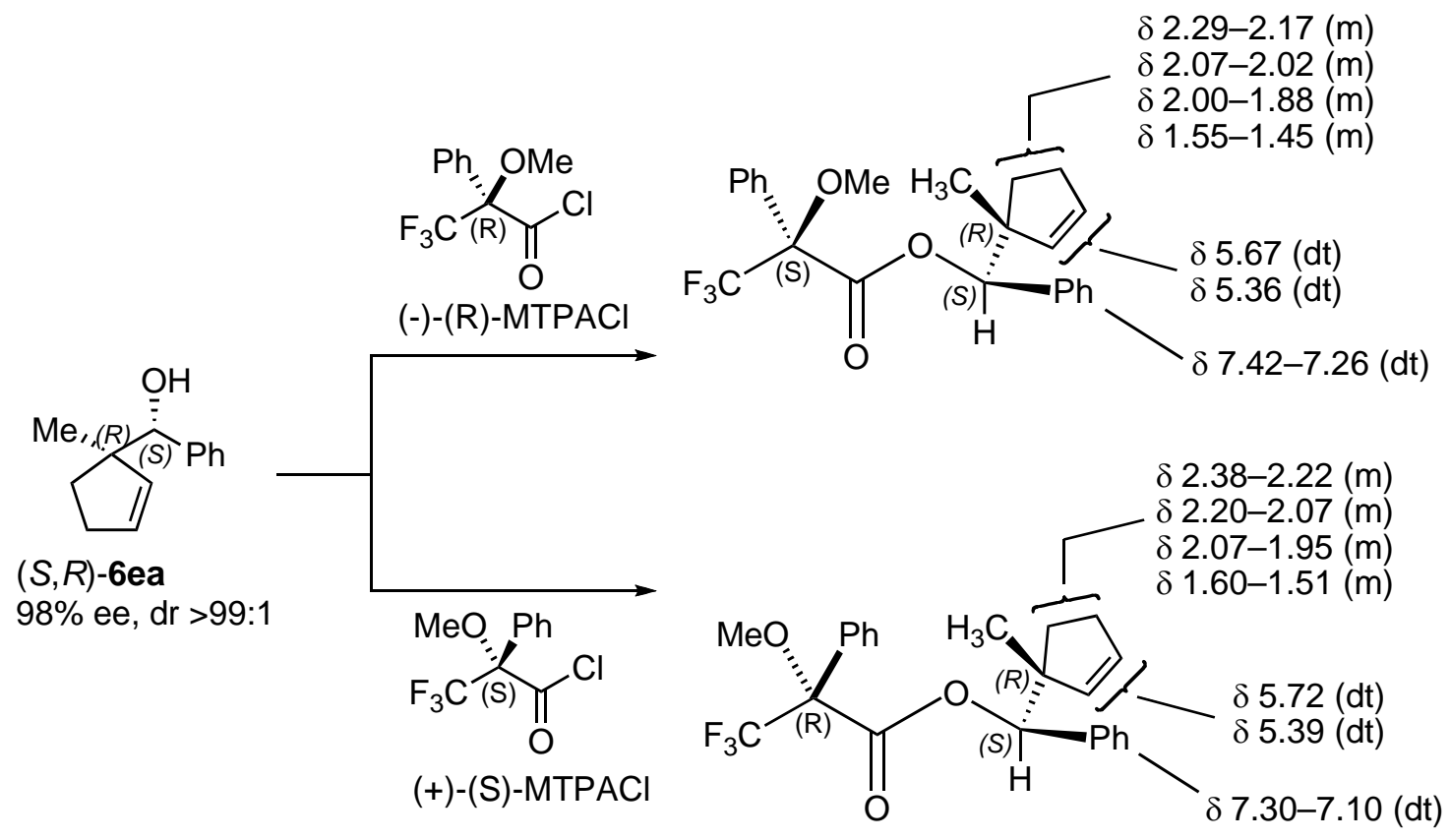




\section{Preparation of $(1 S, 5 R)-1 d$ and $(1 R, 5 S)-1 d$ (Figure 3$)$.}<smiles>[2H][C@@H]1C=CC[C@H]1[OH2+]</smiles>

(rac)-8

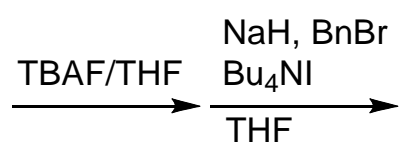

(rac)-1d

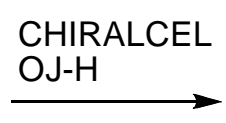

D

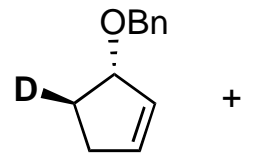

$(1 S, 5 R)-1 d$ $>99 \%$ ee
D..

$(1 R, 5 S)-1 d$ $>99 \%$ ee

The $d$-labelled silyl ether (rac)-8 (>98 atom \% D) was prepared according to the literature procedure. $^{9}$ In a $20 \mathrm{~mL}$ of round-bottomed flask, (rac)-8 (436 mg, $2.2 \mathrm{mmol}$ ) was dissolved in hexane $(4.0 \mathrm{~mL})$ and a THF solution of TBAF $(1.0 \mathrm{M}, 3.3 \mathrm{~mL}, 3.3 \mathrm{mmol})$ was added at $0{ }^{\circ} \mathrm{C}$ with stirring. The reaction mixture was stirred for $18 \mathrm{~h}$ at room temperature and the solvents were removed under reduced pressure $\left(20^{\circ} \mathrm{C}\right.$, approx. $\left.30 \mathrm{hPa}\right)$. The resultant mixture was directly subjected to column chromatography (pentane:diethyl ether, 70:30 v/v). The solvents of the combined fractions were removed by using distillation apparatus with a Vigreux condenser under atmospheric pressure. The residue was dissolved in THF and passed through a short $\mathrm{K}_{2} \mathrm{CO}_{3}$ column and transferred into a THF (11 mL) suspension of $\mathrm{NaH}$, which was prepared by washing $\mathrm{NaH}$ in mineral oil (60\%, $158.4 \mathrm{mg}, 4.0 \mathrm{mmol})$, at $0{ }^{\circ} \mathrm{C}$ under an argon atmosphere. After stirred for $1 \mathrm{~h}$, benzyl bromide (261 $\mu \mathrm{L}, 2.2 \mathrm{mmol}$ ) and tetrabutylammonium iodide (81.4 mg, $0.22 \mathrm{mmol}$ ) were successively added at room temperature. After stirred for $6 \mathrm{~h}$, the reaction mixture was quenched by addition of aqueous $\mathrm{Na}_{2} \mathrm{CO}_{3}$, extracted three times with EtOAc. The combined organic layer was dried over $\mathrm{MgSO}_{4}$, filtered and evaporated. The crude product was purified by column chromatography ( $\mathrm{SiO}_{2}$, hexane:EtOAc, 99.5:0.5 v/v) to give (rac)-1d as a colorless oil (200 mg, $1.14 \mathrm{mmol}$, 52\%). (rac)-1d was subjected to preparative HPLC on a chiral phase (CHIRALCEL OJ-H, diameter: $20 \mathrm{~mm}$, length: $250 \mathrm{~mm}$, hexane:ethanol, $98: 2 \mathrm{v} / \mathrm{v}, 6.0 \mathrm{~mL} / \mathrm{min}, .:(1 S, 5 R)-1 \mathbf{d}: \mathrm{t}_{\mathrm{R}}=$ 30.5 min., $(1 R, 5 S)-\mathbf{1 d}: t_{\mathrm{R}}=35.3 \mathrm{~min}$. The ee values of $(1 S, 5 R)-\mathbf{1 d}$ and $(1 R, 5 S)-\mathbf{1 d}$ were determined by HPLC analysis on a chiral phase (CHIRALCEL OJ-H, hexane, v/v, $0.5 \mathrm{~mL} / \mathrm{min}, 40{ }^{\circ} \mathrm{C}$ ). 


\section{Copper(I)-catalyzed reaction of $(1 S, 5 R)-1 d$.}

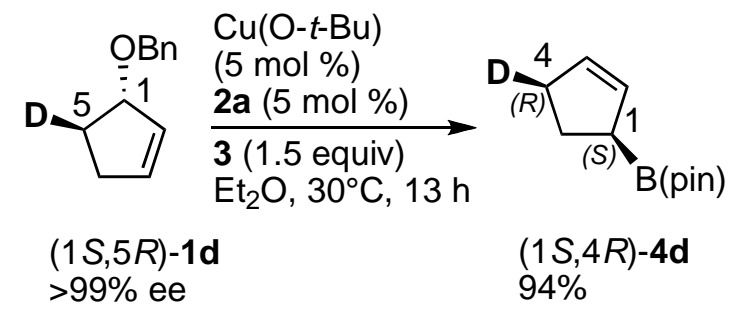

The copper(I)-catalyzed reaction of $(1 S, 5 R)$-1d was cared out in $0.26 \mathrm{mmol}$ scale with $5 \mathrm{~mol} \%$ catalyst. In a glove box, $\mathrm{Cu}(\mathrm{O}-\mathrm{t}-\mathrm{Bu})(5.2 \mathrm{mg}, 0.038 \mathrm{mmol})$, bis(pinacolato)diboron 2 (285.2 mg, $1.12 \mathrm{mmol})$ and $(R, R)$-QuinoxP* (12.6 $\mathrm{mg}, 0.0366 \mathrm{mmol})$ was placed into a vial and mixed with dry $\mathrm{Et}_{2} \mathrm{O}(0.75 \mathrm{~mL})$. The $0.26 \mathrm{~mL}$ of this catalyst/diboron mixture was added to an other reaction vial and mixed with (1S,5R)-1d (45.4 mg, $0.259 \mathrm{mmol})$. After being sealed with the rubber septum, the reaction vial was removed from the glove box and connected to an argon line through a needle and the reaction vial was maintained at $30{ }^{\circ} \mathrm{C}$ with stirring. After the reaction was complete, the reaction mixture was directly subjected to column chromatography (Florisil, hexane:EtOAc $=95: 5$ ) to give crude allylboronates 4 . The ${ }^{1} \mathrm{H}-\mathrm{NMR}$ yield of $(1 S, 4 R)-\mathbf{4 d}$ was determined using mesitylene as an internal standard (94\%). The crude product was further purified by column chromatography $\left(\mathrm{SiO}_{2}\right.$, hexane:EtOAc, 99.5:0.5 v/v) to give pure $(1 \mathrm{~S}, 4 R)-\mathbf{4 d}$ as a colorless oil (39.5 $\mathrm{mg}, 0.20 \mathrm{mmol}$, 78\%). (1S,4R)-4d: ${ }^{1} \mathrm{H}-\mathrm{NMR}\left(300 \mathrm{MHz}, \mathrm{CDCl}_{3}\right): \delta$ 5.76-5.69 (m, 2H), 2.36-2.27 (m, 1H), 2.232.11 (m, 1H), 2.09-1.95 (m, 1H), 1.93-1.79 (m, 1H), 1.24 (s, 12H) p.p.m.; ${ }^{13} \mathrm{C}-\mathrm{NMR}(75.4 \mathrm{MHz}$, $\left.\mathrm{CDCl}_{3}\right): \delta 131.5(\mathrm{CH}) 129.8(\mathrm{CH}), 83.1(\mathrm{C}), 32.4(\mathrm{q}, \mathrm{CDH}), 25.3\left(\mathrm{CH}_{2}\right), 24.6\left(\mathrm{CH}_{3}\right)$ p.p.m. HRMSEI (m/z): $[\mathrm{M}+]^{+}$calcd for $\mathrm{C}_{11} \mathrm{H}_{18} \mathrm{DBO}_{2}, 196.16191$; found, 196.16158. The de value of the product was determined by HPLC after derivatization described as follows.

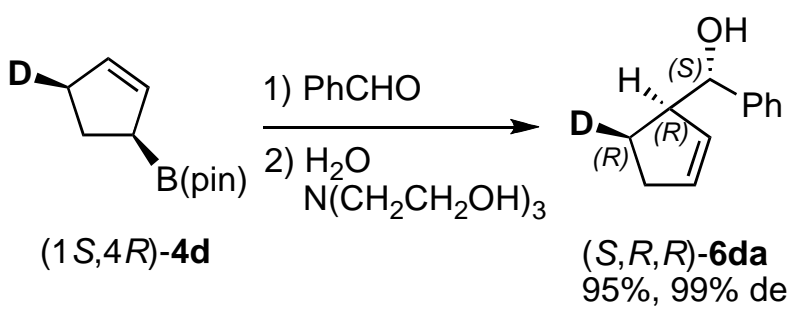


In a reaction vial, benzaldehyde (35.4 $\mathrm{mg}, 0.33 \mathrm{mmol})$ was added to a THF $(0.2 \mathrm{~mL})$ solution of (1S,4R)-4d (13.0 mg, $0.067 \mathrm{mmol})$ at room temperature. After $6.5 \mathrm{~h}, \mathrm{CH}_{2} \mathrm{Cl}_{2}$ solution of triethanolamine $(10 \% \mathrm{v} / \mathrm{v}, 0.5 \mathrm{~mL})$ was added and the reaction mixture was further stirred for $0.5 \mathrm{~h}$, separated with $\mathrm{CH}_{2} \mathrm{Cl}_{2}$ and water, then extracted two times with $\mathrm{CH}_{2} \mathrm{Cl}_{2}$. The combined organic layer was dried over $\mathrm{MgSO}_{4}$, filtered and evaporated. The crude product was further purified by column chromatography $\left(\mathrm{SiO}_{2}\right.$, hexane:EtOAc, 99.5:0.5-98:2 v/v) to give pure $(S, R, R)-\mathbf{6 d a}$ as an colorless oil (11.1 mg, $0.063 \mathrm{mmol}, 95 \%) .{ }^{1} \mathrm{H}-\mathrm{NMR}\left(300 \mathrm{MHz}, \mathrm{CDCl}_{3}\right): \delta$ 7.39-7.20 (m, 5H), 5.89-5.83 (m, 1H), 5.44-5.38 (m, 1H), 4.59 (dd, $J=6.6,1.9$ Hz, 1H), 3.15-3.05 (m 1H), 2.44-2.22 (m, 2H), $1.97-1.88(\mathrm{~m}, 1 \mathrm{H}), 1.88$ (d, $J=2.5 \mathrm{~Hz}, 1 \mathrm{H})$ p.p.m. The de value (99\% de) of $(S, R, R)-6 \mathbf{d a}$ was determined by HPLC analysis on a chiral phase (CHIRALCEL OD-3, hexane:2-propanol, 98.5:1.5, v/v, $\left.0.5 \mathrm{~mL} / \mathrm{min}, 40^{\circ} \mathrm{C}\right) .(S, R, R)-6$ da: $\mathrm{t}_{\mathrm{R}}=26.8 \mathrm{~min} .,(R, S, R)-6$ da: $\mathrm{t}_{\mathrm{R}}=29.1 \mathrm{~min}$.

\section{Copper(I)-catalyzed reaction of $(1 R, 5 S)-1 d$.}

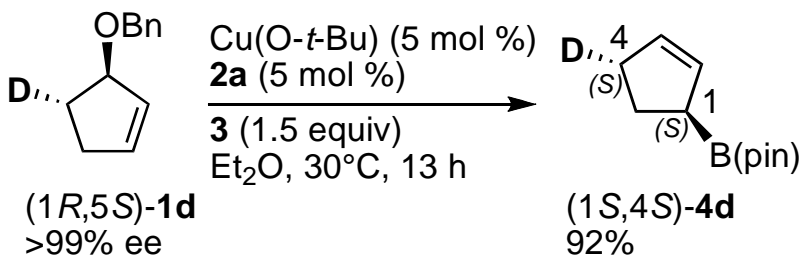

The reaction was carried out according to the similar procedure described for the reaction of (1S,5R)-1d. (92\% NMR yield, 71\% isolated yield). (1S,4S)-4d: ${ }^{1} \mathrm{H}-\mathrm{NMR}$ (300 MHz, $\left.\mathrm{CDCl}_{3}\right): \delta$ 5.76-5.69 (m, 2H), 2.40-2.29 (m, 1H), 2.23-2.12 (m, 1H), 2.08-1.96 (m, 1H), 1.93-1.79 (m, 1H), 1.24 (s, 12H) p.p.m.; ${ }^{13} \mathrm{C}-\mathrm{NMR}$ (75.4 MHz, $\left.\mathrm{CDCl}_{3}\right): \delta 131.5(\mathrm{CH}) 129.8(\mathrm{CH}), 83.1(\mathrm{C}), 32.4$ (q, CDH), $25.3\left(\mathrm{CH}_{2}\right), 24.6\left(\mathrm{CH}_{3}\right)$ p.p.m. 


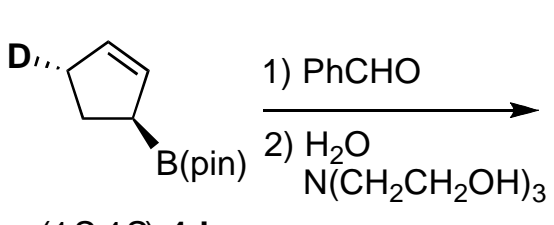
$(1 S, 4 S)-4 d$ $94 \%$

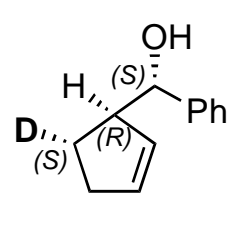

$(S, R, S)-6 \mathbf{d a}$ $95 \%, 88 \%$ de

The reaction was carried out according to the similar procedure described for the reaction of (1S,4R)-4d. (95\% isolated yield). ${ }^{1} \mathrm{H}-\mathrm{NMR}\left(300 \mathrm{MHz}, \mathrm{CDCl}_{3}\right): \delta$ 7.39-7.20 (m, 5H), 5.89-5.83 (m, 1H), 5.44-5.38 (m, 1H), 4.59 (d, $J=6.6 \mathrm{~Hz}, 1 \mathrm{H}), 3.15-3.05$ (m 1H), 2.45-2.24 (m, 2H), 1.88 (d, $J$ $=2.5 \mathrm{~Hz}, 1 \mathrm{H}), 1.88-1.79(\mathrm{~m}, 1 \mathrm{H})$ p.p.m. The de value $(88 \%$ de) of $(S, R, S)-6$ da was determined by HPLC analysis on a chiral phase (CHIRALCEL OD-3, hexane:2-propanol, 98.5:1.5 v/v, 0.5 $\left.\mathrm{mL} / \mathrm{min}, 40^{\circ} \mathrm{C}\right) .(S, R, S)-6 d a: \mathrm{t}_{\mathrm{R}}=27.0 \mathrm{~min} .,(R, S, S)-\mathbf{6 d a}: \mathrm{t}_{\mathrm{R}}=29.1 \mathrm{~min}$.

\section{4-Ntirobenzoate derivatization of $(S, R)$-6ea, $(S, R, R)-6 \mathrm{da}$ and $(S, R, S)$-6da and their structural characterization.}

4-Nitrobenzoate derivatives of $(S, R)$-6ea, $(S, R, R)$-6da and $(S, R, S)$-6da were prepared by using $\mathrm{N}, \mathrm{N}$-dimethyl-4-aminopyridine (3.0 equiv) and 4-nitorobenzoyl chloride (2.5 equiv) in $\mathrm{CH}_{2} \mathrm{Cl}_{2}$. The purification of the compounds was carried out by using PTLC. The relative stereochemistry of the compounds were determined by NOE experiment of $(S, R)$-6ea and comparison of ${ }^{1} \mathrm{H}-\mathrm{NMR}$ spectra of $(S, R)-\mathbf{6 e a},(S, R, R)-\mathbf{6 d a}$ and $(S, R, S)$-6da as illustrated in Figure $\mathrm{S} 2$. 
<smiles>C[C@@H]1CC=C[C@H]1[C@H](OC(=O)c1ccc([N+](=O)[O-])cc1)c1ccccc1</smiles>

$(S, R)$-6ea-4-nitrobenzoate

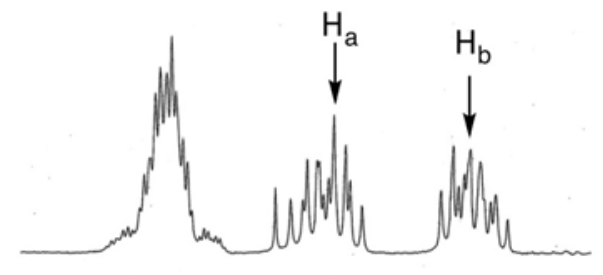

nOe experiment

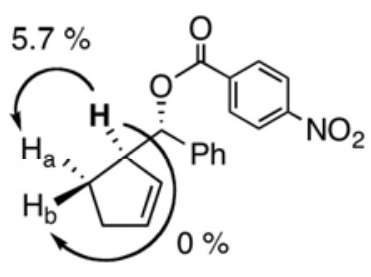

$(S, R)$-6ea-4-nitrobenzoate

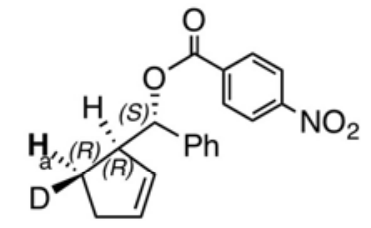

$(S, R, R)$-6da-4-nitrobenzoate $99 \%$ de

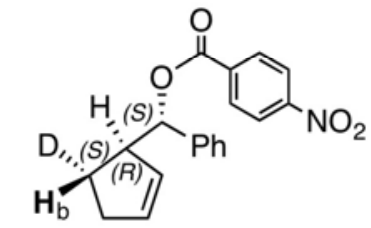

$(S, R, S)$-6da-4-nitrobenzoate $88 \%$ de

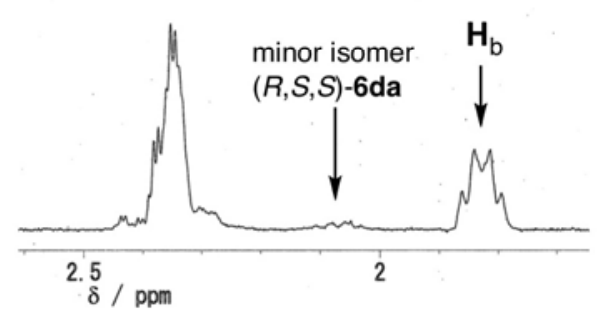

Figure S2. NMR measurements for characterization of 4-nitrobenzoate derivatives of 6ea. 


\section{Computational methods.}

Calculations were performed using the Gaussian 03 program package. ${ }^{10}$ Density functional theory with the M05-2X functional ${ }^{11}$ and $6-31 G(d)$ basis set ${ }^{12}$ was employed for structure optimization. Stationary points were characterized by vibrational frequencies; IA, IB, IC, ID, IIA, and IIB have no imaginary frequencies and $\mathbf{T} \mathbf{S}_{\mathbf{A}}, \mathbf{T S}_{\mathbf{B}}, \mathbf{T} \mathbf{S}_{\mathbf{C}}$, and $\mathbf{T} \mathbf{S}_{\mathbf{D}}$ have only one imaginary frequencies. The complete characterization of the local minimum structures for IIC and IID were not successful; imaginary frequencies with very small absolute values (IIC: $15.3 \mathrm{i} \mathrm{cm}^{-1}$, IID: $5.9 \mathrm{i}$ $\mathrm{cm}^{-1}$ ) were found after vibrational frequency analysis. Intrinsic reaction coordinate (IRC) analysis was conducted for the four reaction pathways and all the stationary points were smoothly connected to each other.

\section{Results of DFT calculations.}

Using M05-2X functional and the model complex, in which the quinoxaline backbone of the QuinoxP* ligand and the pinacolato were replaced by ethene and ethyleneglycolato, respectively, we carried out the calculations on the basis of insertion-elimination mechanism, which have been supposed as the plausible mechanism for the copper(I)-catalyzed allylic substitution with diboron (Figure S3). ${ }^{13-15}$ We calculated four different pathways A-D and obtained their activation free energies at the insertion steps, which are considered to be the key process for the enantioselection. The activation energies of $16.4 \mathrm{kcal} / \mathrm{mol}\left(\mathbf{T S}_{\mathbf{A}}\right)$ and $18.9 \mathrm{kcal} / \mathrm{mol}\left(\mathbf{T S}_{\mathbf{B}}\right)$ were obtained for anti-S $2_{\mathrm{N}}$ ' type and syn- $\mathrm{S}_{\mathrm{N}} 2$ ' routes from $(S)-\mathbf{1}$, respectively, indicating the reaction of $(S)-\mathbf{1}$ prefer anti-S $2_{\mathrm{N}}$ ' pathway. The theoretical ratio of the kinetic constants $\left(k_{\mathrm{A}} / k_{\mathrm{B}} 98.4: 1.6\right)$ derived from these calculated activation energies shows well agreements with the experimental results (Table 1, entry 9, 99\% ee, e.r. 99.5:0.5). We also calculated the activation energies from $(R)-\mathbf{1}$ and obtained $15.9 \mathrm{kcal} / \mathrm{mol}$

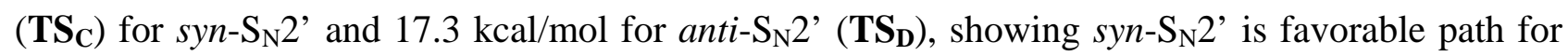
$(R)$-1. The theoretical ratio of the kinetic constants $\left(k_{\mathrm{C}} / k_{\mathrm{D}} 91: 9\right)$ also shows rough agreements with the experiments (Table 1, entry 10, 88\% ee, e.r. 94:6). The barriers for path A and path B is similar. 
This is consistent with the fact that $(S)-\mathbf{1}$ and $(R)-\mathbf{1}$ were consumed at the similar reaction rates (Table 1, entries 9-13).

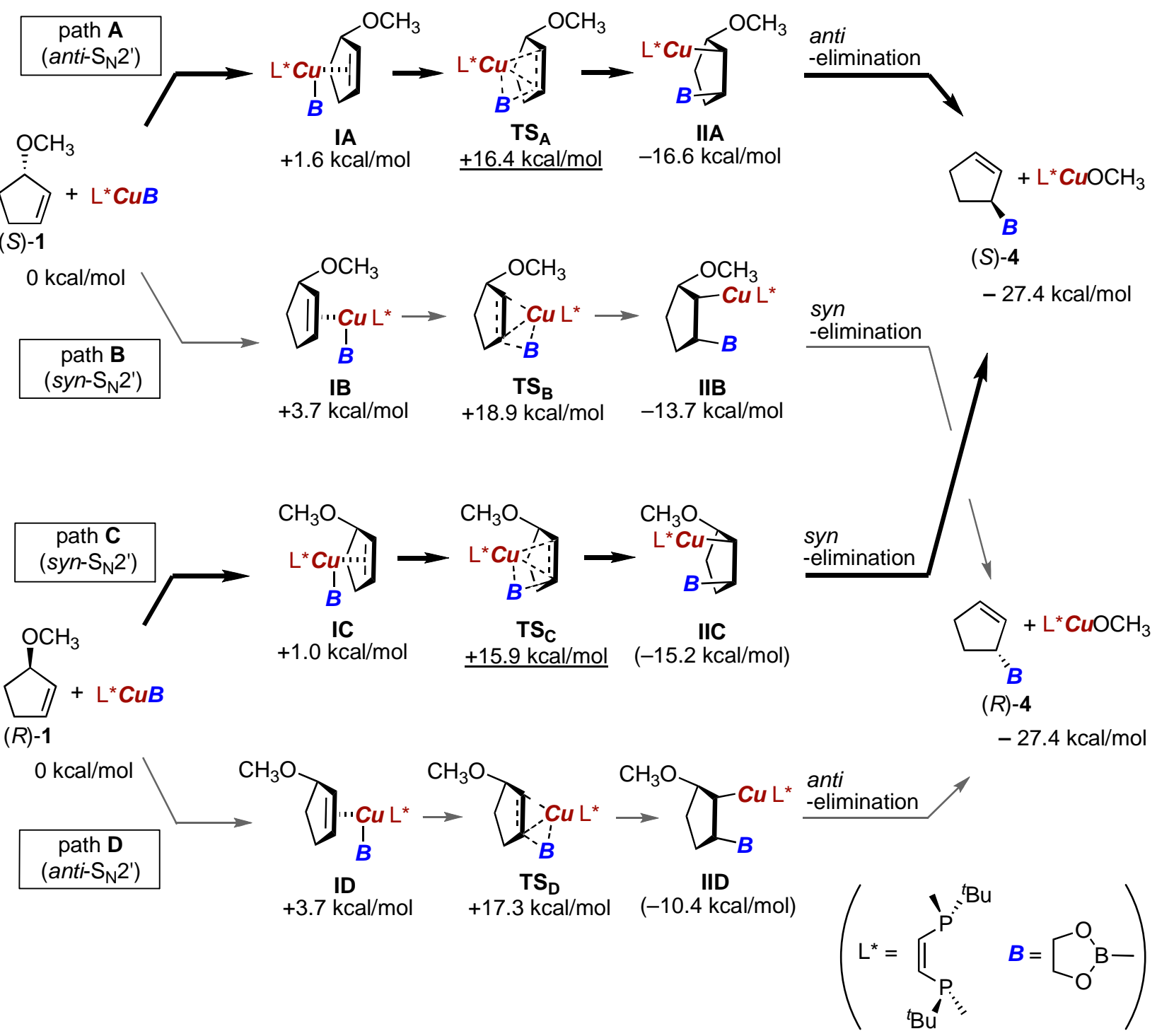

Figure S3. DFT calculations of four distinct pathways in copper(I)-catalyzed enantio-convergent transformation. Relative free energies (M05-2X/6-31G*//M05-2X/6-31G*) are shown.

Schematic and molecular model structures for the transition states $\left(\mathbf{T S}_{\mathbf{A}}, \mathbf{T S}_{\mathbf{B}}, \mathbf{T S}_{\mathbf{C}}, \mathbf{T} \mathbf{S}_{\mathbf{D}}\right)$ were shown in Figure S4. The steric environment around copper(I) center takes pseudo $\mathrm{C}_{2}$ symmetry; methyl groups of the $(R, R)$-QuinoxP* model ligand are located in quadrants I and III and bulky tertbutyl groups are located in quadrants II and IV, resulting that quadrants I and III are less sterically 
congested sites and quadrants II and IV provide sterically more demanding sites. In $\mathbf{T S}_{\mathbf{A}}$, the $\mathrm{C}_{3}$ and $\mathrm{C}_{4}$ part of the substrate is located in sterically less congested quadrant I. The anti- $\mathrm{S}_{\mathrm{N}} 2$ ' pathway from (S)-1 that proceeds via $\mathbf{T S}_{\mathbf{A}}$ is favorable (Figure S4b). Contrary to this, $\mathbf{T S}_{\mathbf{B}}$, for syn-S $\mathbf{S}_{\mathbf{N}}$ ' from (S)-1 is much unfavorable than $\mathbf{T} \mathbf{S}_{\mathbf{A}}$, because substrate methoxy group is located in quadrant II causes severe steric congestion with ligand tert-butyl group (Figure S4a). For the reaction of (R)-1, $\mathbf{T S}_{\mathbf{C}}\left(\operatorname{syn}-\mathrm{S}_{\mathrm{N}} 2^{\prime}\right)$, in which methoxy group is in quadrant $\mathrm{I}$, is more favorable than $\mathbf{T S}_{\mathbf{D}}\left(\right.$ anti-S $\left.\mathbf{S}_{\mathrm{N}} \mathbf{2}^{\prime}\right)$. In $\mathbf{T S}_{\mathbf{D}}, \mathrm{C}_{3}$ and $\mathrm{C}_{4}$ part of the substrate is located in the sterically congested quadrant II. These models give reasonable explanation for the transition state structures and reaction pathway preferences.

(a)

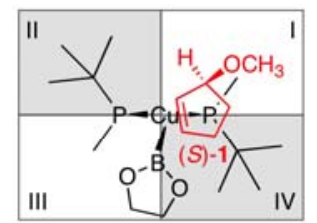

(c)

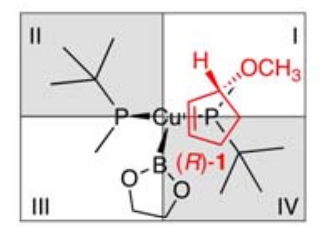

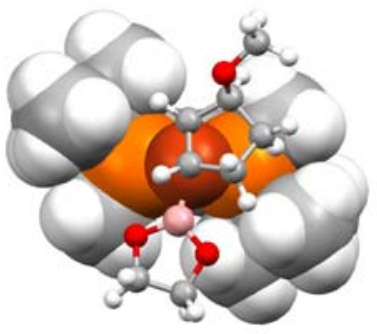

$\mathrm{TS}_{\mathrm{A}}$

$+16.4 \mathrm{kcal} / \mathrm{mol}$

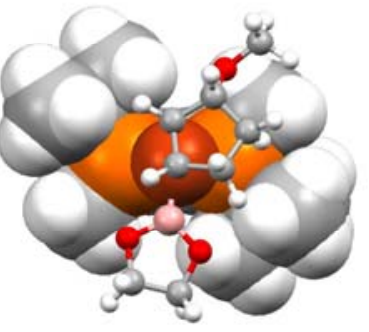

$\mathrm{TS}_{\mathrm{C}}$

$+15.9 \mathrm{kcal} / \mathrm{mol}$ (b)

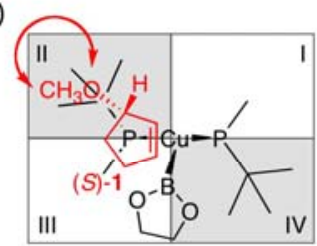

(d)

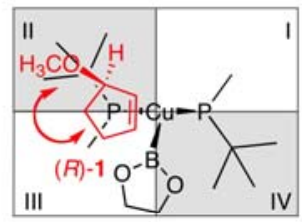

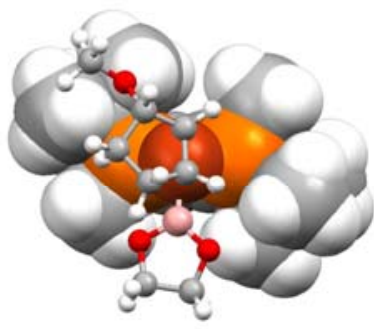

$\mathrm{TS}_{\mathrm{B}}$ $+18.9 \mathrm{kcal} / \mathrm{mol}$

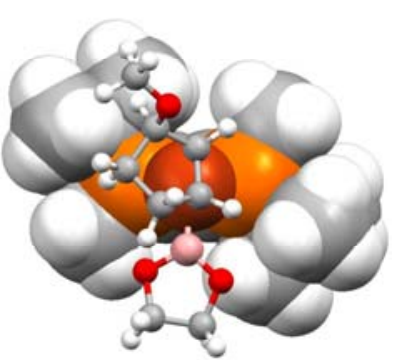

$\mathrm{TS}_{\mathrm{D}}$ $+17.3 \mathrm{kcal} / \mathrm{mol}$

Figure S4. The schematic and molecular model structures of transition states $\left(\mathbf{T S}_{\mathbf{A}-\mathbf{D}}\right)$ calculated by DFT (M05-2X/6-31G*//M05-2X/6-31G*). The structures of LCu part of the catalyst were shown in space filling models and the allyl ether substrate and $\mathrm{B}(\mathrm{OR})_{2}$ part were shown in ball \& stick models. Relative free energies are also shown. 


\section{References}

1. For preparation of $\mathrm{Cu}(\mathrm{O}-t-\mathrm{Bu})$ : (a) Suto, Y.; Kumagai, N.; Matsunaga, S.; Kanai, M.;

Shibasaki, M. Org. Lett. 2003, 5, 3147-3150. (b) Suto, Y.; Tsuji, R.; Kanai, M.;

Shibasaki, M. Org. Lett. 2005, 7, 3757-3760.

2. Sasaki, Y.; Zhong, C.; Sawamura, M.; Ito, H. J. Am. Chem. Soc. 2010, 132, 1226-1227.

3. (a) Czernecki, S.; Georgoulis, C.; Provelenghiou, C. Tetrahedron Lett. 1976, 17, 35353536. (b) Kanai, K.; Sakamoto, I.; Ogawa, S.; Suami, T. Bull. Chem. Soc. Jpn. 1987, 60, 1529-1531.

4. Wrackmeyer, B. Prog. Nucl. Magn. Reson. Spectrosc. 1979, 12, 227-259.

5. $\quad$ Pelz, N, F.; Woodward, A. R.; Burks, H, E.; Sieber, J. D.; Morken, J. P. J. Am. Chem. Soc. 2004, 126, 16328-16329.

6. $\quad$ Kobayashi, S.; Nishio, K. J. Org. Chem. 1994, 59, 6620-6628.

7. Hayashi, T.; Han, J. S.; Takeda, A.; Tang, J.; Nohmi, K.; Mukaide, K.; Tsuji, H.; Uozumi, Y. Adv. Synth. Catal. 2001, 343, 279-283.

8. (a) Howell, G. P.; Minnaard, A. J.; Feringa, B. L. Org. Bio. Chem. 2006, 4, 1278-1283.

(b) Ggrimbeck, A.; Stadtmiiller, S. J. Am. Chem. Soc. 2001, 111, 6923-6928.

9. $\quad$ Liu, G.; Stahl, S. S. J. Am. Chem. Soc. 2007, 129, 6328-6335.

10. Frisch, M. J. et al., Gaussian 03, Revision E.01 (Gaussian Inc., Wallingford, CT, 2004).

11. Zhao, Y.; Schultz, N. E.; Truhlar, D. G. J. Chem. Theory. Comput. 2006, 2, 364-382.

12. Hehre, W. J., Radom, L., Schleyer, P. R., \& Pople, J. A., Ab Initio Molecular Orbital Theory. (John Wiley \& Sons, Inc., New York, 1986) and references cited therein.

13. Ito, H.; Ito, S.; Sasaki, Y.; Matsuura, K.; Sawamura, M. J. Am. Chem. Soc. 2007, 129, 14856-14857.

14. Ito, H.; Kosaka, Y.; Nonoyama, K.; Sasaki, Y.; Sawamura, M. Angew. Chem., Int. Ed. 2008, 47, 7424-7427.

15. Ito, H.; Okura, T.; Matsuura, K.; Sawamura, M. Angew. Chem. Int., Ed. 2010, 49, 560563. 


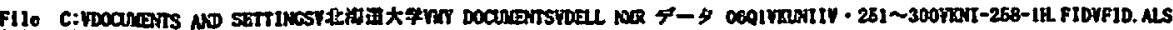
Orfiginol Filo: Jun 100

STANANA IH OBSERVE

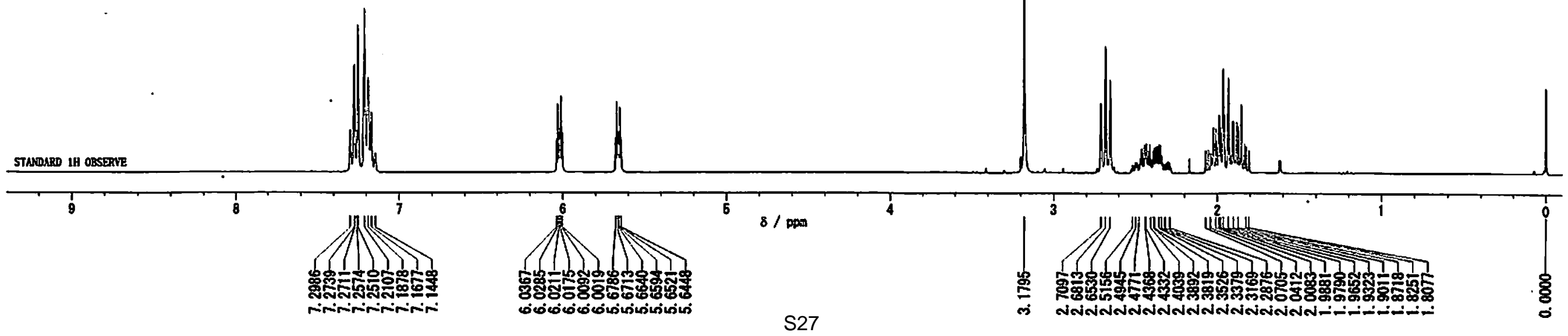




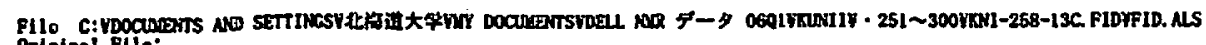

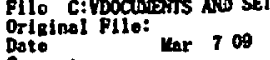

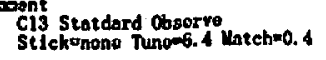

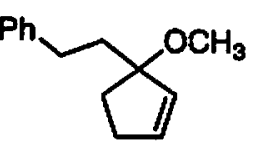

ta

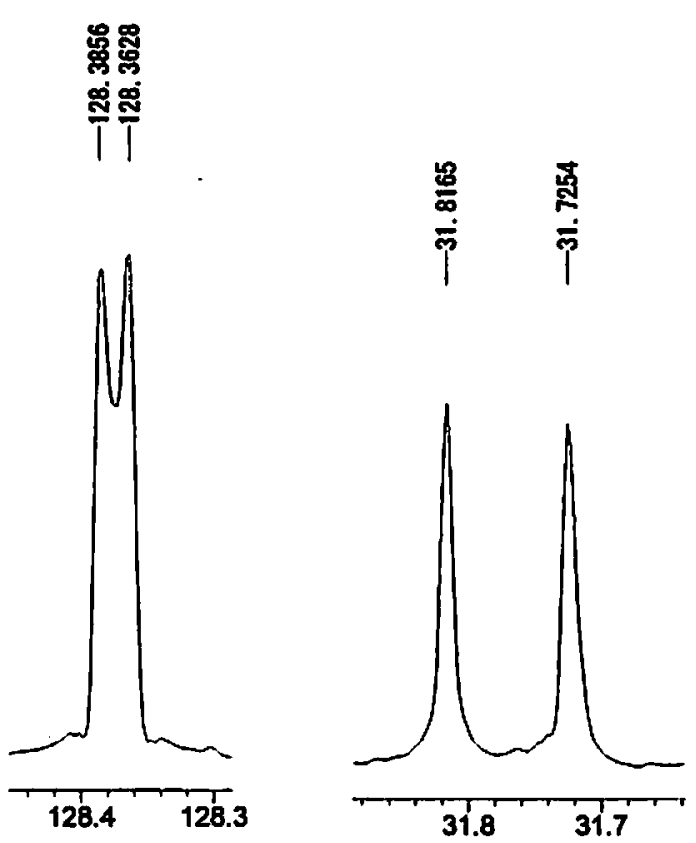

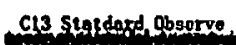

180

160

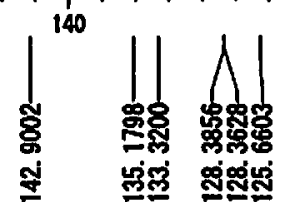

120

$8 / 100$

章

80

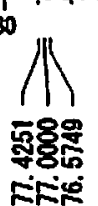

60

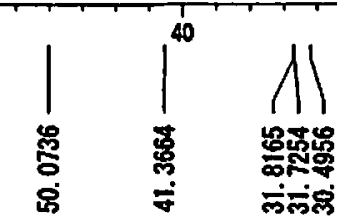




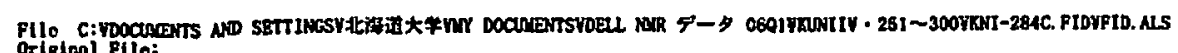
Dato

SThined us oeserve 


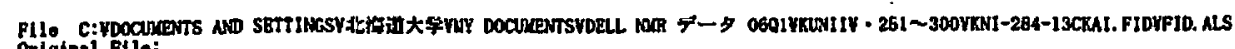
Doto 1500

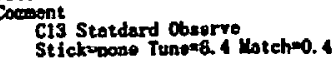

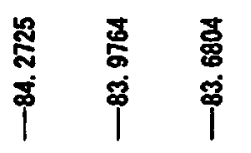

f13 Statdaxd Posotag

$\mid$

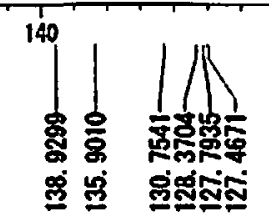

120

180

160

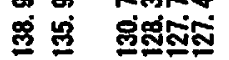

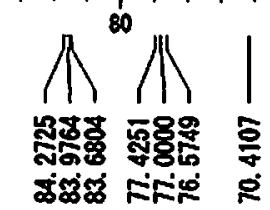

11

20 


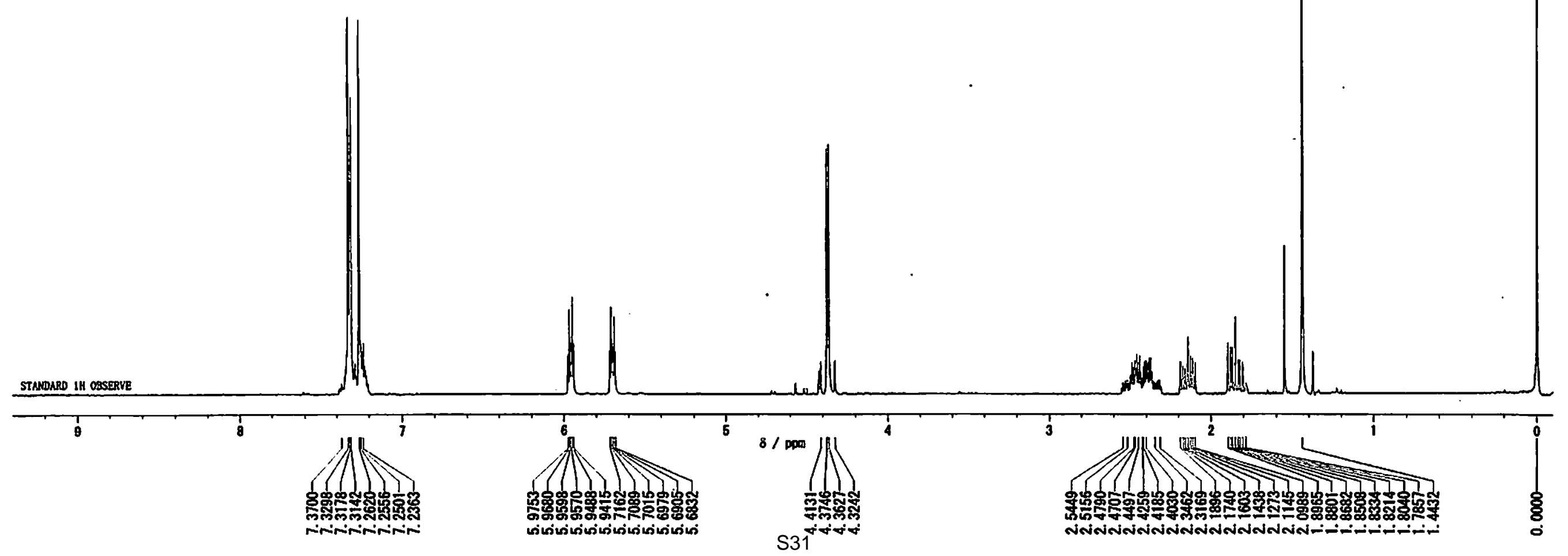




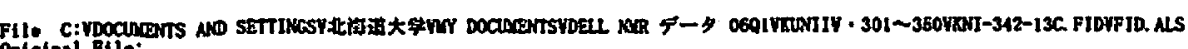
Aug 1708
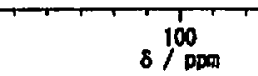

$8 / 000$

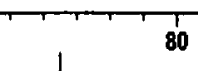

180 


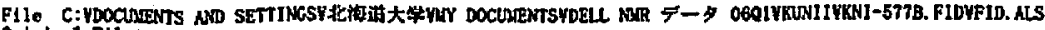
Original Fllo: Lar 12

STANOARD IH OBSERYE
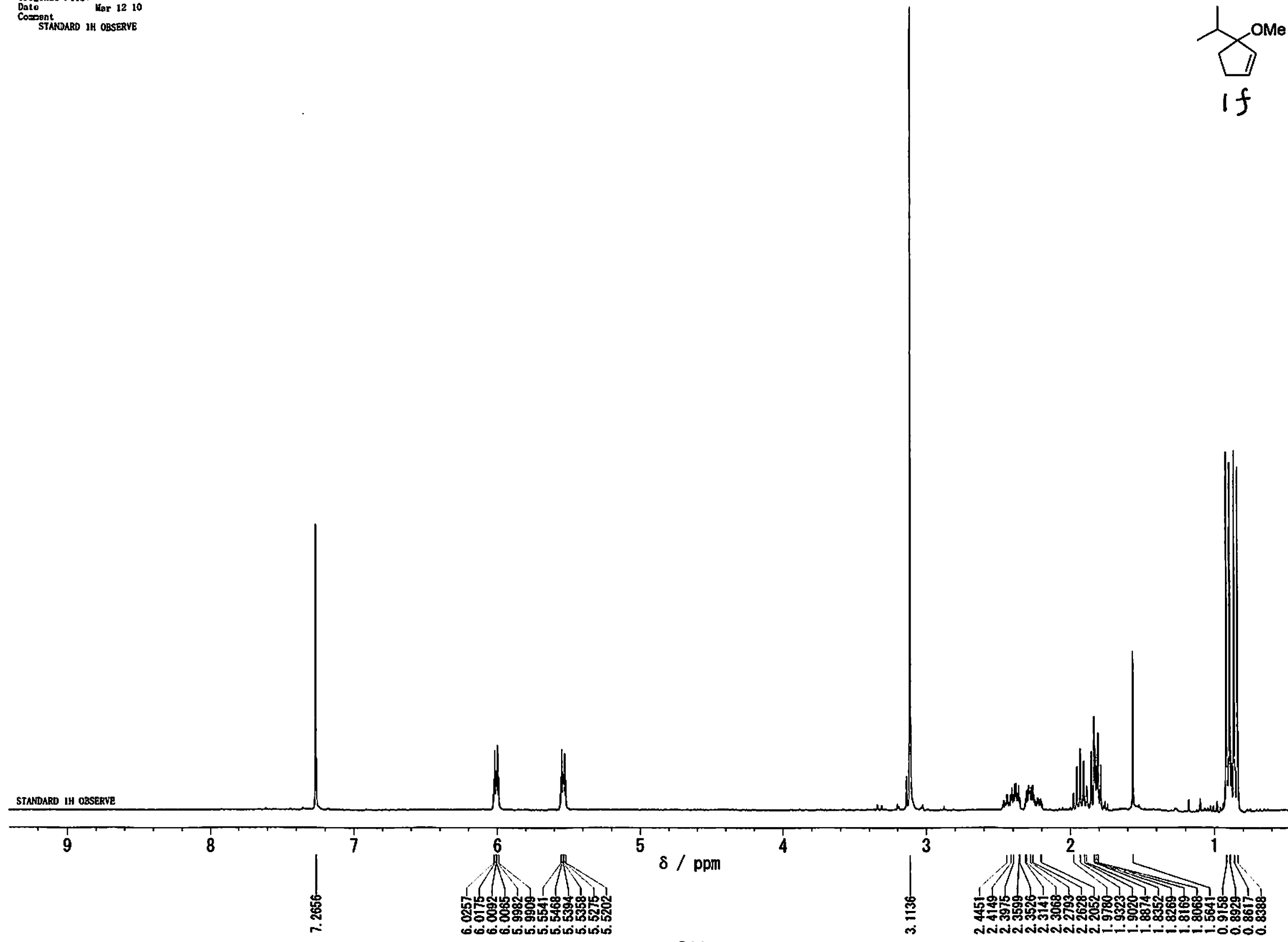


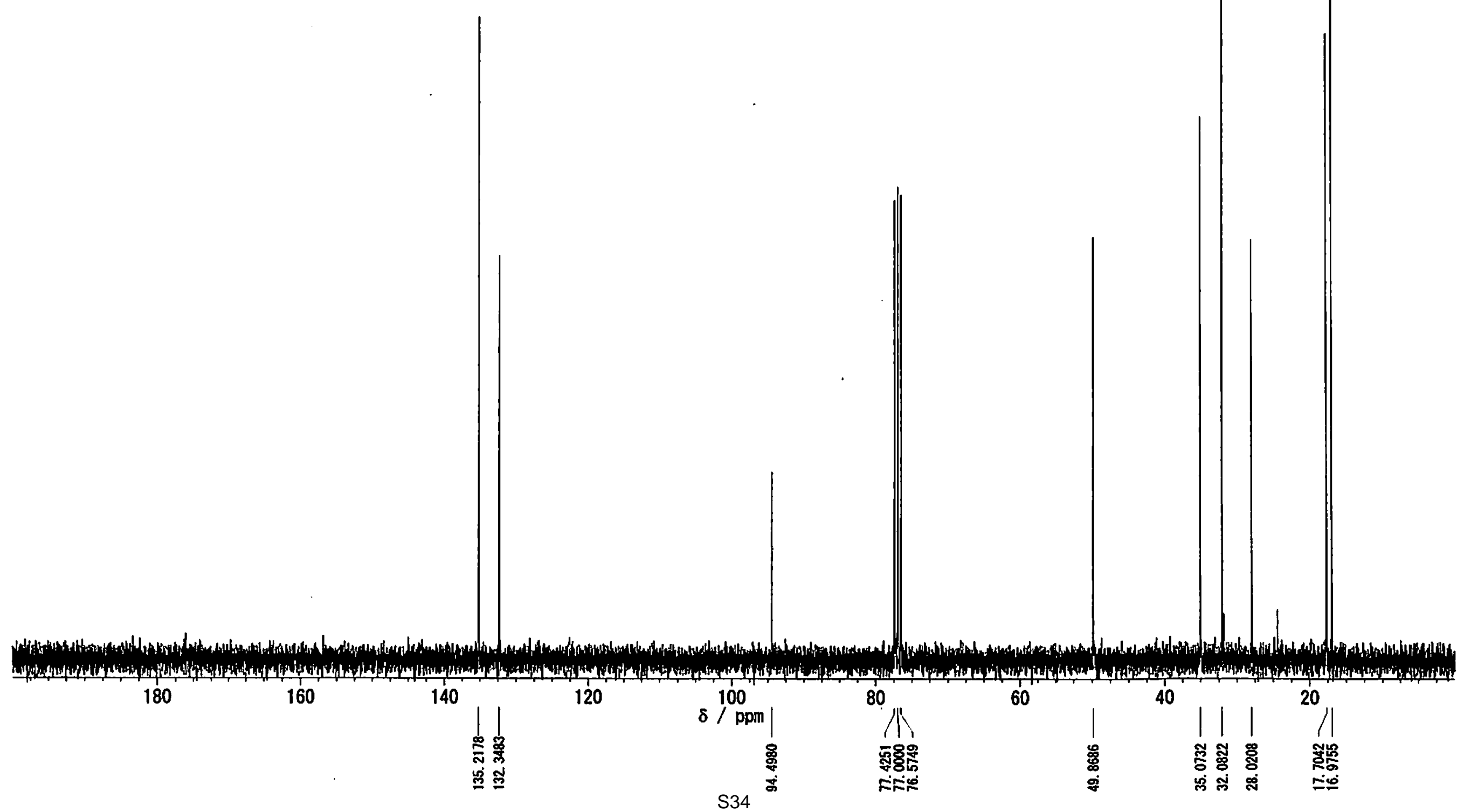




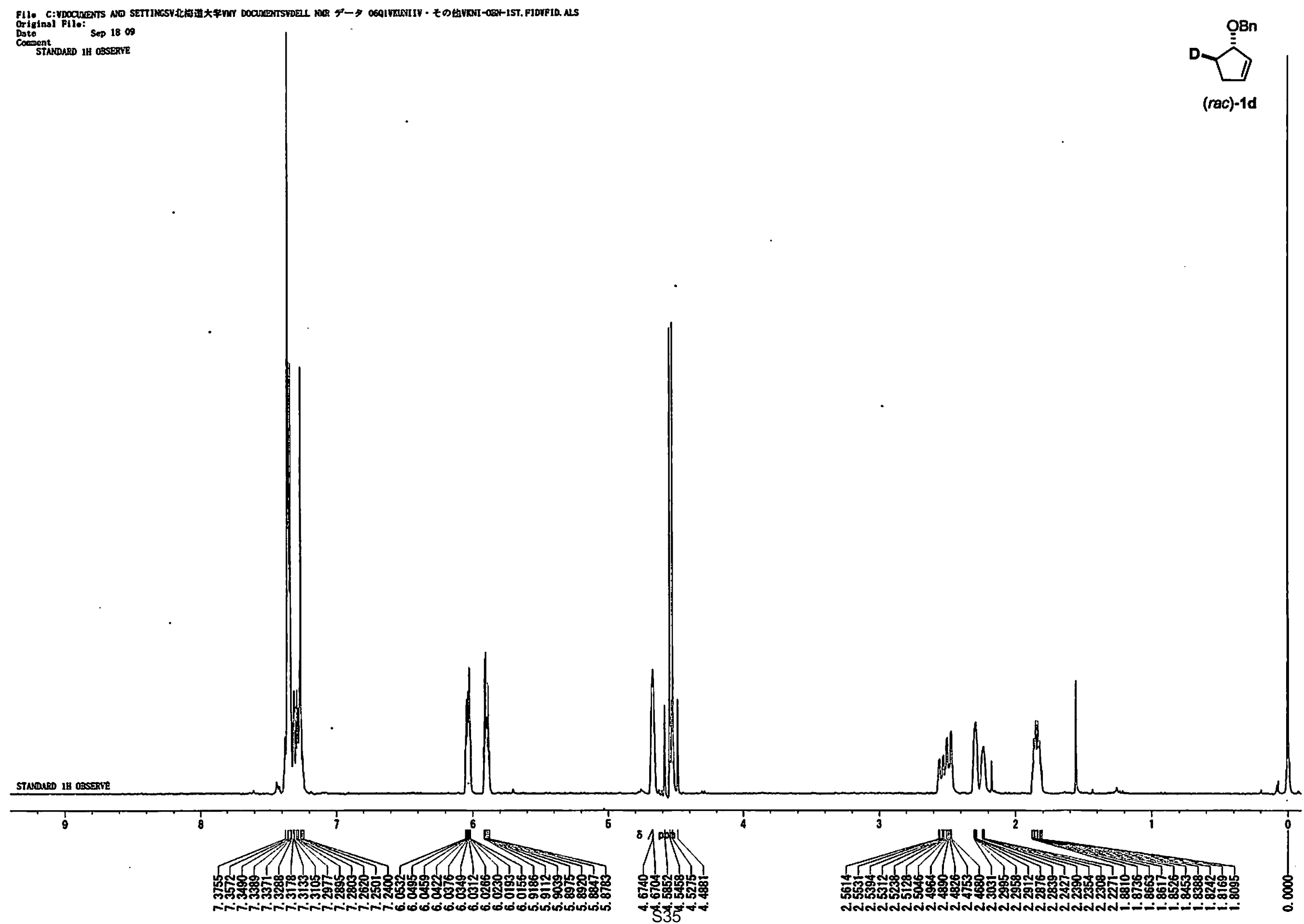




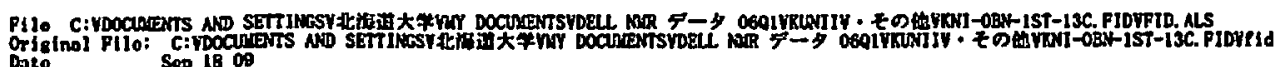
Sep 1800

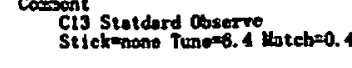

范

จุ

120

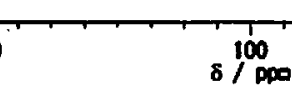

$8 / \mathrm{ppo}$

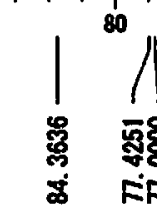

80

M 1

10

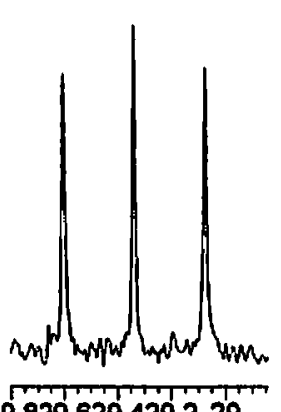

29.829 .629 .429 .228

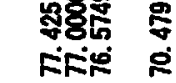




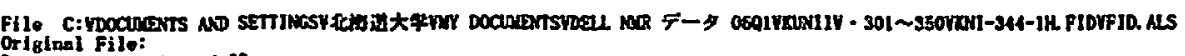
Cate
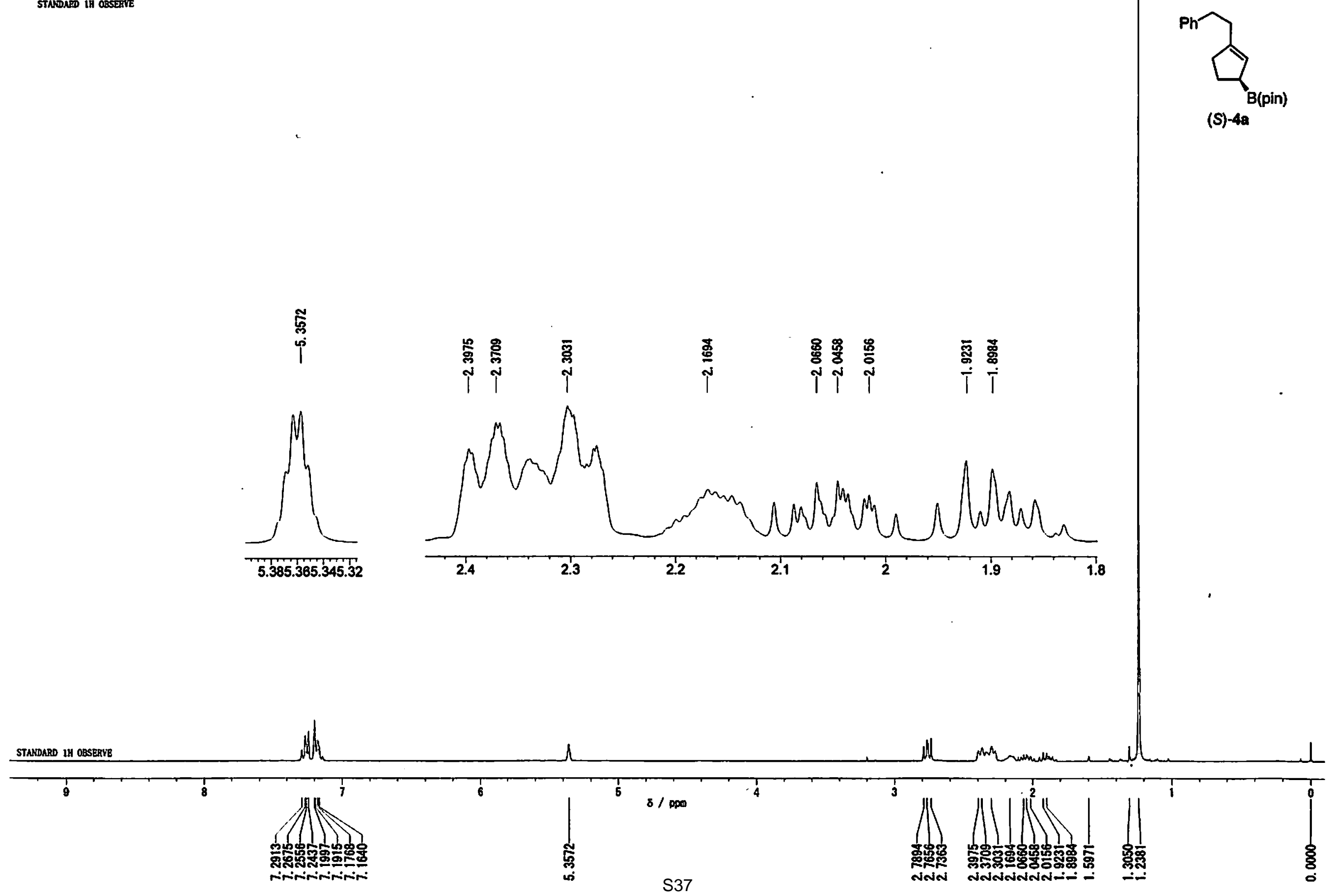


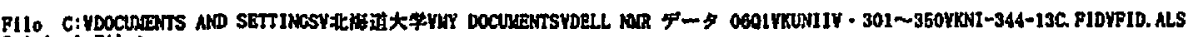
Oate

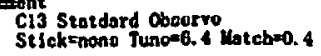

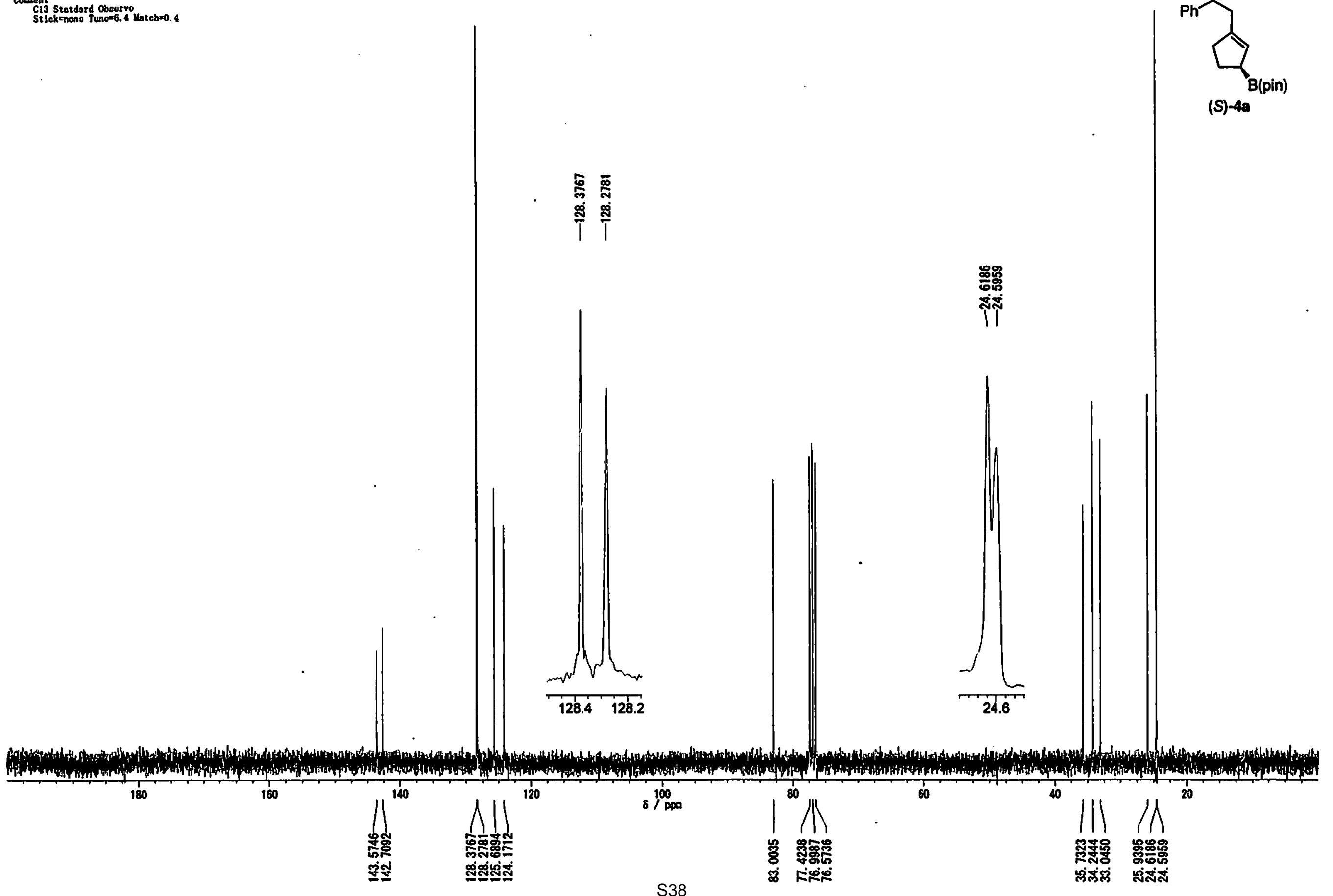




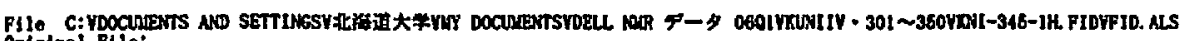
Orisinai fillo: hus 3 og

STANDAR IH OZSERV

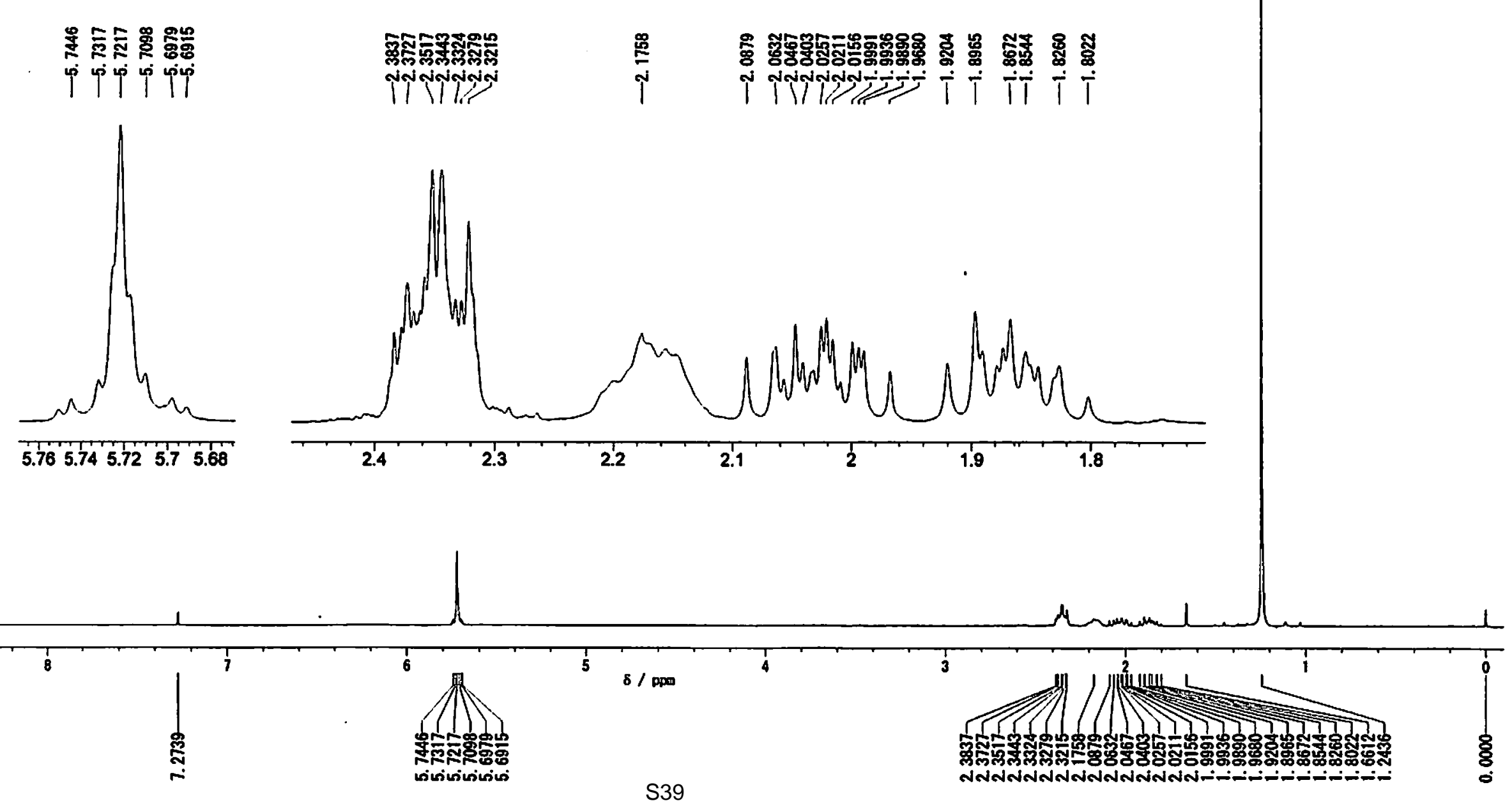




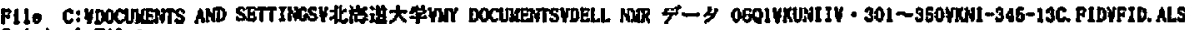
Oate Originol Filo: hug 309

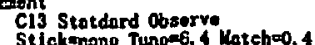

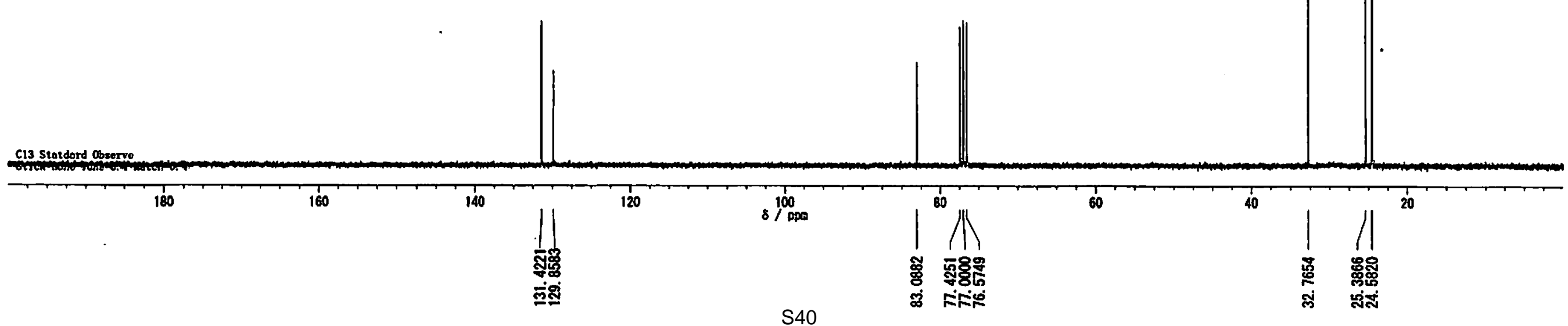



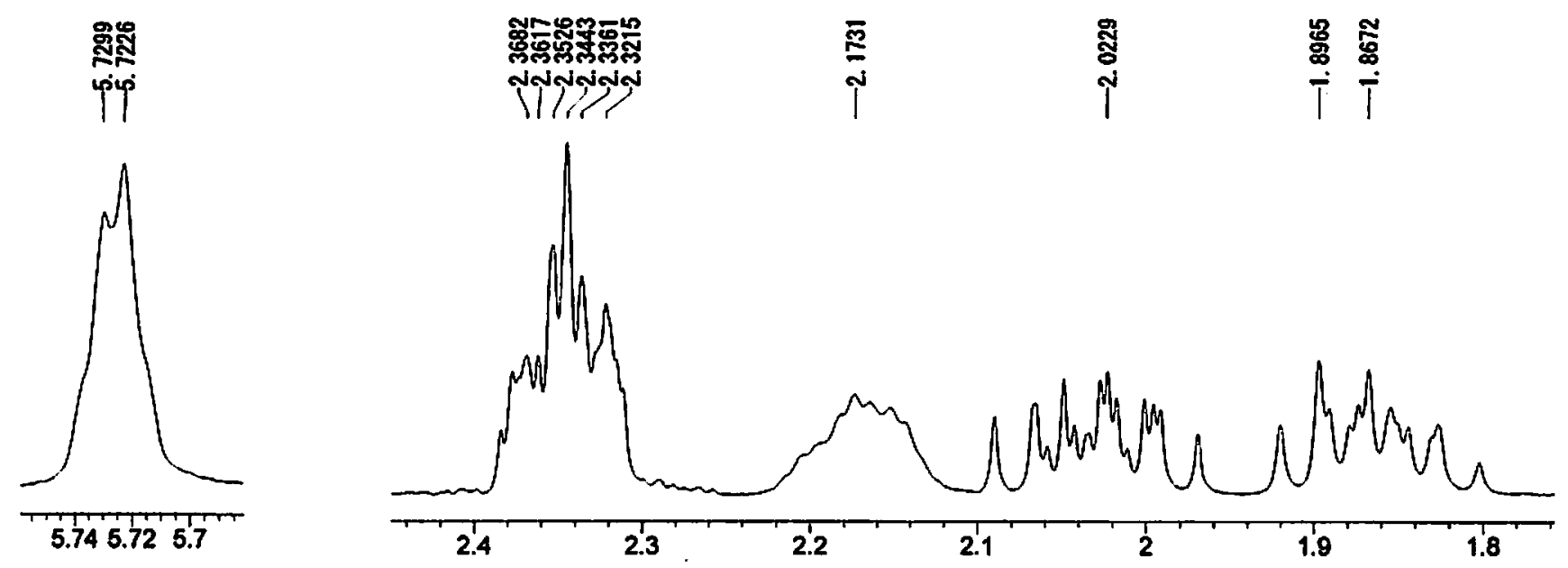

STNEAED $1 \mathrm{H}$ OBSERE
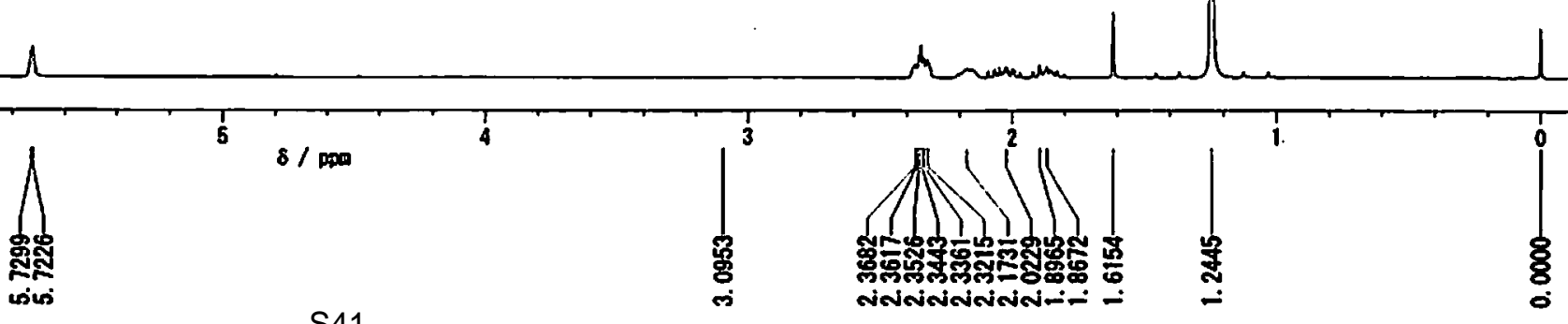


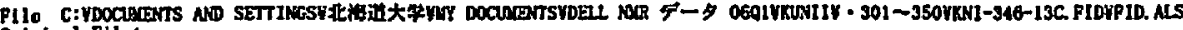
Original Filo: aug 300

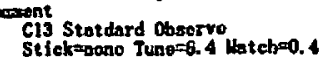

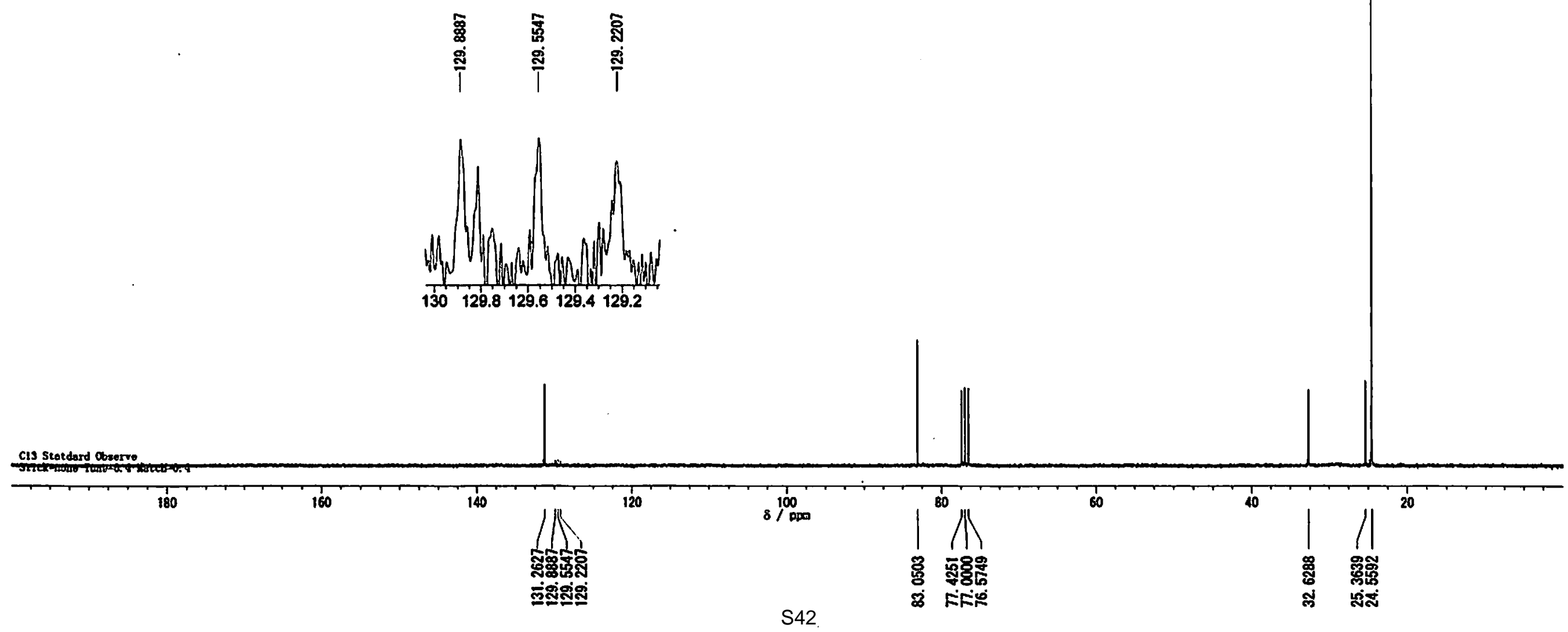




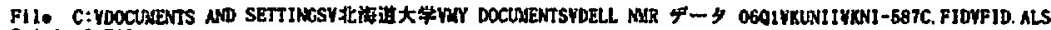
Originai Filo: Har 2310

STANDARD IH OBSERVE

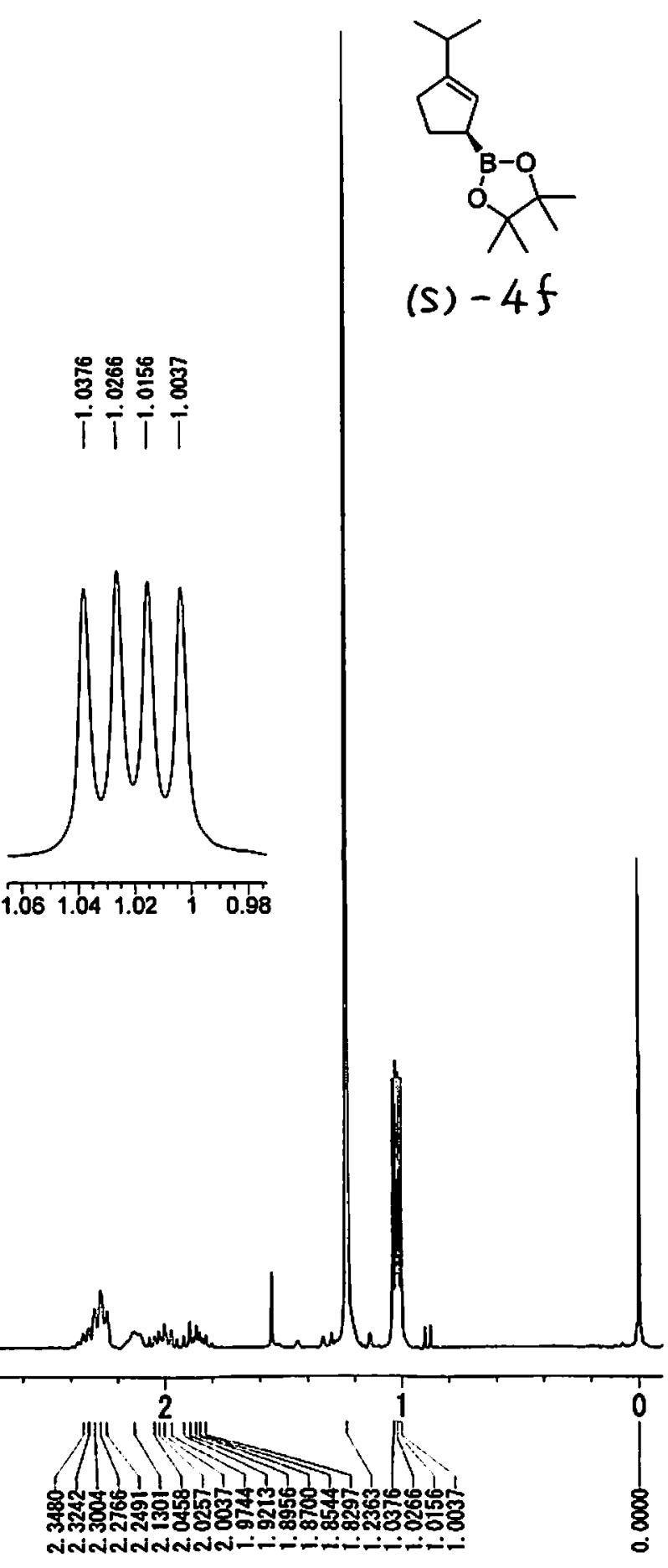




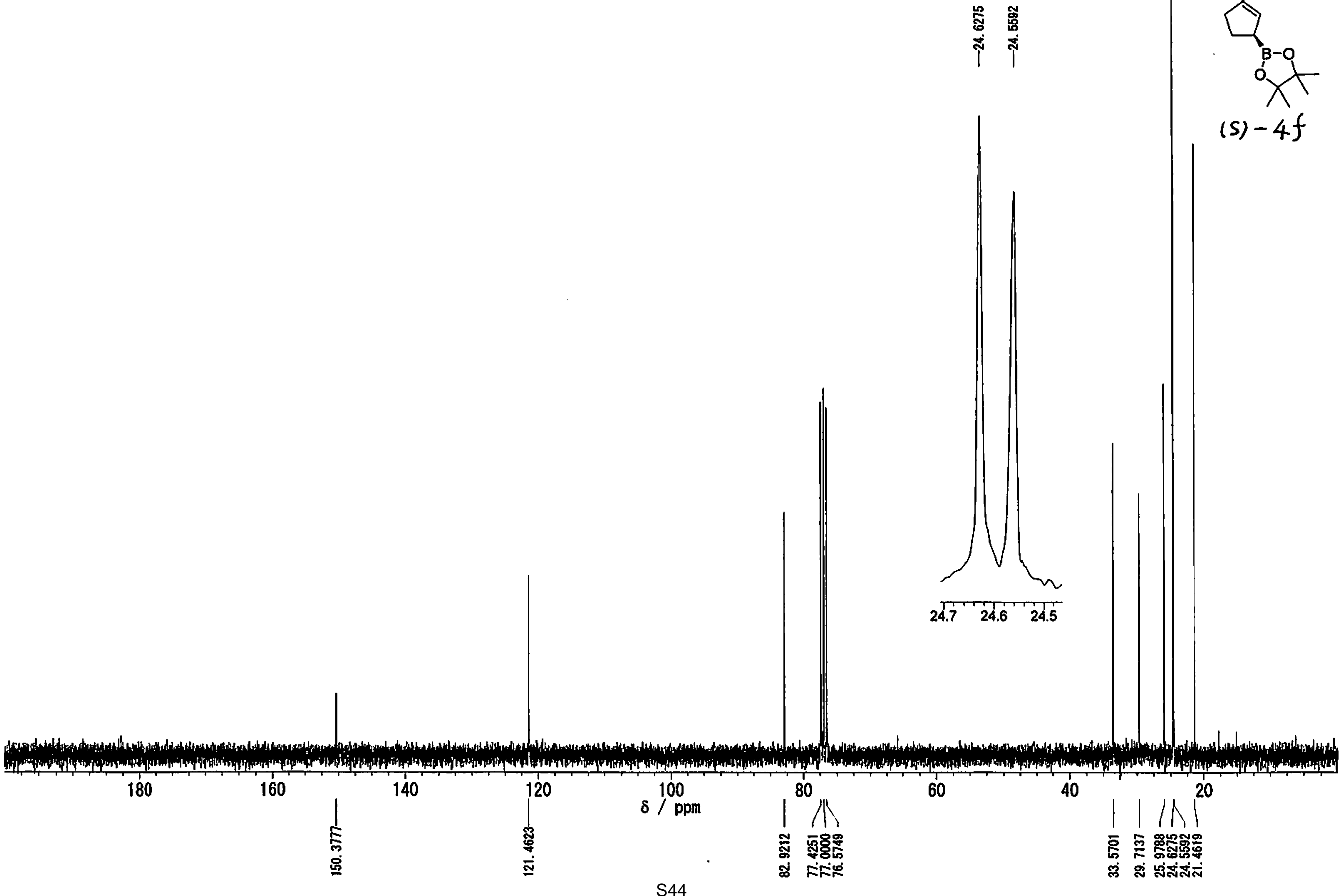




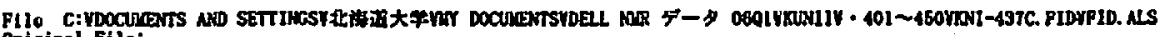
Original Filo: det 16 og

STMOARD IH OBSERE

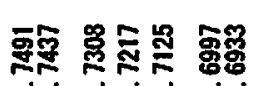

pipj pipipi pipi

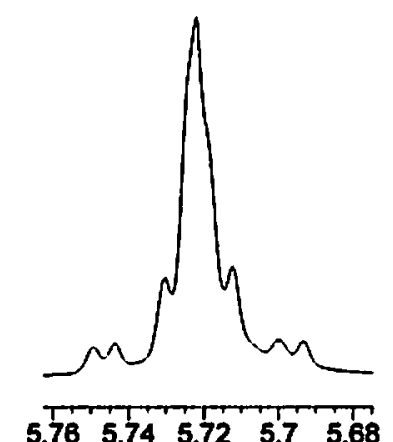

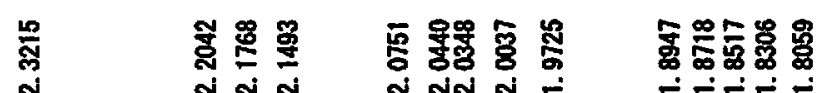

T TT TNTT TTTT

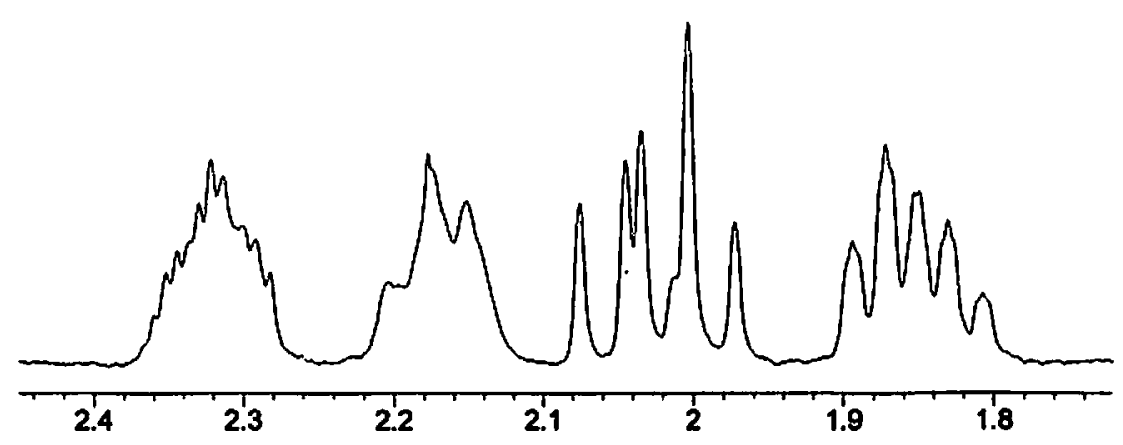

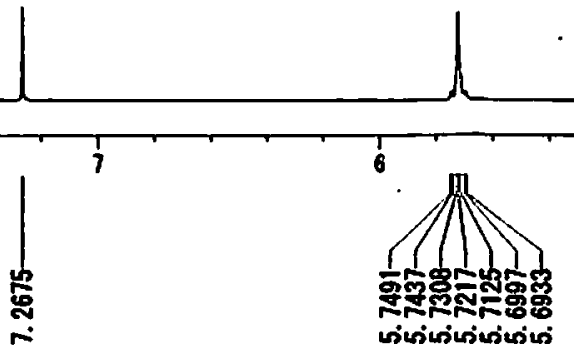

5

$8 / \mathrm{mog}$

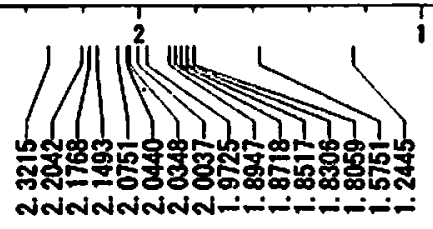




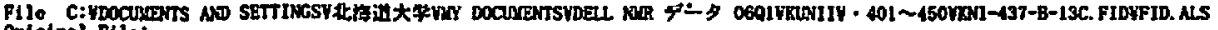
Orjeginsl File: Oet 18 or

C13 Statdard 0bsorve

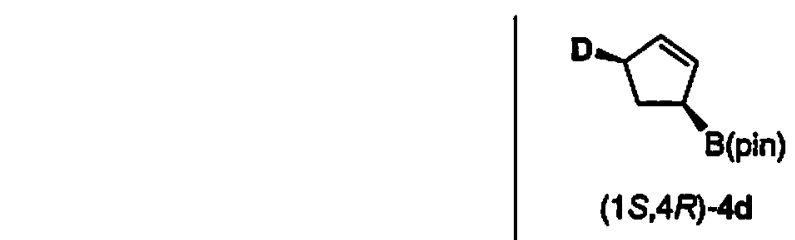

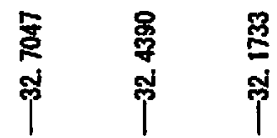

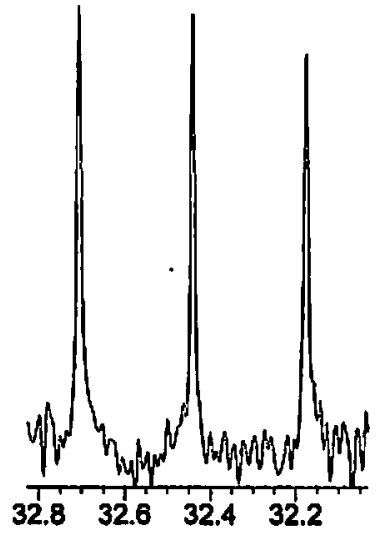

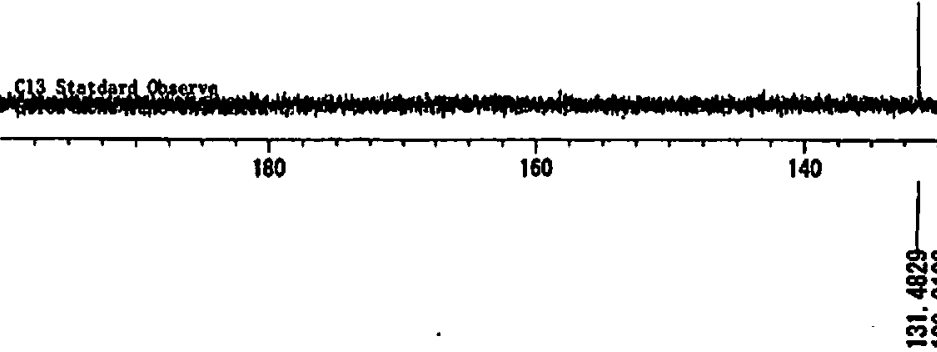

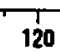

120

$8 / 100$

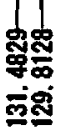

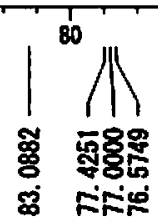

60

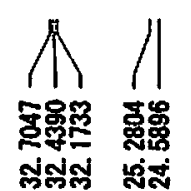

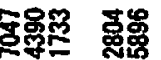

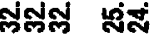

20 


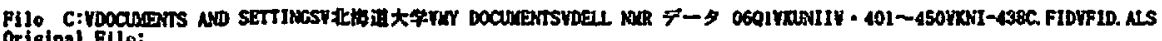
Ortiginal Filo: Oce 18 oo

STADABD IH CRSERE

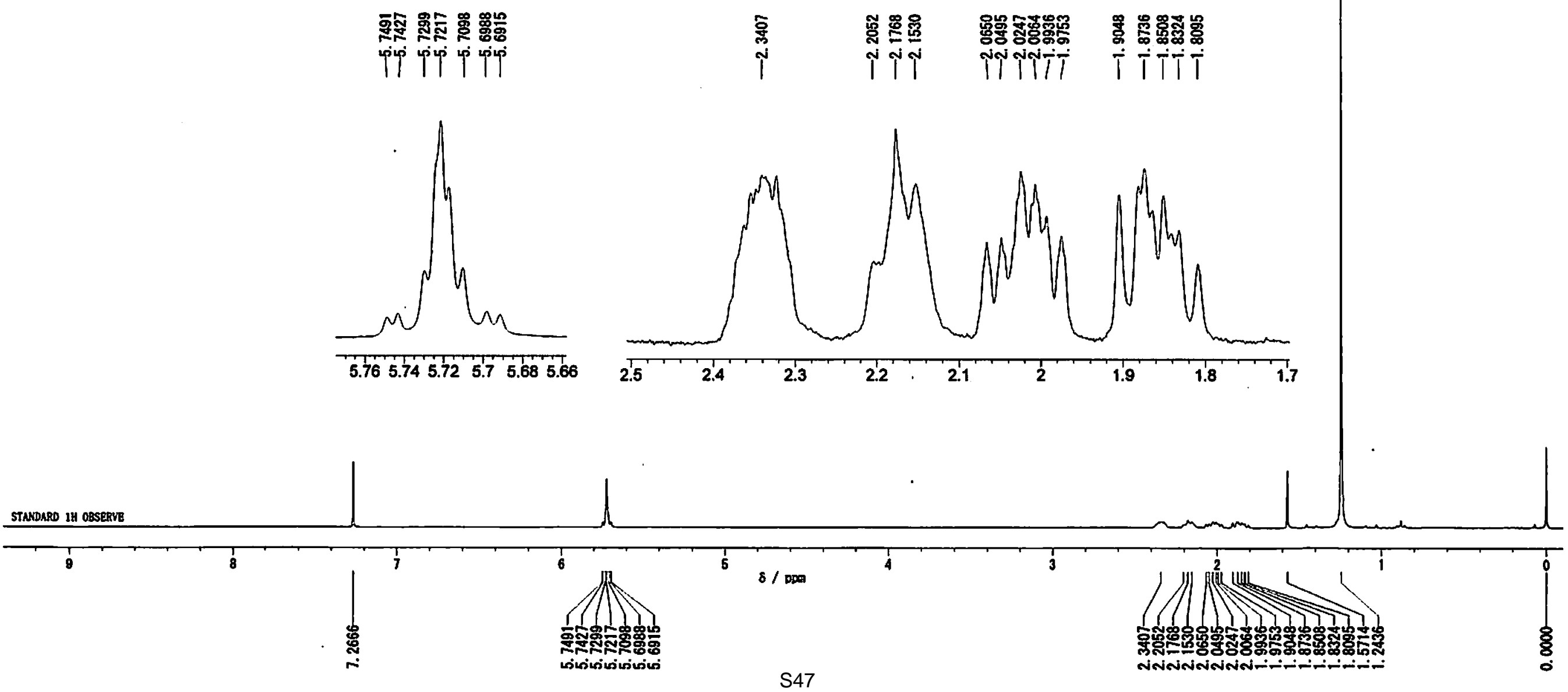

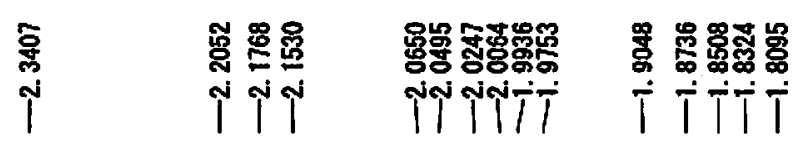




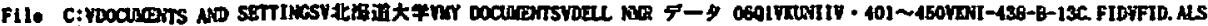
Oziginal Fllo: Oet 1000

C13 Statdard Obserre
Stick

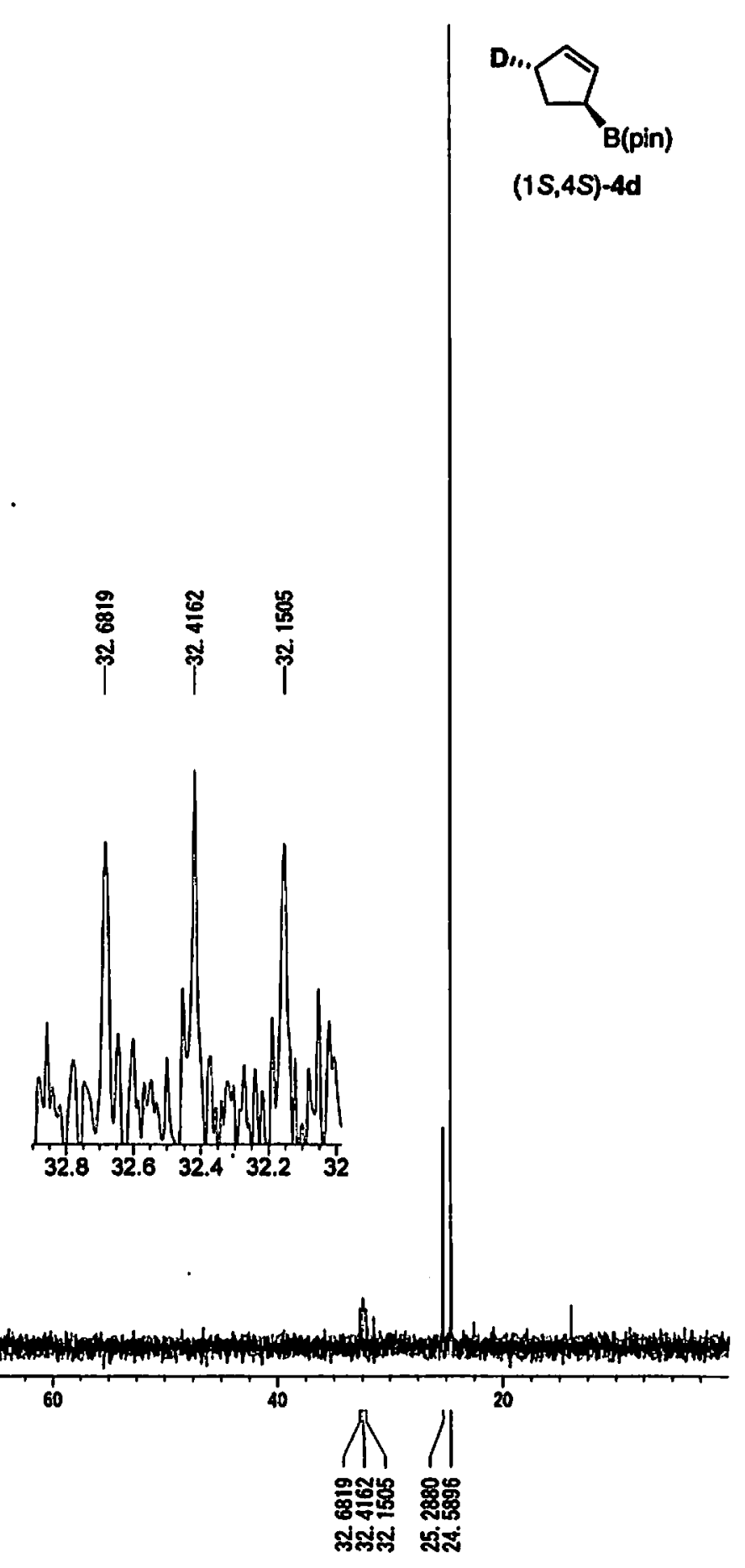




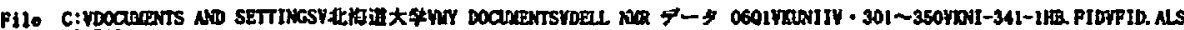
Orreinai PIlo: Jul 3000

STANDARD IH OBSERTE

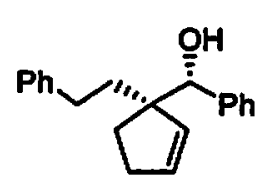

$(S, S)-6 a a$

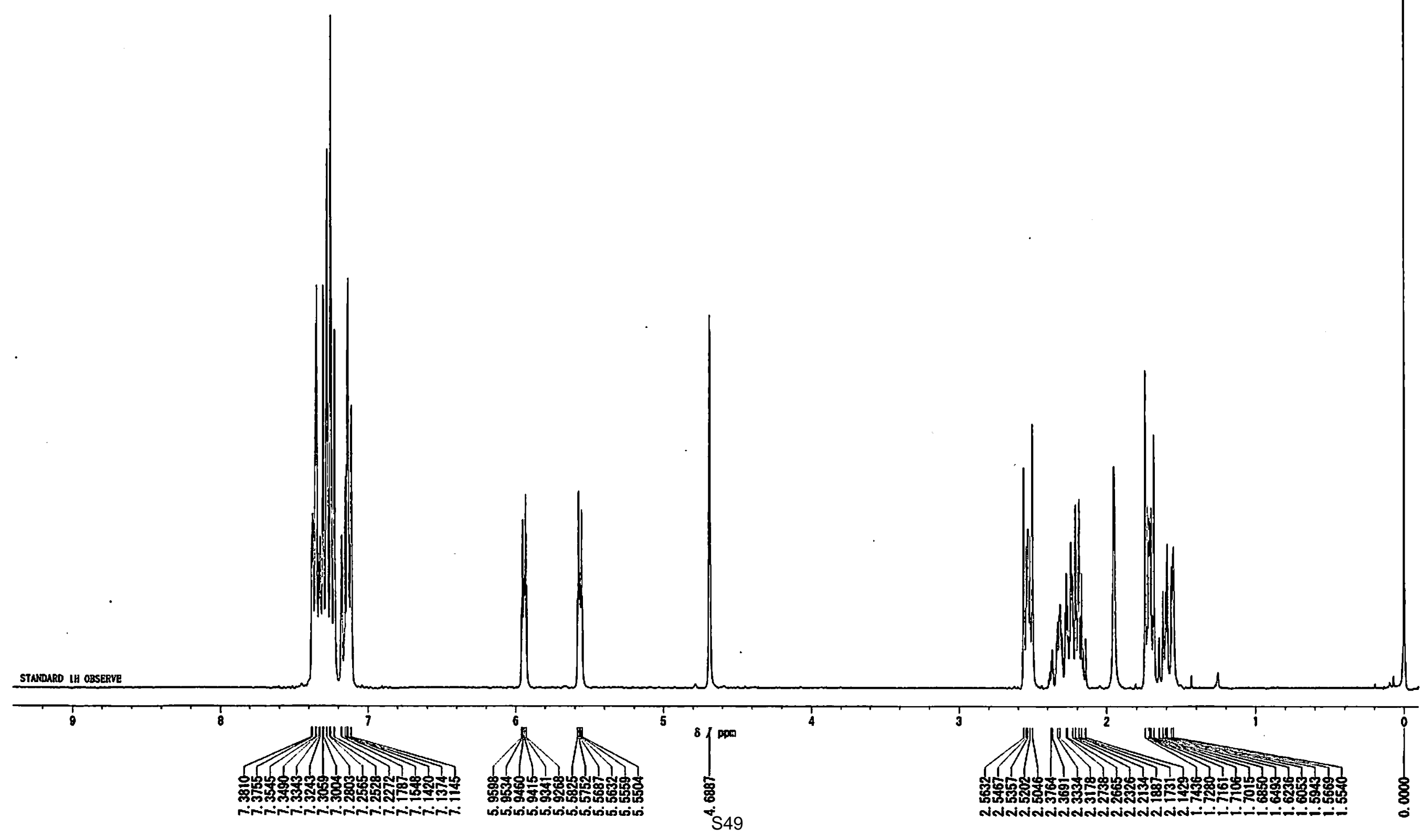




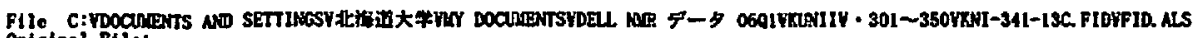
Original Pilo: Jul 3009

Cl3 Statdard Obsorro unteh $=0.4$
Stichonono Tuno=6.4

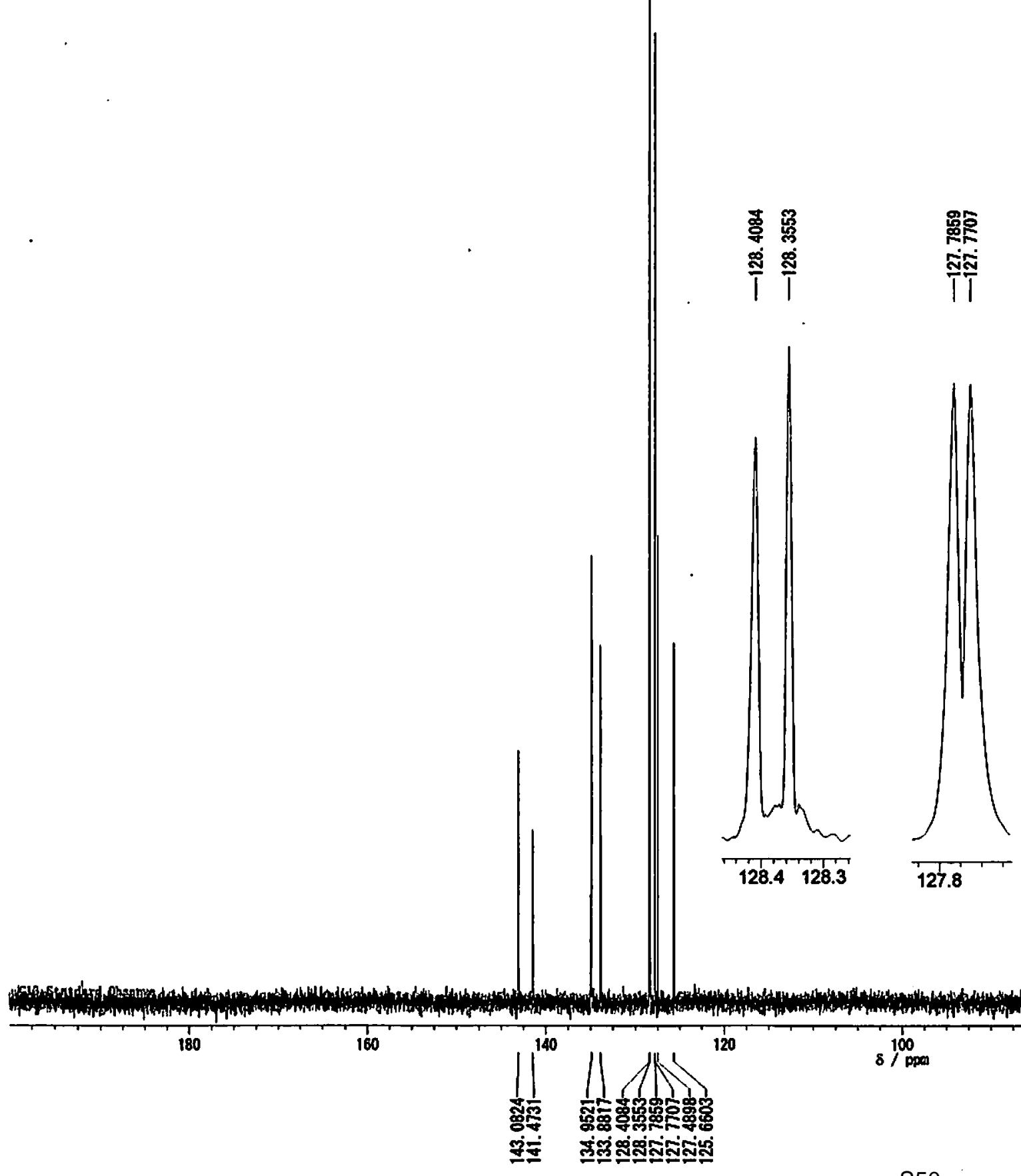

พิ่งิ่
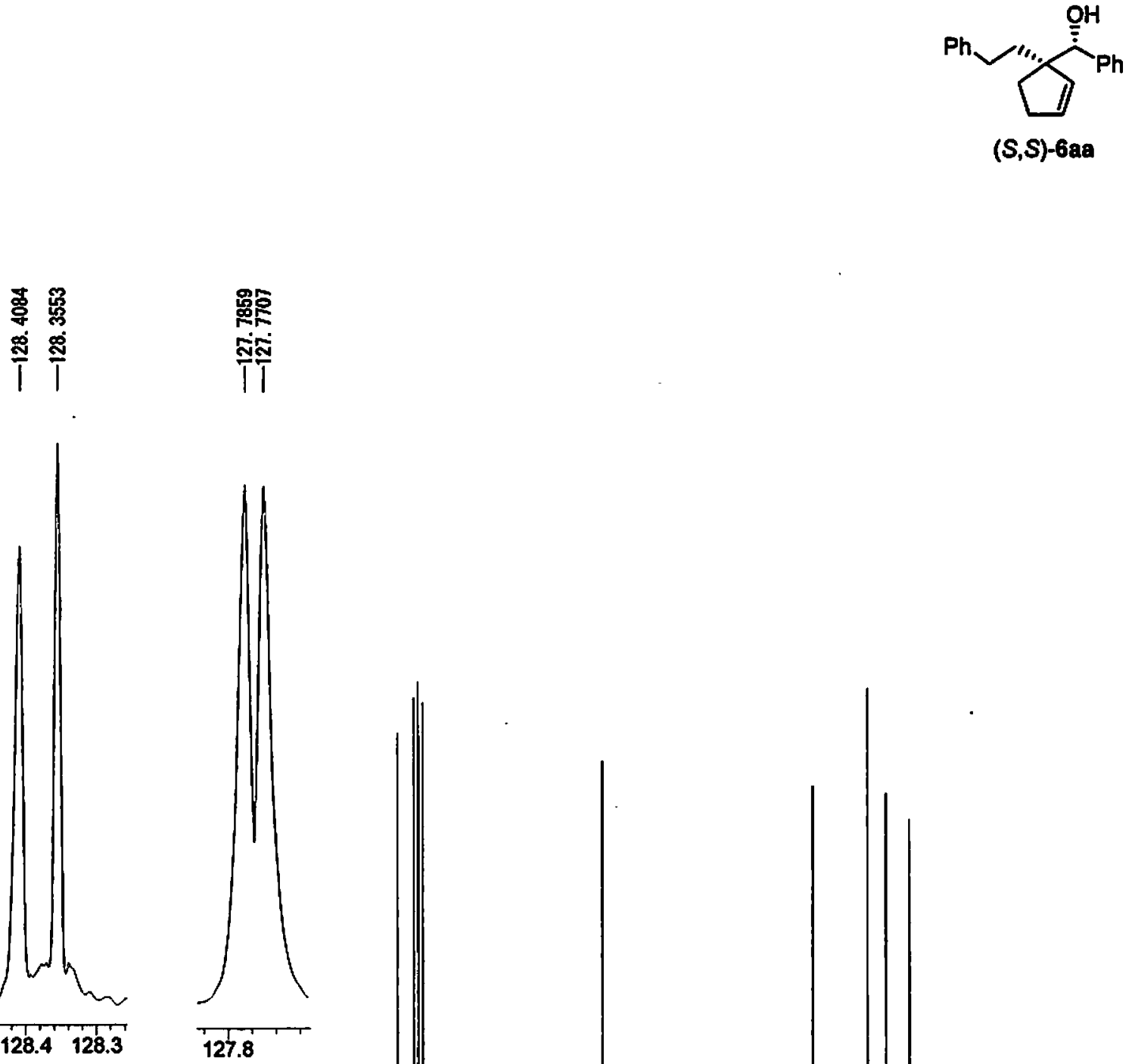

$(\mathbf{S}, \mathbf{S})-6 \mathbf{a a}$

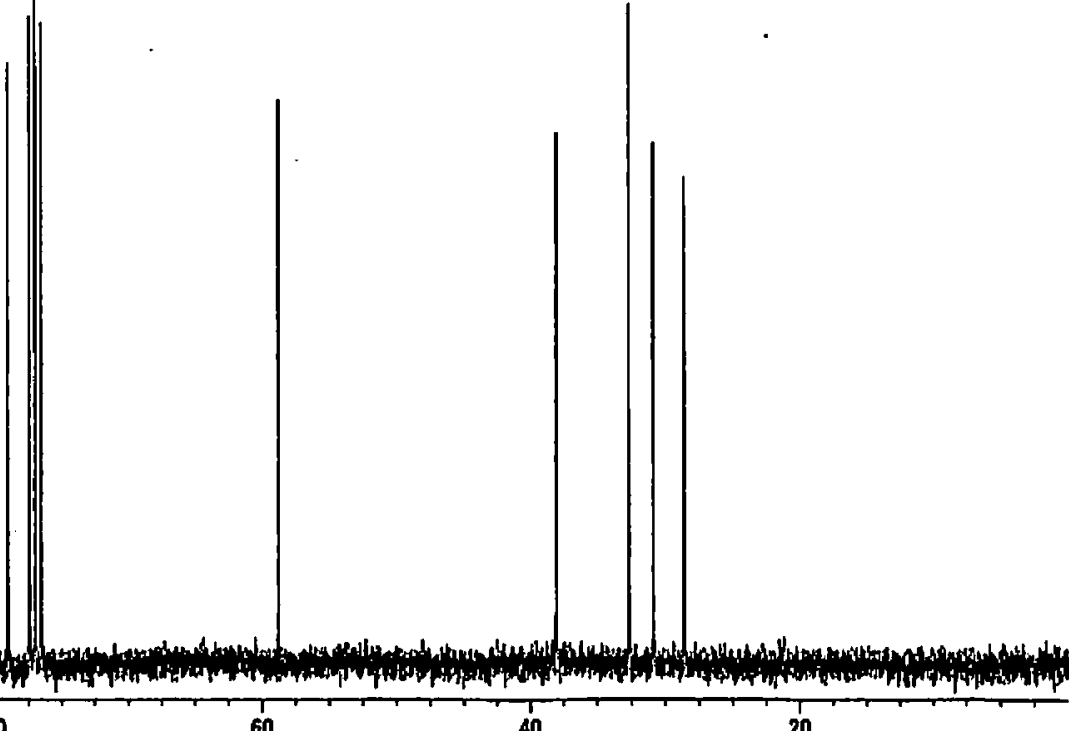

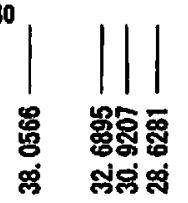

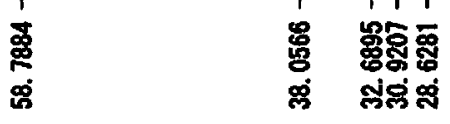




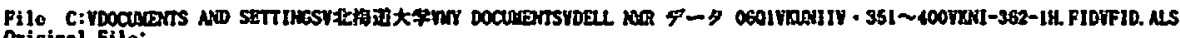
Original Filo: Aug 19 og

STMARED IH OBSENE

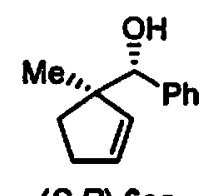

$(S, R)$-6ea

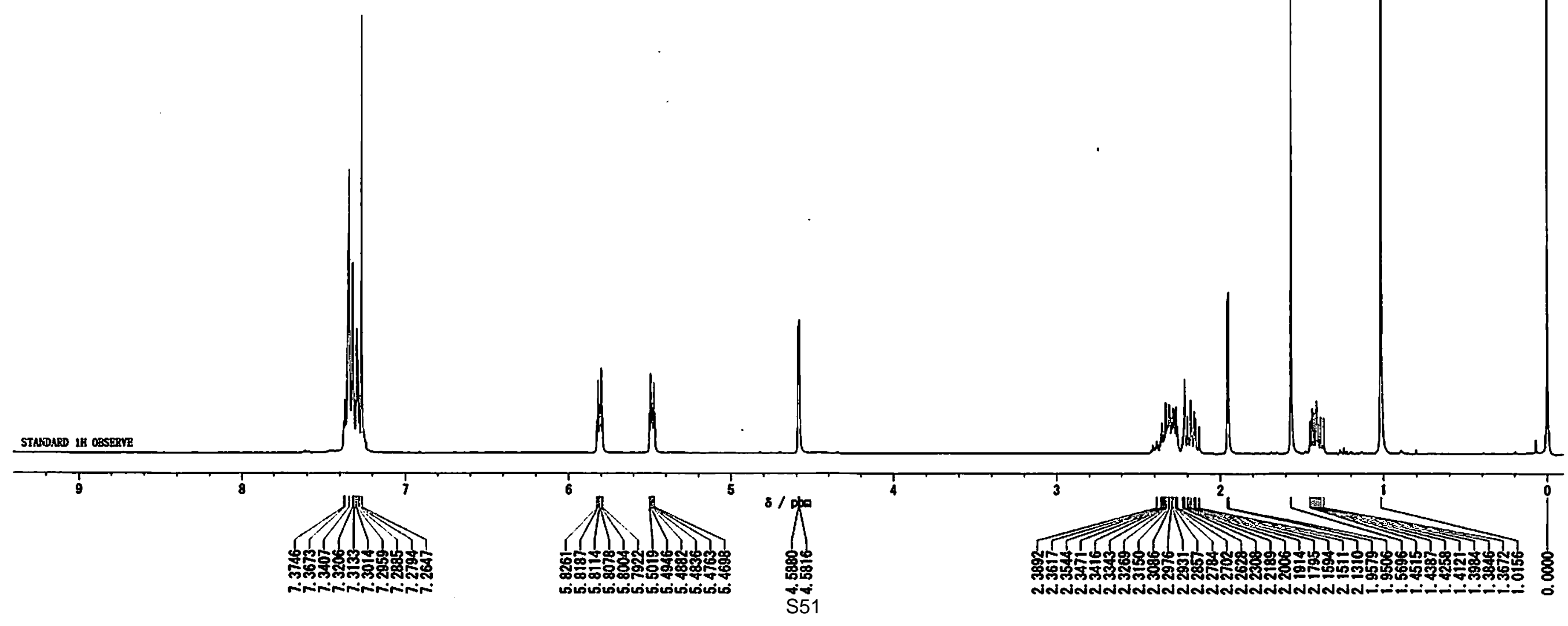




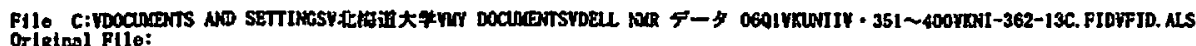
pilo: aug 19 og

Cll Statdard Doserve
Stick

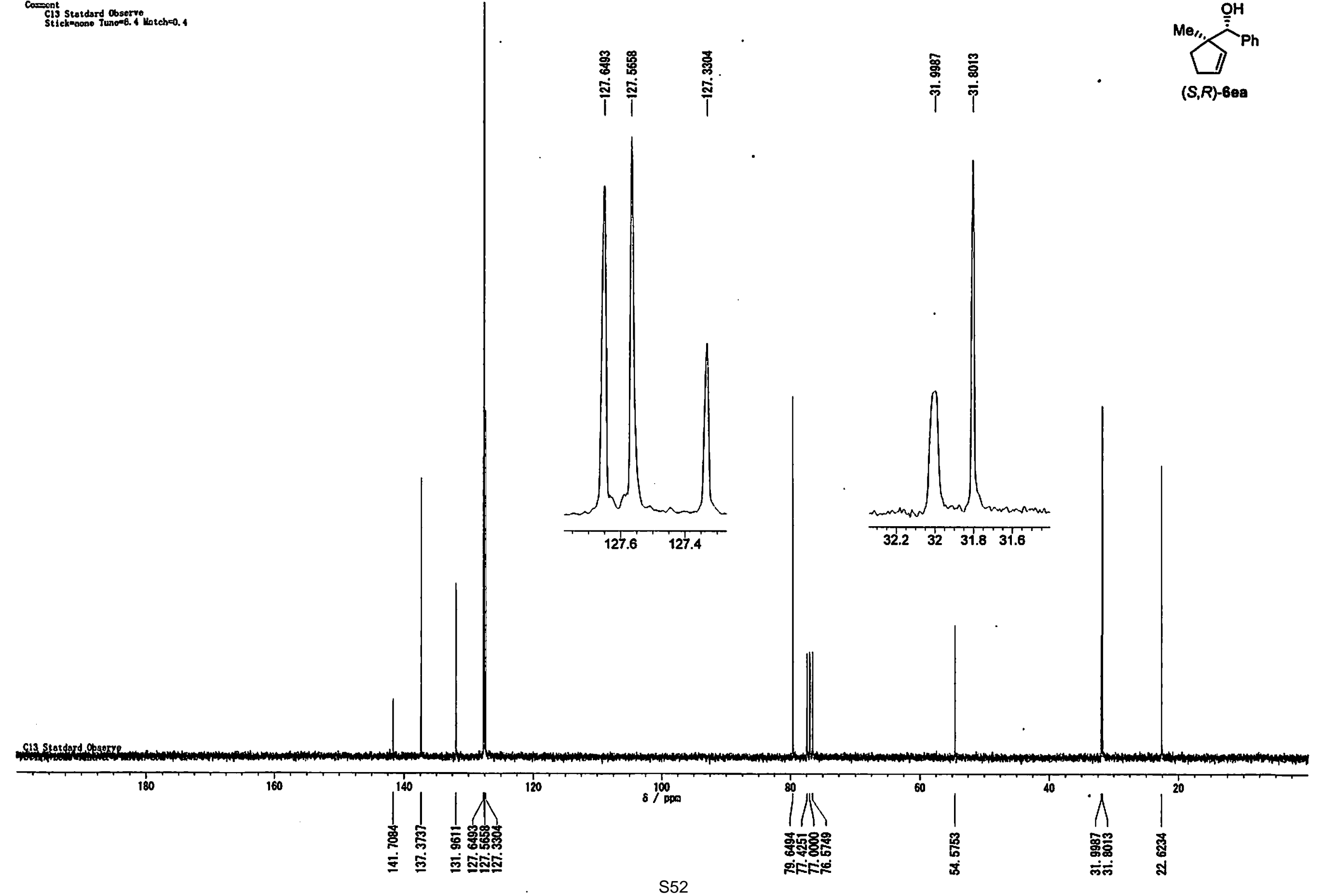




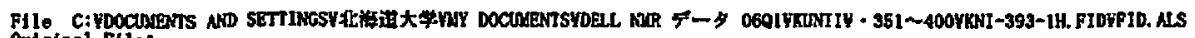

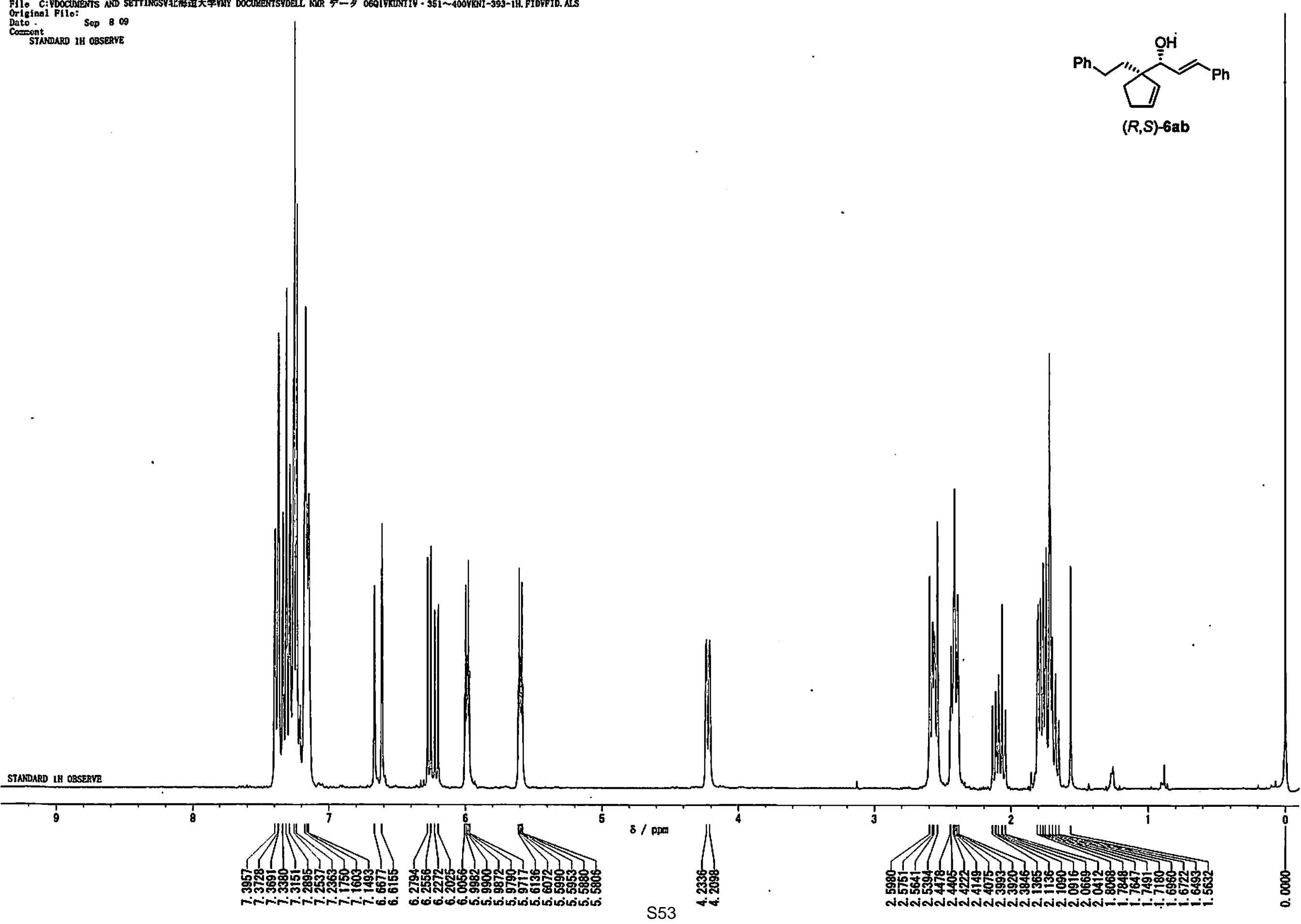




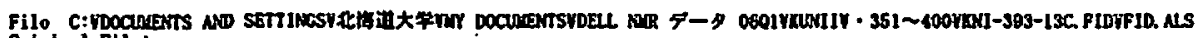
Griginal Filo: $\operatorname{sep} 800$

C13 Statdard Obsorvo
Stick=0esso Turo $=6.4$ Match $=0.4$

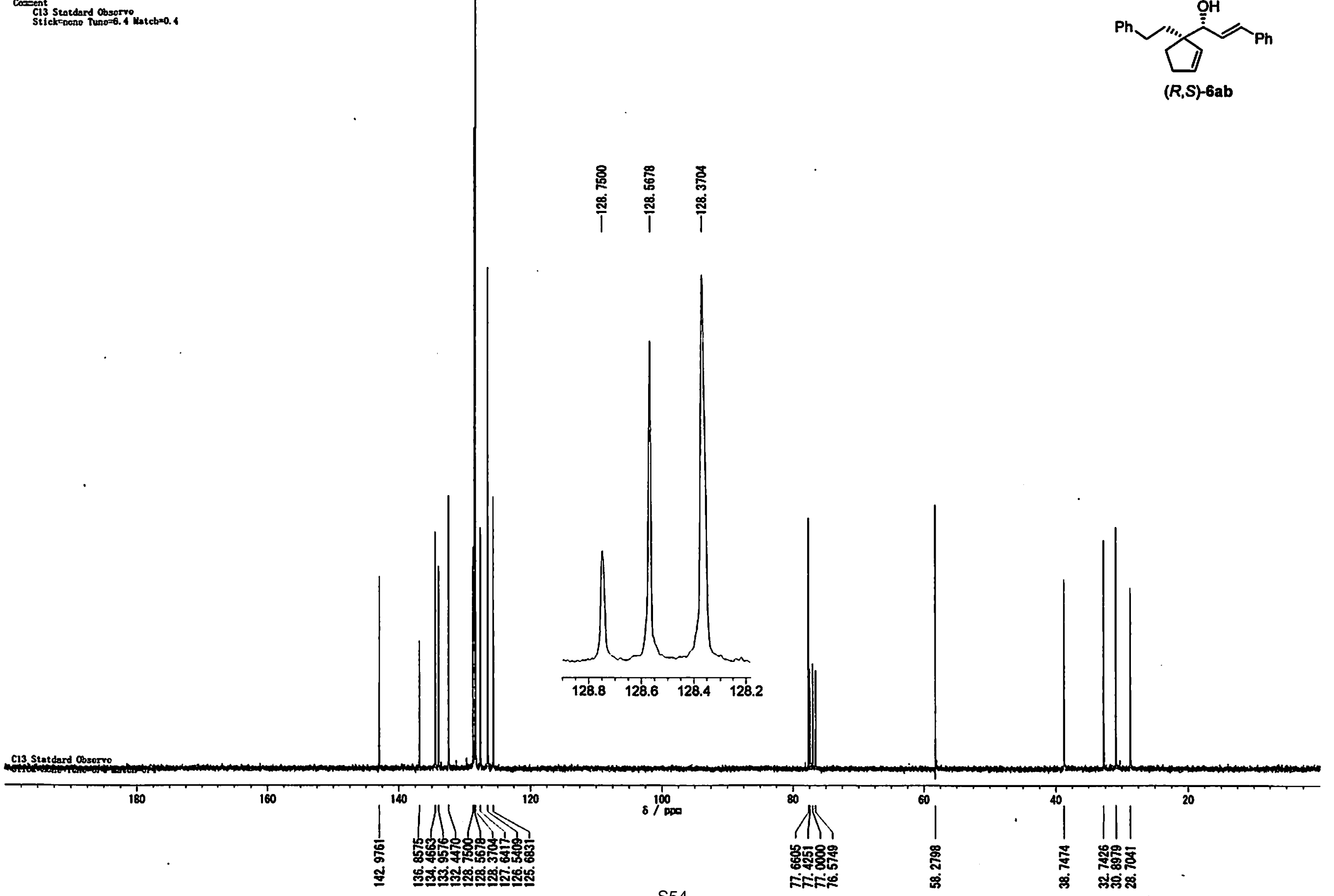




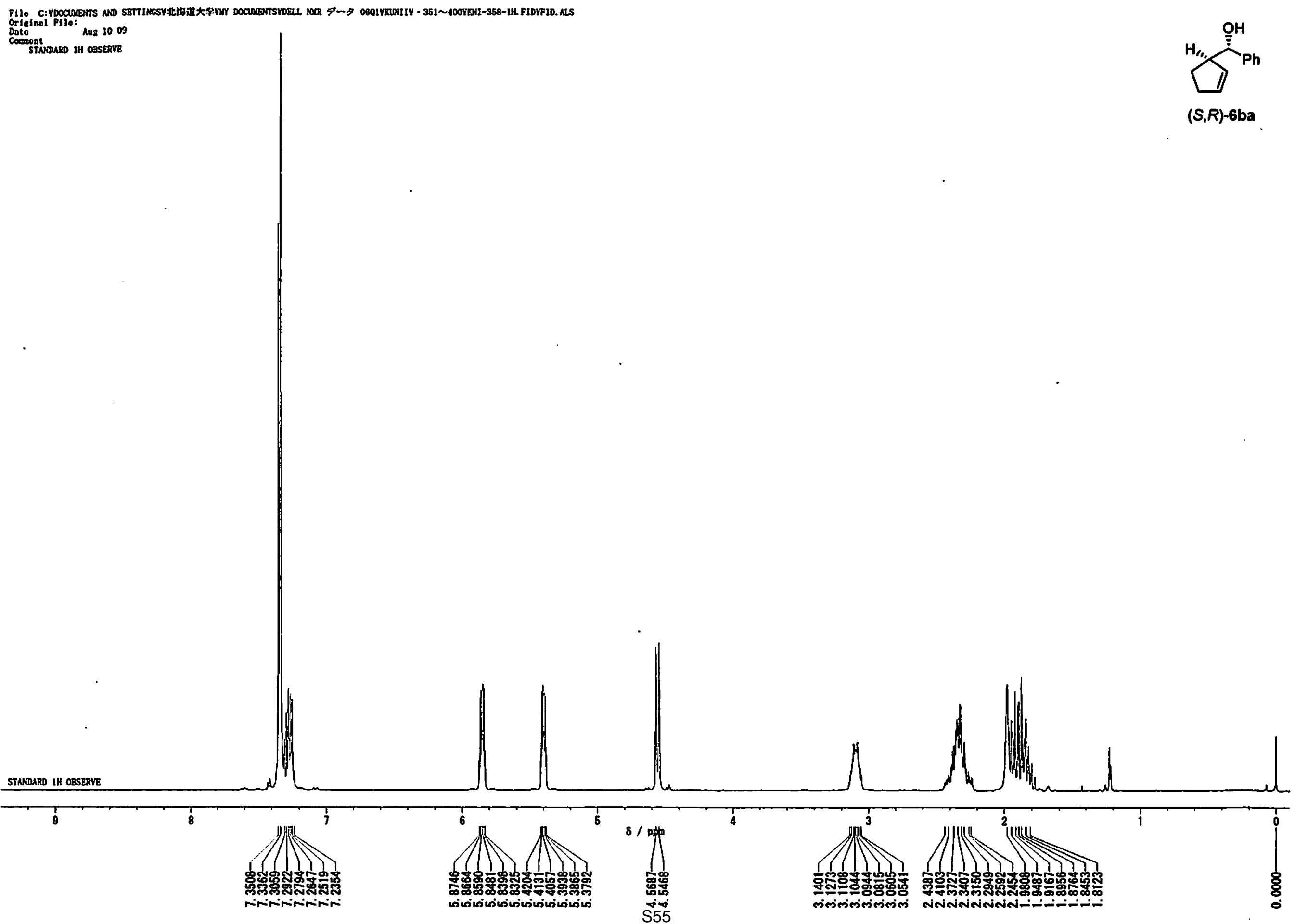




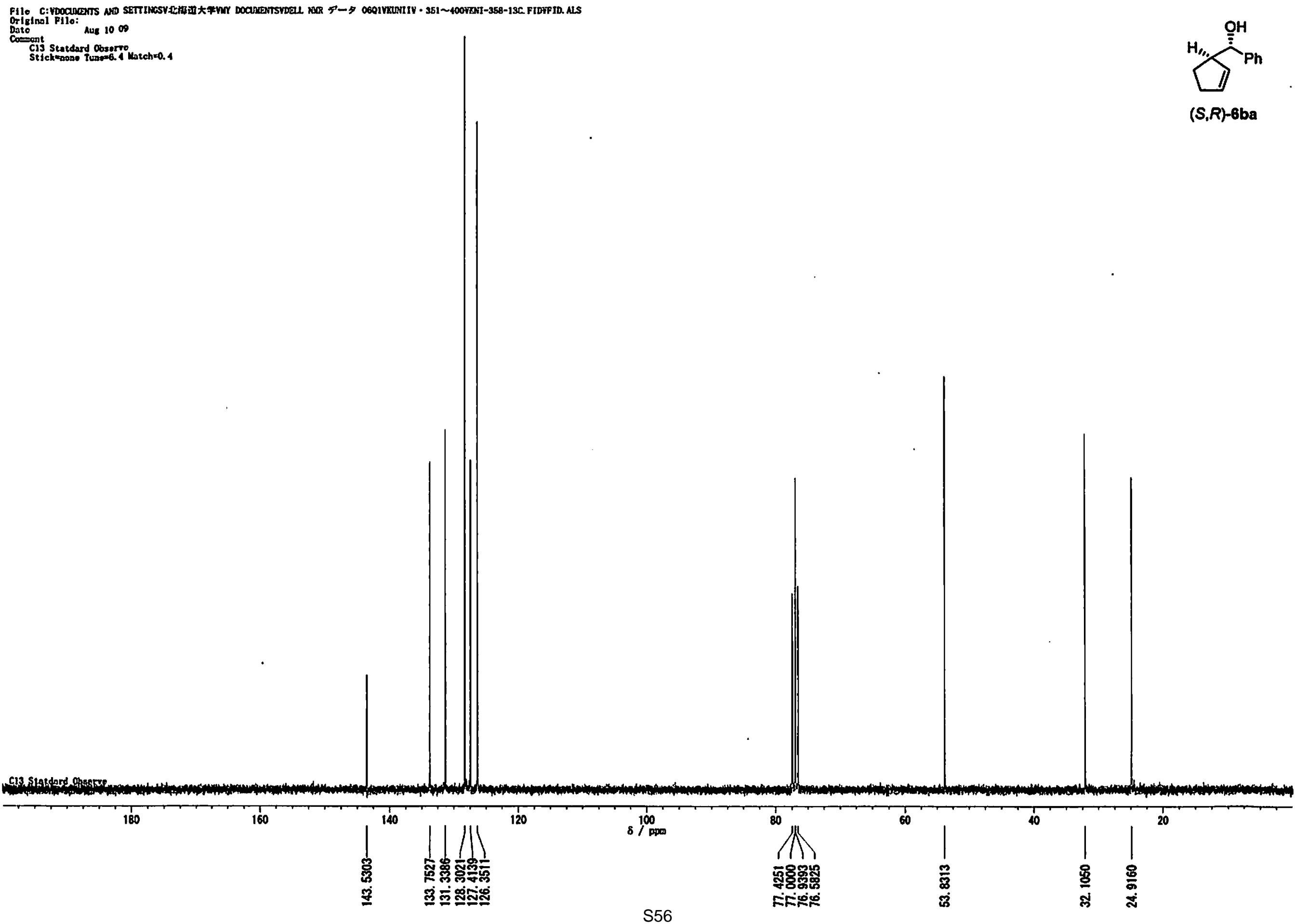




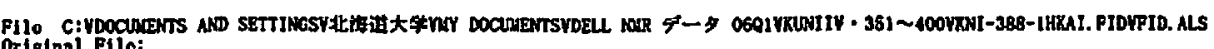

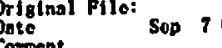

STANDARD IH OBSERVE
STsme
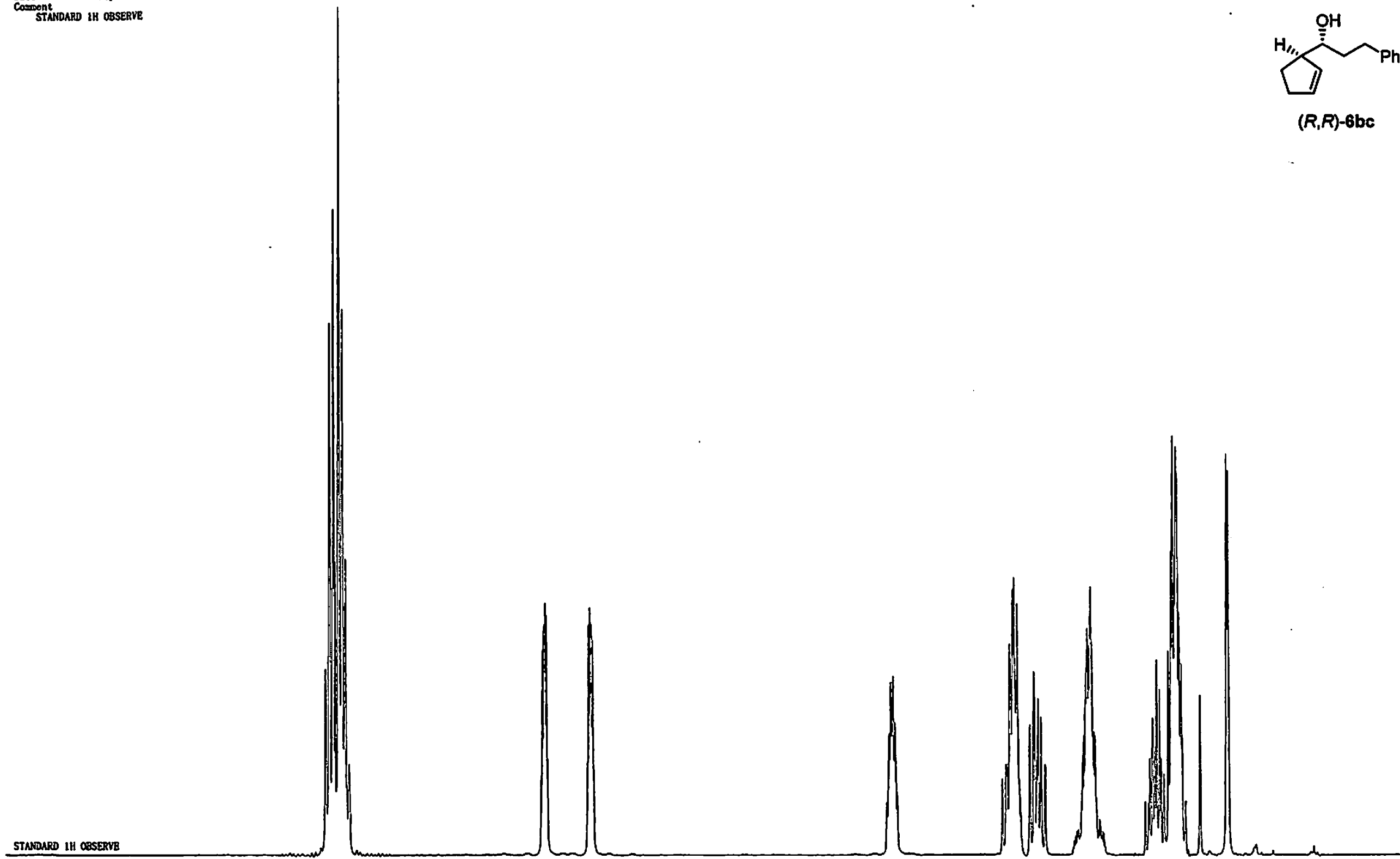

(R,R)-6bc

STMOARO IH COSERE

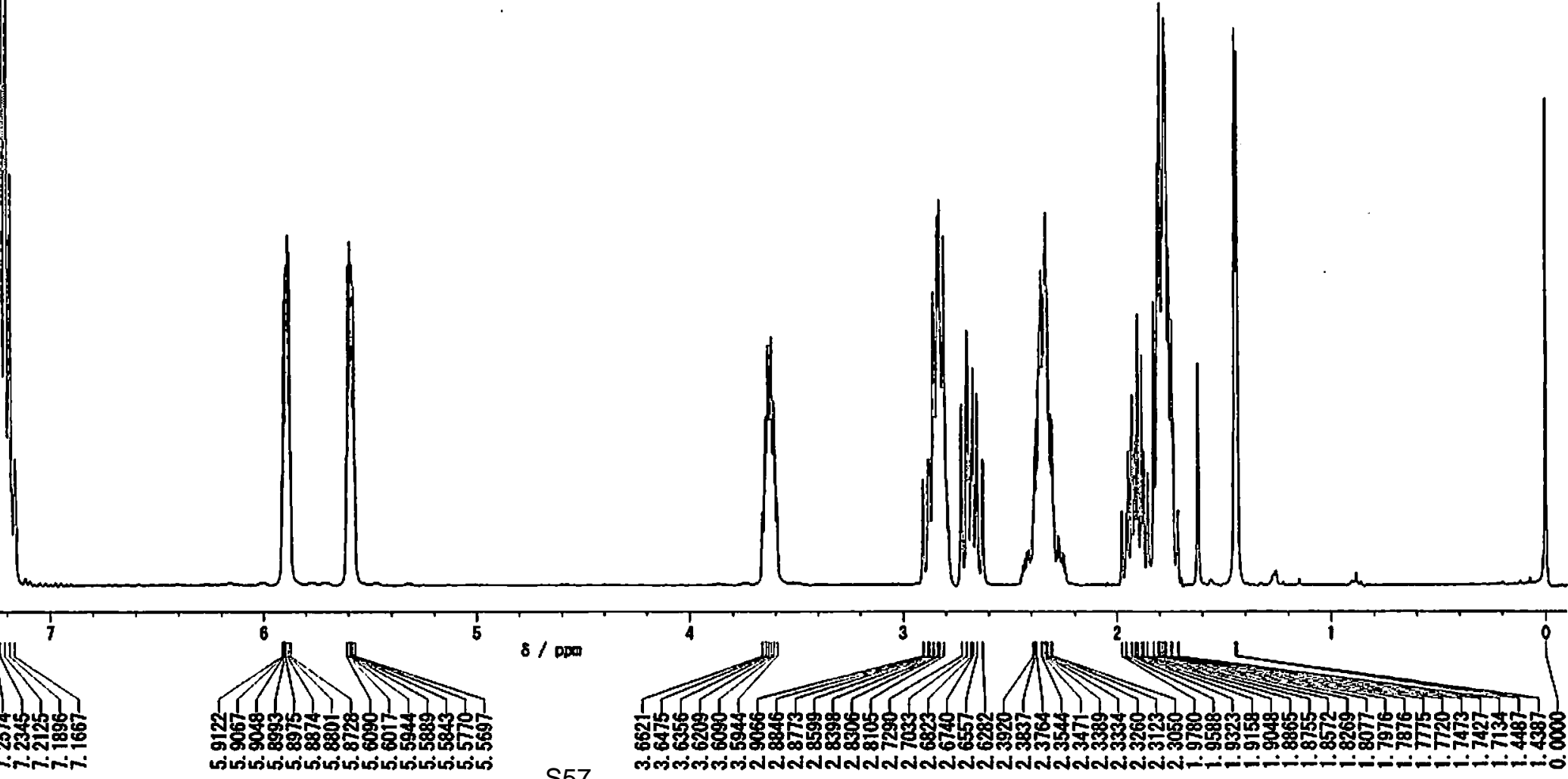




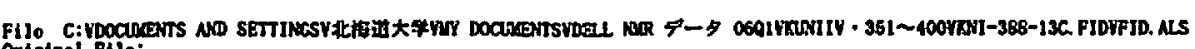

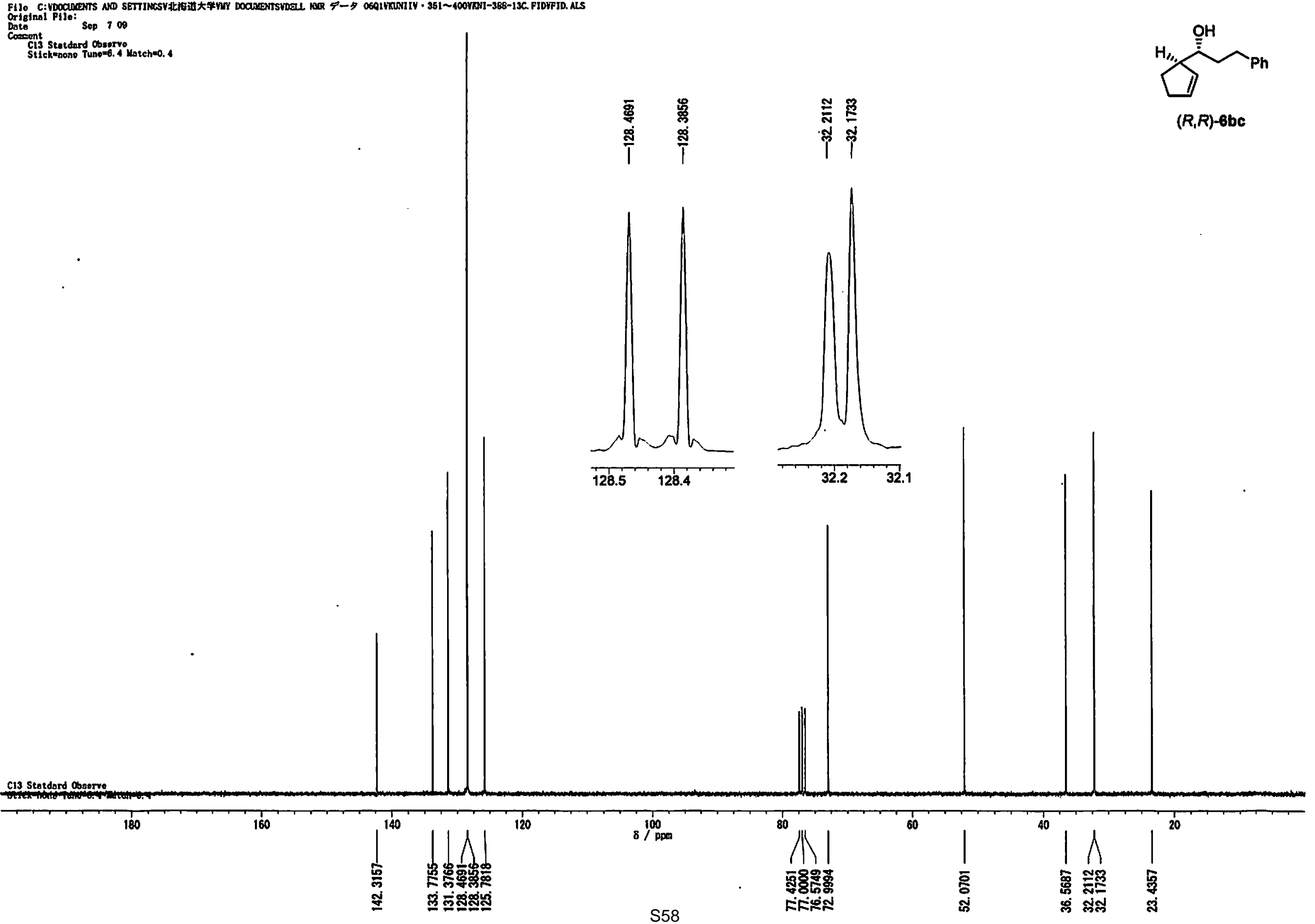




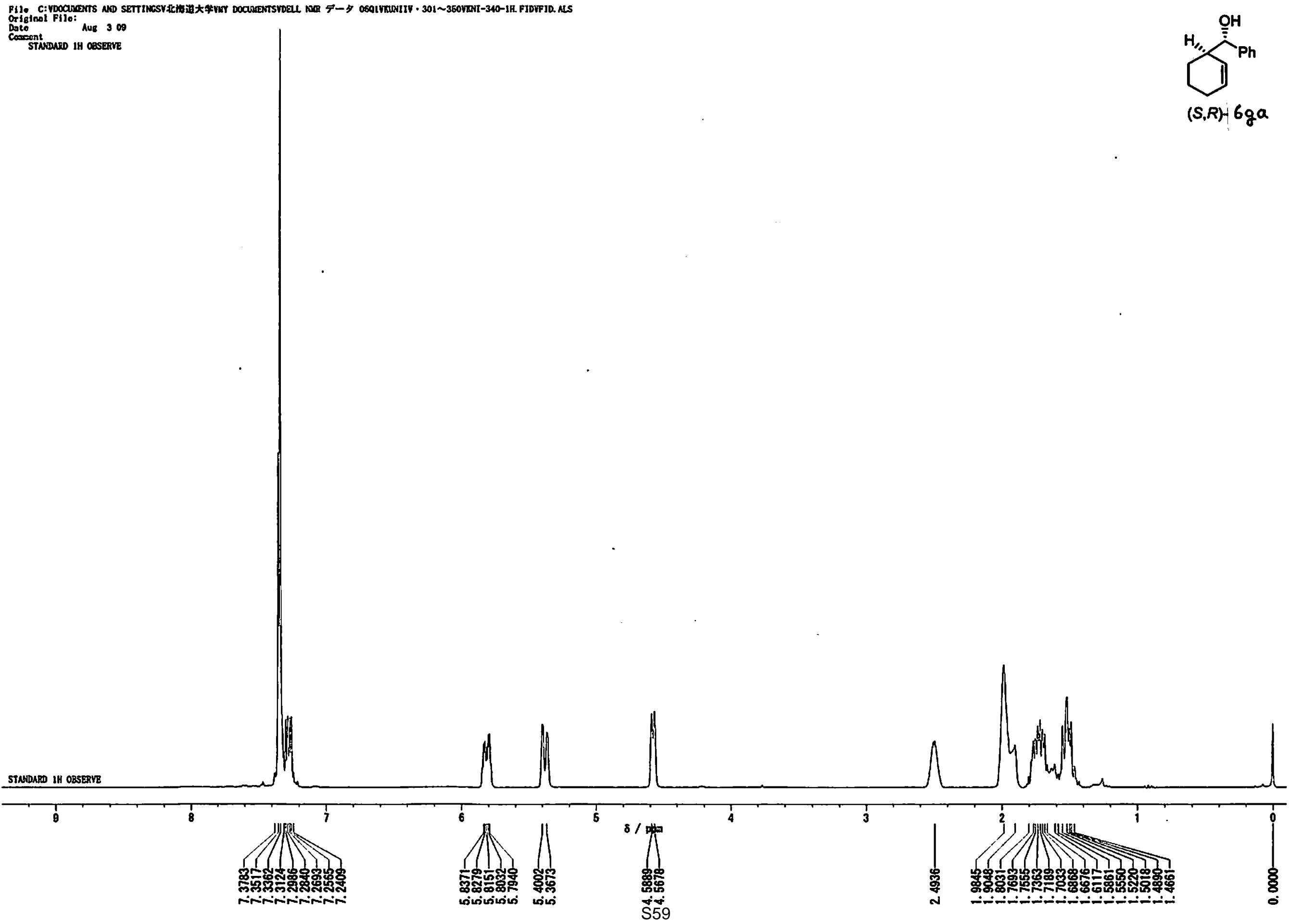




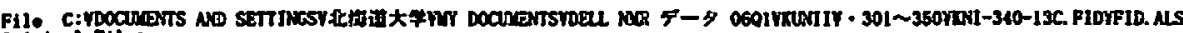
Daro fursl Filo: ay 3 og

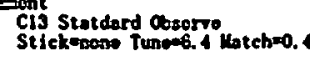

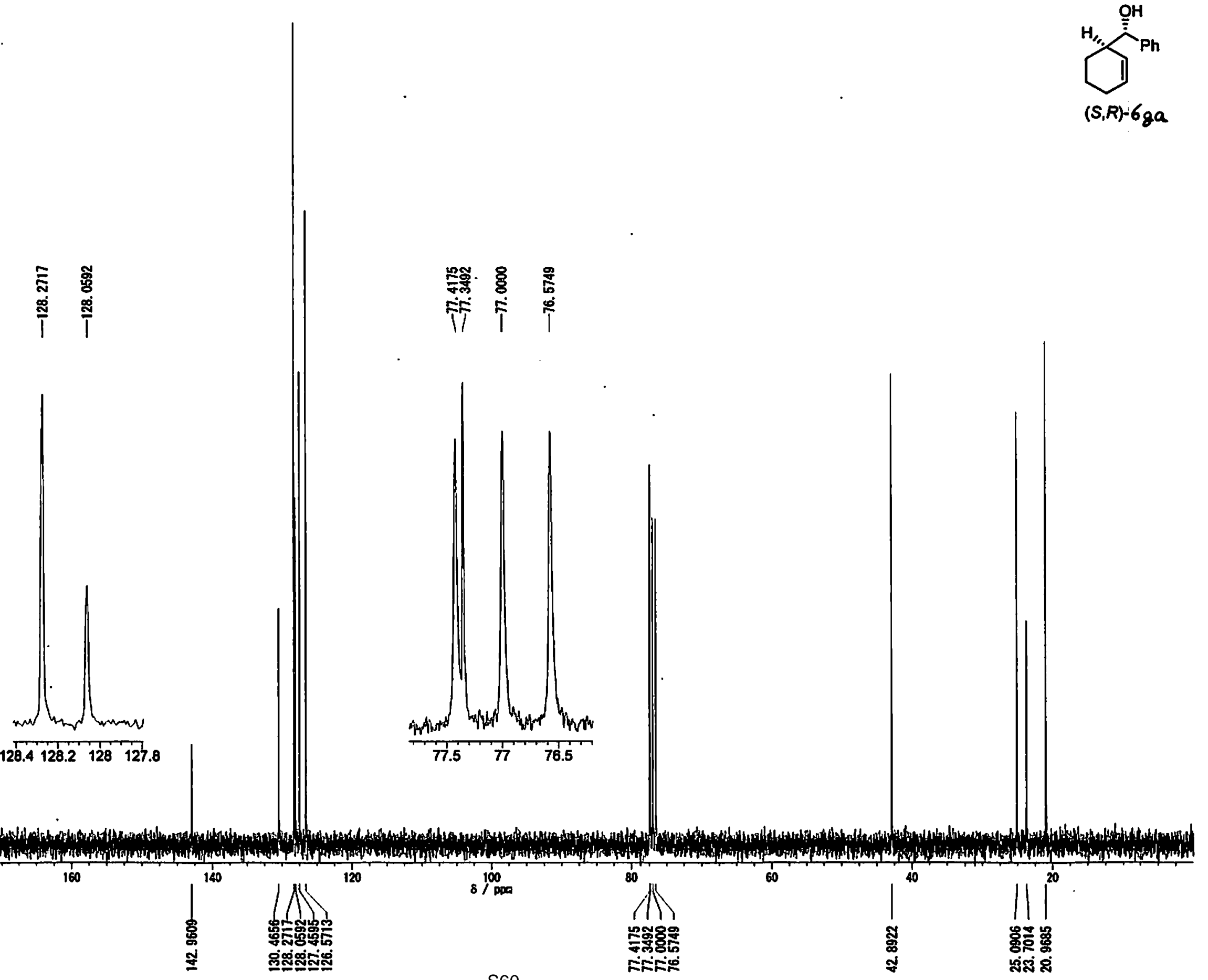

